\title{
Satisfazibilidade probabilística
}

\author{
Glauber De Bona
}

\author{
DisSERTAÇÃO APRESENTADA \\ $\mathrm{AO}$ \\ Instituto DE Matemática E Estatística \\ DA \\ Universidade DE SÃo PAUlo \\ PARA \\ OBTENÇ̃̃O DO TÍTULO \\ $\mathrm{DE}$ \\ Mestre em CiÊnCIAS
}

\author{
Programa: Ciência da Computação \\ Orientador: Prof. Dr. Marcelo Finger
}

Durante o desenvolvimento deste trabalho o autor recebeu auxílio financeiro do $\mathrm{CNPq}$

São Paulo, junho de 2011 


\section{Satisfazibilidade probabilística}

Esta dissertação contém as correções e alterações sugeridas pela Comissão Julgadora durante a defesa realizada por Glauber De Bona em 20/5/2011.

O orginal encontra-se disponível no Instituto de Matemática e Estatística da Universidade de São Paulo.

Comissão Julgadora:

- Prof. Dr. Marcelo Finger (orientador) - IME-USP

- Prof. Dr. Fábio Gagliardi Cozman - EP-USP

- Prof. Dr. Marcus Vinícius Soledade Poggi de Aragão - PUC-RJ 


\section{Agradecimentos}

Qualquer lista explícita de agradecimento às pessoas que colaboraram, direta ou indiretamente, para a realização deste trabalho seria incompleta, então agradeço a todos que o fizeram. Porém algumas pessoas merecem tal privilégio, e certamente uma citação de gratidão ainda é pouco para retribuí-las.

Agradeço ao Prof. Dr. Marcelo Finger, orientador deste trabalho, a atenção e dedicação, não só na indicação dos caminhos, mas também no trilhar dos mesmos, desbravando boa parte das ideias originais desta dissertação.

Agradeço a meus pais, Neivor e Neiva, e a minha irmã, Aracelli, por fornecerem uma base familiar propícia a minha educação, além do apoio financeiro.

Agradeço a todos os amigos, principalmente aos iteanos, que me incentivaram no ingresso à carreira acadêmica, confiando no meu potencial e apoiando minha decisão de abandonar o trabalho no mundo corporativo.

Agradeço também àqueles que dividiram comigo a vida nestes dois anos de mestrado, compensando as minhas horas de trabalho com dias de alegria, especialmente Gleyce, Abelardo, Richard, Migue e Arthur.

Finalmente, porém não menos importante, agradeço a todos os gigantes da ciência, e da filosofia, que emprestam seus ombros para que sobre tais tentemos enxergar mais longe. 


\section{Resumo}

Este trabalho estuda o problema da Satisfazibilidade Probabilística (PSAT), revendo a sua solução via programação linear, além de propor novos algoritmos para resolvê-lo através da redução ao SAT. Construímos uma redução polinomial do PSAT para o SAT, chamada de Redução Canônica, codificando operações da aritmética racional em bits, como variáveis lógicas. Analisamos a complexidade computacional dessa redução e propomos uma Redução Canônica de Precisão Limitada para contornar tal complexidade. Apresentamos uma Redução de Turing do PSAT ao SAT, baseada no algoritmo Simplex e na Forma Normal Atômica que introduzimos. Sugerimos modificações em tal redução em busca de eficiência computacional. Por fim, implementamos essas reduções a fim de investigar o perfil de complexidade do PSAT, observamos o fenômeno de transição de fase e discutimos as condições para sua detecção.

Palavras-chave: lógica probabilística, satisfazibilidade probabilística (PSAT), satisfazibilidade (SAT), transição de fase, redução polinomial, redução de Turing. 


\section{Abstract}

This work studies the Probabilistic Satisfiability problem (PSAT), reviewing its solution through linear programming, and proposing new algorithms to solve it. We construct a polynomial manyto-one reduction from PSAT to SAT, called Canonical Reduction, codifying rational arithmetic operations into bits, as logical variables. We analyze the computational complexity of this reduction and we propose a Limited Precision Canonical Reduction to reduce such complexity. We present a Turing Reduction from PSAT to SAT, based on the Simplex algorithm and the Atomic Normal Form we introduced. We suggest modifications in such reduction looking for computational efficiency. Finally, we implement these reductions in order to investigate the complexity profile of PSAT, the phase transition phenomenom is observed and the conditions for its detection are discussed.

Keywords: probabilistic logic, probabilistic satisfiability (PSAT), satisfiability (SAT), phase transition, polynomial reduction, Turing reduction. 


\section{Sumário}

Lista de Abreviaturas $\quad$ ix

Lista de Símbolos $\quad$ xi

1 Introdução $\quad 1$

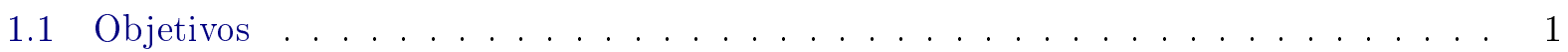

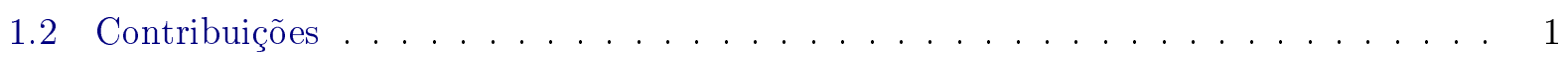

1.3 Organização do Texto . . . . . . . . . . . . . . . . . . . 2

2 O Problema PSAT $\quad 3$

2.1 A Lógica Proposicional Clássica e o Problema SAT . . . . . . . . . . . . . . . . . 3

$2.1 .1 \quad$ A Linguagem Proposicional . . . . . . . . . . . . . . . . . . . 3

2.1 .2 Semântica . . . . . . . . . . . . . . . . . . . . 4

2.1.3 Forma Normal Conjuntiva . . . . . . . . . . . . . . . . . . . . 4

2.1.4 O Problema da Satisfazibilidade Booleana . . . . . . . . . . . . . . 5

2.2 Definição Formal do Problema PSAT . . . . . . . . . . . . . . . . . . . . 5

2.3 Complexidade Computacional . . . . . . . . . . . . . . . . . 7

2.4 Casos Polinomiais . . . . . . . . . . . . . . . . . . . . . 8

2.5 A Forma Normal Atômica . . . . . . . . . . . . . . . . . . . . 10

2.6 Variações do PSAT . . . . . . . . . . . . . . . . . . . . . . . . . 12

2.6 .1 PSAT na Forma de Otimização . . . . . . . . . . . . . . . . . 12

2.6.2 PSAT com Probabilidades Imprecisas . . . . . . . . . . . . . . . . . 13

2.6.3 PSAT com Probabilidades Condicionais . . . . . . . . . . . . . . . . 15

3 Solução do PSAT via Programação Linear $\quad 17$

3.1 O Algoritmo Simplex . . . . . . . . . . . . . . . . . . . . . . . 17

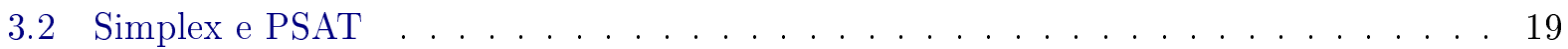

3.3 Método de Geração de Colunas e PSAT . . . . . . . . . . . . . . . . . . . . . 20

3.4 O Problema Auxiliar . . . . . . . . . . . . . . . . . . . . . . . . 21

3.4.1 Busca Local com Profundidade Variável . . . . . . . . . . . . . . . . . . 22

3.4 .2 Busca Tabu . . . . . . . . . . . . . . . . . . . 23

3.4 .3 Soluções Exatas . . . . . . . . . . . . . . . . . . . . . . . . 24

4 Redução Canônica do PSAT ao SAT $\quad 27$

4.1 Esboço da Redução . . . . . . . . . . . . . . . . . . . . . . . . 28

4.2 Cálculo da Precisão Necessária . . . . . . . . . . . . . . . . . . . . . 28 
4.3 Construção da Instância SAT ． . . . . . . . . . . . . . . . . . . . . . . . 29

4.3 .1 Variáveis . . . . . . . . . . . . . . . . . . . 29

4.3 .2 Fórmulas . . . . . . . . . . . . . . . . . . . . . 31

4.4 Algoritmo da Redução Canônica . . . . . . . . . . . . . . . . . . . . . . 33

4.5 Análise da Complexidade Computacional . . . . . . . . . . . . . . . . . . . 33

4.5 .1 Análise do Algoritmo . . . . . . . . . . . . . . . . . . . 33

4.5.2 Análise do Tamanho da Saída . . . . . . . . . . . . . . . . . . . . . 35

4.6 Redução Canônica de Precisão Limitada . . . . . . . . . . . . . . . . . . . . . 36

5 Redução de Turing do PSAT para o SAT 39

5.1 Esboço do Algoritmo . . . . . . . . . . . . . . . . . . . . . . . . . . 39

5.2 O Problema Auxiliar para Instâncias na Forma Normal Atômica . . . . . . . . . . . 43

5.2 .1 De Inequações para Instâncias SAT . . . . . . . . . . . . . . . . . . . . . . . 44

5.2 .2 Algoritmo para o Problema Auxiliar . . . . . . . . . . . . . . . . . 45

5.3 Análise da Complexidade Computacional . . . . . . . . . . . . . . . . . . . 48

5.3 .1 Análise do Algoritmo $5.1 \ldots \ldots \ldots \ldots$. . . . . . . . . . 48

5.3.2 Análise do Tamanho das Instâncias SAT . . . . . . . . . . . . . . . . . 48

5.4 Problema Auxiliar para Instâncias na Forma Normal Atômica Modificado . . . . . . 49

5.4 .1 Uma Nova Função Objetivo . . . . . . . . . . . . . . . . . . . . . . . . . . . . 49

5.4 .2 O Algoritmo para o Problema Auxiliar Modificado . . . . . . . . . . . . . 50

5.4 .3 Análise do Algoritmo e da Instância SAT . . . . . . . . . . . . . . . . . . 51

5.5 Problema Auxiliar com Critério de Otimalidade . . . . . . . . . . . . . . . 53

6 Resultados e Transição de Fase $\quad \mathbf{5 5}$

6.1 Implemetação dos Algoritmos e Geração dos Testes . . . . . . . . . . . . . . . . . . 55

6.2 Resultados . . . . . . . . . . . . . . . . . . . 56

6.3 A Transição de Fase . . . . . . . . . . . . . . . . . . . . . . . . . . 58

6.3.1 A Detecção da Transição de Fase no PSAT . . . . . . . . . . . . . . . . . 60

6.3.2 A Localização do Ponto Transição de Fase no PSAT . . . . . . . . . . . . . . 61

7 Conclusões $\quad 65$

7.1 Contribuições e Considerações Finais . . . . . . . . . . . . . . . . . . 65

7.2 Sugestões para Pesquisas Futuras . . . . . . . . . . . . . . . . . . . 66

$\begin{array}{ll}\text { A Listagem de Código Fonte } & 67\end{array}$

B Exemplo de Redução Canônica

Referências Bibliográficas $\quad 85$ 


\section{Lista de Abreviaturas}

CONDSAT PSAT com Probabilidades Condicionais.

CSP Constraint Satisfaction Problem (Problema de Satisfação de Restrições).

MAXSAT Problema da Satisfazibilidade Máxima.

NP Classe dos problemas de decisão resolvidos não deterministicamente em tempo polinomial.

OPSAT PSAT na forma de Otimização.

$P \quad$ Classe dos problemas de decisão resolvidos em tempo polinomial.

PSAT Problema da Satisfaziblidade Probabilística (Probabilistic Satisfiability).

PSAT-PI PSAT com Probabilidades Imprecisas.

SAMD Steepest Ascent Mildest Descent (Subida mais Íngreme Descida mais Branda).

SAT Problema da Satisfazibilidade da Lógica Proposicional Clássica .

SBV Solução Básica Viável.

sse $\quad$ "se, e somente se,". 


\section{Lista de Símbolos}

$\wedge \quad$ Conjunção da lógica clássica.

$\vee \quad$ Disjunção da lógica clássica.

$\neg \quad$ Negação da lógica clássica.

$\rightarrow \quad$ Implicação da lógica clássica.

$\leftrightarrow \quad$ Equivalência da lógica clássica.

$\pi \quad$ Distribuição de probabilidade.

$\Gamma \quad$ Conjunto de fórmulas da lógica clássica proposicional.

$\Psi \quad$ Atribuição de probabilidades.

$O()$ Notação assintótica definida em [CLRS01].

$\Theta()$ Notação assintótica definida em [CLRS01].

$\Omega() \quad$ Notação assintótica definida em [CLRS01].

$\omega()$ Notação assintótica definida em [CLRS01]. 


\section{Capítulo 1}

\section{Introdução}

O estudo do raciocínio sob incerteza é de interesse de diversas áreas e, na Ciência da Computação, tem aplicações úteis na análise de programas sob premissas probabilísticas. Ainda no século XIX, Boole [Boo54] já estudava a atribuição de probabilidades a sentenças lógicas, e nós vemos sua influência no trabalho de de Finetti, em sua teoria subjetiva de probabilidade [DF74]. Em 1965 Hailperin [Hai65] revisitou o problema, trazendo-o para a programação linear. Já em 1986, Nilsson [Nil86] formalizou o problema da satisfazibilidade probabilística para comunidade de Inteligência Artificial: dadas fórmulas lógicas, e probabilidades atribuídas a elas, deseja-se saber se esta atribuição é consistente.

A maior expressividade da lógica probabilística acarreta sua maior complexidade computacional. O problema da satisfazibilidade probabilística (PSAT) é NP-completo, mas na prática tem se mostrado significantemente mais difícil do que o problema da satisfazibilidade clássica (SAT), outro problema NP-completo. Entretanto, o Teorema de Cook-Levin [Coo71] garante a existência de uma redução polinomial do PSAT para o SAT. Tal redução é atraente devido à existência de bons algoritmos para se resolver o SAT, estes em contínua pesquisa. Outro interesse em reduzir o PSAT ao SAT vem da busca por um melhor entendimento da relação entre a raciocínio lógico e a raciocínio probabilístico.

\subsection{Objetivos}

Este trabalho tem por objetivo investigar a relação entre o PSAT e o SAT, procurando por caminhos que possibilitem a redução desejada. Além disso, deseja-se investigar a desconhecida transição de fase do PSAT, implementando os algoritmos oriundos das reduções.

\subsection{Contribuições}

As principais contribuições teóricas apresentadas são uma Forma Normal Atômica para o problema PSAT e a aparente deteç̧ão de sua transição de fase; enquanto as principais contribuições práticas advêm da implementação dos algoritmos propostos para resolver o PSAT, via redução ao SAT. Os principais resultados deste trabalho estão condensados no artigo [FDB11], a ser apresentado na Conferência Internacional Conjunta sobre Inteligência Artificial (IJCAI) de 2011. 


\subsection{Organização do Texto}

O Capítulo 2 apresenta formalmente o PSAT, seus casos polinomiais, sua forma normal atômica e algumas variações do problema. O Capítulo 3 mostra como o algoritmo Simplex, da programação linear, pode ser usado para resolver o PSAT com o Método de Geração de Colunas. O problema auxiliar derivado deste método é apresentado juntamente com algumas heurísticas para resolvêlo. O Capítulo 4 propõe uma redução polinomial do PSAT para o SAT, analisa sua complexidade computacional e propõe uma alternativa para contornar esta. No Capítulo 5, uma redução de Turing é apresentada do PSAT ao SAT, e melhorias são sugeridas em busca de eficiência. As implementações dos algoritmos propostos são utizadas para investigar o fenômeno de transição de fase do PSAT

no Capítulo 6. Finalmente, o Capítulo 7 sumariza as principais contribuições desta dissertação e sugere trabalhos futuros. 


\section{Capítulo 2}

\section{O Problema PSAT}

A consistência de probabilidades associadas a fórmulas lógicas foi primeiramente estudada de forma analítica por Boole [Boo54], atribuindo-se probabilidades desconhecidas às variáveis, cujo método foi estendido por Hailperin [Hai86]. O presente trabalho se dedica ao estudo do problema numérico, quando as probabilidades são dadas em números racionais, passíveis de representação e manipulação computacional. Métodos algébricos para soluções analíticas podem ser vistos em [HJ00].

Na teoria da complexidade computacional, a Satisfazibilidade Probabilística (PSAT) é um problema de decisão, onde se pergunta se há consistência em um conjunto de probabilidades atribuídas a fórmulas da lógica proposicional clássica.

Antes de definirmos formalmente o PSAT, apresentaremos brevemente a lógica proposicional clássica e seu problema de decisão inerente (SAT), do qual o PSAT pode ser entendido como extensão probabilística.

\subsection{A Lógica Proposicional Clássica e o Problema SAT}

A Lógica Proposicional é um sistema formal onde as fórmulas podem ser interpretadas como representando proposições. Assim, há o comprometimento ontológico com a existência de fatos (proposições). A seguir, apresentamos brevemente a construção de tais fórmulas (sintaxe) e a interpretação de seu significado (semântica).

\subsubsection{A Linguagem Proposicional}

A linguagem da lógica proposicional é formada por um conjunto de proposições constituídas de variáveis (variáveis Booleanas ou átomos) combinadas por conectivos lógicos, possivelmente com elementos de pontuação. Assim, temos o alfabeto da linguagem:

- um conjunto infinito e enumerável de símbolos $X=\left\{x_{1}, x_{2}, x_{3}, \ldots\right\}$ correspondente às variáveis;

- O conectivo unário $\neg$ (negação);

- Três conectivos binários: $\vee($ disjunção $), \wedge($ conjunção $)$ e $\rightarrow($ implicação $)$;

- Parênteses para pontuação: '(' e ')'. 
De posse do alfabeto, podemos agora definir uma fórmula bem formada da lógica proposicional, que denotaremos simplesmente por fórmula ou sentença:

- Toda variável proposicional é uma fórmula;

- Se $\alpha$ é uma fórmula, então $\neg \alpha$ é uma fórmula;

- Se $\alpha$ e $\beta$ são fórmulas, então $(\alpha \vee \beta),(\alpha \wedge \beta)$ e $(\alpha \rightarrow \beta)$ são fórmulas.

Para completar a definição, é necessário acrescentar que nada além destas regras de formação é fórmula. O conjunto de todas as fórmulas forma a a linguagem da lógica proposicional, $\mathcal{L}_{L P}$.

Os parênteses nas fórmulas podem ser omitidos para simplificar a notação, uma vez que há uma precedência entre os conectivos, que segue a ordem: $\neg, \wedge, \vee \mathrm{e} \rightarrow$. Ainda para economizar notação, utilizaremos o conectivo $\leftrightarrow$ (bi-implicação), onde $\alpha \leftrightarrow \beta$ denota $(\alpha \rightarrow \beta) \wedge(\beta \rightarrow \alpha)$.

\subsubsection{Semântica}

Cada variável proposicional pode assumir um valor verdade, verdadeiro ou falso, que representaremos por 1 e 0 , respectivamente. Uma valoração é uma função $v: X \rightarrow\{0,1\}$ que leva variáveis a um valor verdade.

Valorações podem ter seu domínio estendido para todo o conjunto $\mathcal{L}_{L P}$, respeitando as regras que definem a semântica dos conectivos na lógica. Sejam $\alpha$ e $\beta$ fórmulas da lógica proposicional clássica, tem-se:

- $v(\alpha \wedge \beta)=1$ se, e somente se, $v(\alpha)=1$ e $v(\beta)=1$;

- $v(\alpha \vee \beta)=1$ se, e somente se, $v(\alpha)=1$ ou $v(\beta)=1$;

- $v(\neg \alpha)=1$ se, e somente se, $v(\alpha)=0$;

- $v(\alpha \rightarrow \beta)=1$ se, e somente se, $v(\alpha)=0$ ou $v(\beta)=1$;

- $v(\alpha \leftrightarrow \beta)=1$ se, e somente se, $v(\alpha)=v(\beta)$.

Observando a semântica da negação, concluímos que $v(\neg \neg \alpha)=v(\alpha)$. Essa intepretação dos conectivos classifica esta lógica proposicional como clássica.

É sabido que fórmulas equivalentes a todas em $\mathcal{L}_{L P}$ podem ser escritas utilizando apenas a negação e outro conectivo (conjunção, disjunção ou implicação), porém o uso de mais conectivos facilita a notação e o manuseio das fórmulas.

\subsubsection{Forma Normal Conjuntiva}

Para facilitar o estudo de uma lógica, é conveniente o uso de um formato padrão para a escrita de suas fórmulas, uma vez que os conectivos nos permitem escrever fórmulas equivalentes de diferentes maneiras. Durante este trabalho, usamos recorrentemente o formato clausal, bem estabelecido para a representação e manipulação de fórmulas em computador.

Chamamos de literal uma fórmula composta simplesmente por um átomo acompanhado, ou não, do conectivo unário da negação. Por exemplo, $x_{1}$ e $\neg x_{1}$ são literais associados a variável $x_{1}$. 
Uma cláusula é uma fórmula composta pela disjunção de literais; e uma fórmula está na Forma Normal Conjuntiva (ou Formato Clausal) quando é a composta pela conjunção de cláusulas. Quando uma cláusula possui exatamente $L$ literais, a denominamos por $L$-cláusula.

Para toda fórmula em $\mathcal{L}_{L P}$, existe uma fórmula equivalente no formato clausal. Assim, as fórmulas nesse formato correspondem a todo o universo de fórmulas $\mathcal{L}_{L P}$, reduzindo a abordagem exaustiva destas à daquelas. O algoritmo que gera estas fórmulas equivalentes, no formato clausal, pode ser encontrado em [SFM06].

\subsubsection{O Problema da Satisfazibilidade Booleana}

Dizemos que uma valoração $v$, sobre as variáveis $X$, satisfaz a fórmula da lógica proposicional clássica $\alpha$ se, e somente se, $v(\alpha)=1$. Quando uma fórmula $\alpha$ é tal que existe uma valoração que a satisfaz, ela é dita satisfazível; caso contrário, $\alpha$ é insatisfazível.

O problema da Satisfazibilidade Booleana (SAT) é um problema de decisão onde perguntamos se dada fórmula $\alpha$ da lógica clássica proposicional, no formato clausal, é satisfazível. Tal problema é comumente chamado de Satisfazibilidade, mas aqui usaremos Satisfazibilidade Clássica, para diferenciar da Satisfazibilidade Probabilística.

Assim, uma instância SAT é uma fórmula no formato clausal, e denotamos por SAT Solver qualquer implementação de um algoritmo completo que decida a satisfazibilidade destas instâncias. Como o SAT foi o primeiro problema a ser demonstrado NP-completo, em [Coo71], e sua investigação está no cerne da questão aberta $\mathrm{P}=$ ?NP, não se conhece até a presente data SAT Solvers polinomiais em relação ao tamanho da entrada, uma fórmula. Uma investigação mais detalhada do SAT pode ser vista em [SFM06].

Quando todas as cláusulas de $\alpha$ são $L$-cláusulas, temos o problema $L$-SAT. Sabemos que o problema 2-SAT pertence a classe $P$, pois há algoritmo de tempo polinomial para decidi-lo, que pode ser encontrado em [SFM06]. Assim, frequentemente estudos computacionais do SAT se restringem ao 3-SAT, pois este ainda é NP-completo, e um algoritmo polinomial para transformar instâncias SAT em instâncias 3-SAT pode ser visto em [SFM06].

\subsection{Definição Formal do Problema PSAT}

Seja $S=\left\{s_{1}, \ldots, s_{k}\right\}$ um conjunto de $k$ sentenças lógicas sobre um conjunto de $n$ variáveis Booleanas $X=\left\{x_{1}, \ldots, x_{n}\right\}$, com os operadores usuais da lógica proposicional clássica. Dado um conjunto de probabilidades $P=\left\{p_{i} \mid 0 \leq p_{i} \leq 1,1 \leq i \leq k\right\}$, uma instância do problema PSAT (ou instância PSAT) é formada pela atribuição das probabilidades de $P$ a sentenças de $S:\left\{p\left(s_{i}\right)=p_{i} \mid 1 \leq i \leq k\right\}$. Dizemos que uma instância PSAT é satisfazível se, e somente se, tal atribuição de probabilidades é consistente.

Seja $V=\left\{v_{1}, \ldots, v_{2^{n}}\right\}$ o conjunto das valorações possíveis sobre $X$, e $\pi$, uma distribuição de probabilidade sobre $V$. A probabilidade de uma fórmula $s$ de acordo com $\pi$ é dada por $p_{\pi}(s)=$ $\sum\left\{\pi\left(v_{j}\right) \mid v_{j}(s)=1\right\}$. As probabilidades $p_{i}$ atribuídas às fórmulas de $S$ serão consistentes sse ${ }^{1}$ houver uma distribuição de probabilidade $\pi$ sobre $V$ que faça $p_{\pi}\left(s_{i}\right)=p_{i}, 1 \leq i \leq k$. Ressaltamos que as probabilidades aqui respeitam os axiomas de Kolmogorov.

O seguinte exemplo mostra a formalização de um problema prático em uma instância PSAT:

\footnotetext{
${ }^{1}$ Utilizaremos com frequência a abreviação "sse"para "se, e somente se".
} 
Exemplo 2.2.1. Um médico estuda a relação de 3 genes com a ocorrência de uma doença $D$. Sua hipótese é que, para tal doença se desenvolver em uma pessoa, esta precisa possuir pelo 2 daqueles 3 genes. Experimentos mostram que a presença de cada gene foi detectada em $60 \%$ dos pacientes que tem a doença $D$. Quer-se saber se os experimentos são consistentes com a hipótese.

Se associarmos as variáveis lógicas $x_{1}, x_{2}$ e $x_{3}$ à ocorrência de cada um dos 3 genes em paciente, podemos representar a hipótese do médico como $p\left(\left(x_{1} \vee x_{2}\right) \wedge\left(x_{1} \vee x_{3}\right) \wedge\left(x_{2} \vee x_{3}\right)\right)=1$. Atribuir probabilidade 1 para esta fórmula corresponde a esperar que todo paciente da doença $D$ possua pelo menos 2 dos genes. Associando então a medida de frequência de cada gene com a probabilidade de sua ocorrência, os experimentos nos dão três atribuições de probabilidade: $p\left(x_{1}\right)=0,6, p\left(x_{2}\right)=0,6$ e $p\left(x_{3}\right)=0,6$. Temos assim a seguinte instância PSAT:

$$
\begin{array}{r}
p\left(\left(x_{1} \vee x_{2}\right) \wedge\left(x_{1} \vee x_{3}\right) \wedge\left(x_{2} \vee x_{3}\right)\right)=1 \\
p\left(x_{1}\right)=0,6 \\
p\left(x_{2}\right)=0,6 \\
p\left(x_{3}\right)=0,6
\end{array}
$$

Note que cada paciente pode ter ou não cada gene, o que nos permite os classificar em 8 grupos diferentes, correspondentes às valorações sobre $x_{1}, x_{2}, x_{3}$. Se esta instância PSAT for satisfazível, teremos uma possível distribuição dos pacientes nestes 8 grupos onde cada paciente apresenta pelo menos 2 dos três genes e ao mesmo tempo cada gene ocorre apenas em $60 \%$ dos pacientes, confimando a hipótese do médico. Caso contrário, a ausência de solução para tal instância PSAT atesta a incosistência dos experimentos com a hipótese em questão.

O problema PSAT pode ser expresso matematicamente como um problema de programação linear, como feito em [Nil86], que também investigou fórmulas da lógica de primeira ordem. Seja $\Delta$ a instância PSAT formada pela atribuição das probabilidades do conjunto $P$ às $k$ fórmulas do conjunto $S, \Delta=\left\{p\left(s_{i}\right)=p_{i} \mid 1 \leq i \leq k\right\}$. Definimos a matriz $A_{k \times 2^{n}}=\left[a_{i j}\right]$, tal que $a_{i j}=v_{j}\left(s_{i}\right)$, e o vetor $p_{k \times 1}=\left[p_{i}\right]$. Temos que $\Delta$ é satisfazível sse há um vetor $\pi$ que satisfaz as restrições:

$$
\begin{aligned}
A \pi & =p \\
\pi & \geq 0 \\
\sum \pi & =1
\end{aligned}
$$

Se existir tal solução, dizemos que $\pi$ satisfaz $\Delta$, caso contrário dizemos que $\Delta$ é (probabilisticamente) insatisfazível. As restrições (2.2) e (2.3) forçam que $\pi$ seja uma distribuição de probabilidade. A restrição (2.3) pode ser omitida se adicionarmos a $A$ uma linha inteira de $1^{\prime} s$, de tal maneira que $a_{k+1, j}=1,1 \leq j \leq 2^{n}$, e adicionarmos a $p$ um elemento $p_{k+1}=1$, o que faremos com frequência no restante deste trabalho.

O próximo exemplo mostra uma instância PSAT satisfazível em sua formulação de problema de programação linear.

Exemplo 2.2.2. Um morador da Cidade do Trânsito reclama que em média apenas uma vez por semana não encontra engarrafamentos a caminho do trabalho - e se indaga sobre a culpa da chuva. Por outro lado, um jornal local destaca que em $90 \%$ dos dias não chove forte na cidade e que 
em apenas $10 \%$ dos dias tem-se trânsito lento e chuva forte. Queremos saber se a reclamação do morador é consistente com os dados do jornal.

Para formalizar o problema como uma instância PSAT, usaremos duas variáveis lógicas: $c$, que só é verdadeira nos dias de chuva forte; e $t$, que indica a presença de trânsito lento na Cidade do Trânsito. Supondo que o morador trabalhe 5 dias por semana, podemos dizer que ele não encontra trânsito lento em $20 \%$ dos dias, ou $p(\neg t)=20 \%$, usando uma interpretação frequentista da probabilidade. De acordo com o jornal, tem-se $p(\neg c)=90 \%$ e $p(c \wedge t)=10 \%$, se novamente associarmos probabilidades às frequências. A reclamação do morador e os dados do jornal serão consistentes sse a instância PSAT $\Delta=\{p(\neg t)=20 \%, p(\neg c)=90 \%, p(c \wedge t)=10 \%\}$ for satisfazível.

Vamos construir a matriz $A_{k \times 2^{n}}=\left[a_{i j}\right]$, tal que $a_{i j}=v_{j}\left(s_{i}\right)$. Com 2 variáveis, temos 4 valorações, correspondentes às colunas: $v_{1}(c)=0, v_{1}(t)=0, v_{2}(c)=1, v_{2}(t)=0, v_{3}(c)=1, v_{3}(t)=1, v_{4}(c)=0$ e $v_{4}(t)=1$. As 3 sentenças com probabilidade atribuída levam às 3 linhas:

$\begin{array}{ccccc}s_{i} & v_{1} & v_{2} & v_{3} & v_{4} \\ \neg t & 1 & 1 & 0 & 0 \\ \neg c & 1 & 0 & 0 & 1 \\ c \wedge t & 0 & 0 & 1 & 0\end{array}$

Pergunta-se então se existe uma distribuição de probabilidade $\pi$ que, juntamente com a matriz $A$ explicitada, satisfaça as restições (2.1-2.3). Acrescentando uma linha de 1's abaixo de $A$, para representar a condição (2.3), mostramos um vetor $\pi \geq 0$ tal que $A \pi=p$ :

$$
\left.\begin{array}{cccc}
1 & 1 & 0 & 0 \\
1 & 0 & 0 & 1 \\
0 & 0 & 1 & 0 \\
1 & 1 & 1 & 1
\end{array}\right] \cdot\left[\begin{array}{c}
0,2 \\
0 \\
0,1 \\
0,7
\end{array}\right]=\left[\begin{array}{c}
0,2 \\
0,9 \\
0,1 \\
1
\end{array}\right]
$$

Temos finalmente que a instância PSAT $\Delta$ é satisfazível, indicando a consistência da reclamação do morador e dos dados do jornal. Ainda observamos que, de acordo com a distribuição de probabilidade apresentada, embora em todo dia com chuva forte se tenha trânsito lento, na maioria dos dias (70\%) há trânsito lento mesmo sem chuva forte.

\subsection{Complexidade Computacional}

O Lema de Carathéodory [PT01] garante que, se o problema de programação linear (2.1-2.3) tem solução, então há uma solução com o máximo $k+1$ elementos de $\pi$ diferentes de zero. Como observado em [GKP88], isso faz com que o PSAT esteja em NP, pois podemos tomar uma matriz $A_{k+1, k+1}$, incluindo a condição (2.3), e um vetor $\pi_{k+1,1} \geq 0$ como NP-certificado, verificando as relações (2.1-2.3) em tempo polinomial. Além disso, uma instância SAT, formada por um conjunto $S$ de $k$ sentenças, pode ser reduzida a uma instância PSAT, em tempo polinomial em $k$, fazendo $p\left(s_{i}\right)=p_{i}=1$, para $1 \leq i \leq k$. Segue que PSAT é NP-difícil e, logo, NP-completo [GKP88].

Seja $\Pi$ um problema de decisão, e seja $D_{\Pi}$ uma codificação razoável (não unária para os parâmetros numéricos) das instâncias de П em uma liguagem formal. Seja $p$ um polinômio sobre os inteiros. Seja $I$ uma instância codificada de $\Pi$ (uma "string"), tal que $I \in D_{\Pi}$. Denotamos por Length(I) 
o tamanho da instância $I$. Denotamos por $\operatorname{Max}(I)$ a magnitude do maior número em $I$, ou seja, o maior parâmetro númerico (em valor absoluto) na instância representada por $I$. Garey e Johnson definem que um problema de decisão $\Pi$ é um problema numérico se não existe polinômio $p$ tal que $\operatorname{Max}(I) \leq p(\operatorname{Length}(I))$, para todo $I \in D_{\Pi}$ [GJ79]. Como as instâncias do PSAT contêm parâmetros racionais cujos denominadores e numeradores são arbitrariamente grandes, PSAT é um problema numérico. Em outras palavras, se a codificação de uma instância PSAT em uma "string"possui no máximo $c$ caracteres, não conseguimos limitar os denominadores e numeradores das probabilidades atribuídas a um polinômio sobre $c$, pois estes podem estar representados em um sistema posicional (codificação razoável), onde a magnitude do número é exponencial em relação ao seu tamanho.

Seja $\Pi_{p}$ o subproblema de $\Pi$ formado pelas instâncias $I$ que satisfazem $\operatorname{Max}(I) \leq p(\operatorname{Length}(I))$, para algum polinômio sobre os inteiros $p$. Garey e Johnson definem NP-completude no sentido forte: um problema de decisão $\Pi$ é NP-completo no sentido forte se П é NP-completo e existe um polinômio $p$ sobre os inteiros tal que $\Pi_{p}$ é NP-completo [GJ79]. Como o SAT é um subproblema do PSAT, quando limitamos as probabilidades a 1, este também é NP-completo no sentido forte. Alguns problemas NP-completos conhecidos da teoria dos grafos são também simultaneamente problemas numéricos e NP-completos no sentido forte: o Problema do Caixeiro Viajante; e o problema de achar o caminho mais longo entre um par de vértices em um grafo com arestas ponderadas [GJ79].

\subsection{Casos Polinomiais}

Se $P \neq N P$, a NP-completude de um problema de decisão implica tempo super-polinomial, em relação ao tamanho da entrada, no pior caso de qualquer algoritmo que o resolva exatamente. Daí surge o interesse em investigar estruturas de instâncias PSAT que possam ser resolvidas por um algoritmo de tempo polinomial em relação ao tamanho da entrada (denotaremos simplesmente por polinomial). O PSAT é de certa forma uma extensão probabilística do SAT, tendo este como subproblema. Um caso polinomial bem conhecido do SAT é o 2-SAT, onde cada fórmula é uma cláusula com no máximo dois literais. Com base nisso, no primeiro estudo sobre a complexidade do PSAT, o caso 2-PSAT (extensão do 2-SAT) foi investigado, porém interessantemente demonstrado NP-completo via redução do problema de 3-colorabilidade de grafos [GKP88].

Podendo o PSAT ser visto como um problema de programação linear, podemos utilizar-nos dos métodos desta para abordar o problema. Se aplicarmos o Algoritmo da Elipsóide (descrito por exemplo em [PS98]), reduzimos uma instância PSAT a um número polinomial de instâncias da versão de decisão do MAXSAT Ponderado, sobre as mesmas fórmulas do PSAT (desde que sejam cláusulas), mais um número polinomial de operações, como mostrado em [GKP88]. Assim, toda estrutura de fórmulas que leve a um caso polinomial do MAXSAT Ponderado na sua versão de decisão, também será um caso polinomial do PSAT.

O MAXSAT Ponderado é um problema de otimização, onde tem-se um conjunto de cláusulas $C=\left\{c_{1}, \ldots, c_{k}\right\}$, sobre as variáveis $X=\left\{x_{1}, \ldots, x_{n}\right\}$, e procura-se a valoração $v: X \rightarrow\{0,1\}$ que maximiza $\sum_{k} v\left(c_{k}\right) w_{k}$. Em outras palavras, a valoração que maximiza a soma dos pesos das clásulas por ela satisfeita. Em sua versão de decisão, que chamaremos de MAXSAT Pivô Ponderado ${ }^{2}$, tem-se

\footnotetext{
${ }^{2}$ Para as versões de decisão do MAXSAT, usaremos sempre o nome MAXSAT Pivô, para diferenciar do problema de otimização.
} 
ainda um número $W$ e pergunta-se se existe uma valoração $v: X \rightarrow\{0,1\}$ tal que $\sum_{k} v\left(c_{k}\right) w_{k}>W$. Em outras palavras, quer-se saber se existe uma valoração tal que a soma dos pesos das cláusulas por ela satisfeitas é maior que um limiar $W$. O MAXSAT Pivô Ponderado generaliza o MAXSAT Pivô (caso onde $w_{i}=1$, para todo $i$ ), ambos NP-completos [GJ79]. O MAXSAT Ponderado, sendo um problema de otimização, é NP-difícil.

Partindo então do MAXSAT Pivô Ponderado, Georgakopoulos, Kavvadias e Papadimitriou demonstraram os primeiros casos polinomiais do PSAT [GKP88], que apresentaremos neste parágrafo de forma resumida. O 2-MAXSAT Pivô Ponderado é o subproblema resultante da limitação do número de literais por cláusula a 2. Garey e Johnson mostraram que o 2-MAXSAT Pivô Ponderado pode ser reduzido ao MAXCUT, um problema em teoria grafos, em tempo polinomial [GJ79]. O MAXCUT por sua vez pode ser resolvido em tempo polinomial se o grafo for planar. Seja $S$ um conjunto de cláusulas. Define-se $G(S)$ como o grafo de $S$, cujos vértices representam os literais de $S$, e cujas arestas unem vértices correspondentes a literais que aparecem na mesma cláusula, além de unir vértices correspondentes a literais contrários $(x$ e $\neg x)$. Dizemos que um grafo é outerplanar se é planar e, adicionando um vértice adjacente a todos os demais, o grafo continua planar. Seja $S$ o conjunto de cláusulas de uma instância 2-PSAT. Se o grafo $G(S)$ for outerplanar, os grafos das instâncias 2-MAXSAT Pivô Ponderado resultantes também serão, e, reduzindo estas ao MAXCUT, chega-se a grafos planares. Conclui-se que o 2-PSAT sobre um conjunto de cláusulas cujo grafo é outerplanar pode ser resolvido em tempo polinomial. Dizemos que cláusulas são acíclicas quando seu grafo de co-ocorrência, onde os vértices representam as variáveis, e as arestas representam coocorrência em um cláusula, é acíclico. Um corolário é que o 2-PSAT sobre um conjunto de cláusulas acíclicas é também polinomial.

Andersen e Pretolani identificaram outros dois casos polinomiais do PSAT [AP01], cuja definição passa por conceitos da teoria dos grafos que enunciaremos informalmente. Um grafo é cordal se todos seus ciclos com 4 ou mais vértices possuem alguma corda, que é uma aresta ligando vértices não adjacentes no ciclo. Um clique em um grafo é um subconjunto de vértices adjacentes dois-a-dois, e o tamanho de um clique é seu número de vértices. A largura em árvore de um grafo $G$ é um a menos que o tamanho do maior clique contido em qualquer grafo cordal que contenha $G$. Grafos com largura em árvore menor ou igual a $k$ são chamados de $k$-árvores parciais. Andersen e Pretolani reduziram um caso do PSAT, sobre cláusulas cujo grafo de co-ocorrência é uma 2-árvore parcial, a um sistema linear com $O(n)$ equações e $O(n)$ variáveis [AP01], que pode ser resolvido em tempo polinomial.

No mesmo trabalho [AP01], os autores apresentam outro caso polinomial do PSAT, usando hipergrafos. Informalmente, um hipergrafo direcionado é um conjunto de vértices e hiper-arestas direcionadas, que ligam dois conjuntos disjuntos de vértices, chamados de cauda e cabeça da hiperaresta. Diz-se que um vértice pertence a uma hiper-aresta se pertence a sua cauda ou cabeça. Um caminho de tamanho $q$ em um hipergrafo é uma sequência de $q+1$ vértices, $v_{1}, \ldots, v_{q+1}$, intercalados com $q$ hiper-arestas, $e_{1}, \ldots, e_{q}$, de tal forma que $v_{i}, v_{i+1} \in e_{i}$, para $1 \leq i \leq q$. Um ciclo em um hipergrafo é um caminho de tamanho $q$ tal que $v_{1}=v_{q+1}$. Se um hipergrafo é acíclico, e possui um caminho entre qualquer par de vértices, é uma hiper-árvore. Podemos representar um conjunto de cláusulas $S$, sobre as variáveis $x_{1}, \ldots, x_{n}$, por um hipergrafo direcionado da seguinte maneira: associamos um vértice a cada variável e, para cada cláusula $s \in S$, adicionamos uma hiper-aresta que sai do conjunto de vértices associados às variáveis que aparecem negadas em $s$ e chega no 
conjunto de vértices associados às variáveis que aparecem não negadas em $s$. Os autores mostram que uma instância PSAT sobre cláusulas cujo hipergrafo é uma hiper-árvore pode ser reduzida a um sistema de $3 n$ inequações lineares com $n$ variáveis, que também pode ser resolvido em tempo polinomial.

\subsection{A Forma Normal Atômica}

Uma forma normal para um problema nos permite apresentar suas instâncias de uma maneira padronizada. Se um problema de decisão possui uma forma normal, toda instância sua possui uma instância equivalente na forma normal. Isso nos permite focar a atenção em instâncias em tal formato, facilitando a investigação das propriedades do problema. Entretanto, não é encontrada na literatura uma formal normal para o problema PSAT, o que nos motiva a introduzir uma. A forma normal atômica aqui apresentada foi inicialmente definida em [FDB10b].

Seja $S=\left\{s_{1}, \ldots, s_{l}\right\}$ um conjunto de sentenças da lógica proposicional clássica, sobre o conjunto de variáveis Booleanas $X=\left\{x_{1}, \ldots, x_{n}\right\}$. Dizemos que uma instância PSAT, $\Delta=\left\{p\left(s_{i}\right)=\right.$ $\left.p_{i} \mid 1 \leq i \leq l\right\}, 0 \leq p_{i} \leq 1$, está na Forma Normal Atômica sse puder ser particionada em dois conjuntos, $\langle\Gamma, \Psi\rangle$, onde $\Gamma=\left\{p\left(s_{i}\right)=1 \mid 1 \leq i \leq m\right\}$ e $\Psi=\left\{p\left(y_{i}\right)=p_{i} \mid y_{i}\right.$ é um átomo, e $\left.1 \leq i \leq k\right\}$, com $0 \leq p_{i} \leq 1$, onde $l=m+k$. A partição $\Gamma$ é a parte SAT da forma normal atômica, representada geralmente pelo conjunto de fórmulas cuja probabilidade atribuída é igual a 1, nesse caso $\Gamma=\left\{s_{1}, \ldots, s_{m}\right\}$. A partição $\Psi$ é a parte de atribuição de probabilidades atômicas, onde as probabilidades são atribuídas somente às variáveis (átomos). O teorema a seguir mostra como qualquer instância PSAT pode ser trazida para a forma normal atômica, adicionando um número linear de novas variáveis.

Teorema 2.5.1 (Forma Normal Atômica). Seja $\Delta=\left\{p\left(s_{i}\right)=p_{i} \mid 1 \leq i \leq k\right\}$ uma instância do problema PSAT, então pode-se construir, em tempo polinomial, uma instância $P S A T\langle\Gamma, \Psi\rangle$ na forma normal atômica, tal que $\Delta$ é satisfazivel se, e somente se, $\langle\Gamma, \Psi\rangle$ também o é.

Demonstração. Para construirmos, a partir de uma instância PSAT $\Delta=\left\{p\left(s_{i}\right)=p_{i}, 1 \leq i \leq k\right\}$, uma instância PSAT na forma normal atômica $\langle\Gamma, \Psi\rangle$, primeiramente adicionamos $k$ novas variáveis, $y_{1}, \ldots, y_{k}$. Então fazemos $\Gamma=\left\{y_{i} \leftrightarrow s_{i} \mid 1 \leq i \leq k\right\}$, ou $\Gamma=\left\{p\left(y_{i} \leftrightarrow s_{i}\right)=1 \mid 1 \leq i \leq k\right\}$, e $\Psi=\left\{p\left(y_{i}\right)=p_{i} \mid 1 \leq i \leq k\right\}$. Claramente, isso pode ser feito em tempo polinomial sobre $k$.

Suponha que haja uma distribuição de probabilidade $\pi$, sobre as valorações $v:\left\{x_{1}, \ldots, x_{n}\right\} \cup$ $\left\{y_{1}, \ldots, y_{k}\right\} \rightarrow\{0,1\}$, que satisfaça $\langle\Gamma, \Psi\rangle$. Como $\pi$ satisfaz $\langle\Gamma, \Psi\rangle$, temos que $p_{\pi}\left(y_{i}\right)=p_{i}, 1 \leq$ $i \leq k$. Pela construção de $\Gamma$, e pelas leis da probabilidade, temos que $p_{\pi}\left(y_{i}\right)=p_{\pi}\left(s_{i}\right)$ e, logo, $p_{\pi}\left(s_{i}\right)=p_{i}, 1 \leq i \leq k$. Sobre as valorações $v^{\prime}:\left\{x_{1}, \ldots, x_{n}\right\} \rightarrow\{0,1\}$, definimos uma distribuição de probabilidade $\pi$ :

$$
\pi^{\prime}\left(v^{\prime}\right)=\sum\left\{\pi(v) \mid v\left(x_{i}\right)=v^{\prime}\left(x_{i}\right), 1 \leq i \leq n\right\}
$$

Assim $\pi^{\prime}$ é uma distribuição de probabilidade, sobre valorações $v^{\prime}:\left\{x_{1}, \ldots, x_{n}\right\} \rightarrow\{0,1\}$, que satisfaz $p_{\pi^{\prime}}\left(s_{i}\right)=p_{i}, 1 \leq i \leq k$ e consequentemente $\pi^{\prime}$ satisfaz $\Delta$.

Por outro lado, suponha que haja uma distribuição de probabilidade $\pi^{\prime}$ sobre as valorações $v^{\prime}:\left\{x_{1}, \ldots, x_{n}\right\} \rightarrow\{0,1\}$ que satisfaça $\Delta$. Como $\pi^{\prime}$ satisfaz $\Delta, p_{\pi^{\prime}}\left(s_{i}\right)=p_{i}, 1 \leq i \leq k$. Definimos uma distribuição de probabilidade $\pi$ sobre as valorações $v:\left\{x_{1}, \ldots, x_{n}\right\} \cup\left\{y_{1}, \ldots, y_{k}\right\} \rightarrow\{0,1\}$ : 


$$
\pi(v)=\left\{\begin{aligned}
\pi^{\prime}\left(v^{\prime}\right) & , \text { se } v\left(x_{i}\right)=v^{\prime}\left(x_{i}\right) \text { e } v\left(y_{j}\right)=v\left(s_{j}\right), 1 \leq i \leq n \text { e } 1 \leq j \leq k \\
0 & , \text { caso contrário }
\end{aligned}\right.
$$

Claramente, temos $p_{\pi}\left(s_{i}\right)=p_{\pi^{\prime}}\left(s_{i}\right)$ e $p_{\pi}\left(y_{i}\right)=p_{\pi}\left(s_{i}\right), 1 \leq i \leq k$. Daí segue que $p_{\pi}\left(y_{i}\right)=p_{\pi^{\prime}}\left(s_{i}\right)=p_{i}$, $1 \leq i \leq k$, e então $\pi$ satisfaz $\Psi$. Para todo $v$, tal que $\pi(v) \neq 0$, tem-se $v\left(y_{i}\right)=v\left(s_{i}\right), 1 \leq i \leq k$, então $p_{\pi}\left(y_{i} \leftrightarrow s_{i}\right)=1,1 \leq i \leq k$, e $\pi$ satisfaz $\Gamma$. Finalmente, $\pi$ satisfaz $\langle\Gamma, \Psi\rangle$.

O exemplo a seguir ilustra o método para levar qualquer instância PSAT à forma normal atômica.

Exemplo 2.5.2. Seja a instância PSAT $\Delta=\left\{p\left(x_{1} \vee x_{2}\right)=0,7 ; p\left(x_{2} \vee x_{3}\right)=0,4 ; p\left(x_{1} \wedge \neg x_{3}\right)=\right.$ $0,2\}$. Seguindo o algoritmo apresentado na demostração do Teorema 2.5.1, adicionamos 3 novas variáveis: $y_{1}, y_{2}$ e $y_{3}$. Fazemos com que, para toda valoração com probabilidade positiva, cada nova variável tenha o mesmo valor verdade da fórmulas em $\Delta$ correspondente, ou seja $\Gamma=\left\{y_{1} \leftrightarrow\right.$ $\left.x_{1} \vee x_{2}, y_{2} \leftrightarrow x_{2} \vee x_{3}, y_{3} \leftrightarrow x_{1} \wedge \neg x_{3}\right\}$. Então atribuímos as probabilidades aos novos átomos, fazendo $\Psi=\left\{p\left(y_{1}\right)=0,7 ; p\left(y_{2}\right)=0,4 ; p\left(y_{3}\right)=0,2\right\}$. Temos então uma instância PSAT $\langle\Gamma, \Psi\rangle$ na forma normal atômica que é satisfazível sse $\Delta$ o for.

A forma normal atômica permite que vejamos uma instância $\operatorname{PSAT}\langle\Gamma, \Psi\rangle$ como a interação entre uma atribuição de probabilidades, representada por $\Psi$, e uma instância SAT $\Gamma$, desde que suas fórmulas estejam no formato clausal. Claro que, se as estas não forem cláusulas, podemos transformá-las em tempo polinomial. Assim, soluções para $\langle\Gamma, \Psi\rangle$ podem ser vistas como soluções para $\Psi$ restringidas pela instância SAT $\Gamma$.

O 3-SAT é o problema SAT restrito a cláusulas com no máximo 3 literais. Com adição de novas variáveis, qualquer instância SAT $\Gamma$ pode ser reduzida, em tempo polinomial, a uma instância 3-SAT $\Gamma^{\prime}$ que é satisfazível sse $\Gamma$ o for. Tal redução pode ser feita de tal forma que para cada valoração que satisfaz $\Gamma^{\prime}$ existe exatamente 1 valoração que satisfaz $\Gamma$, sendo que ambas as valorações concordam nas variáveis comuns a $\Gamma$ e $\Gamma^{\prime}$. Isso possibilita uma restrição no estudo do PSAT à forma normal atômica com $\Gamma$ sendo uma instância 3-SAT.

Seja $v^{\prime}$ uma valoração sobre $\left\{y_{1}, \ldots, y_{k}\right\}$. Dizemos que $v^{\prime}$ é consistente com $\Gamma$, uma instância SAT sobre as variáveis $\left\{y_{1}, \ldots, y_{k}\right\} \cup\left\{x_{1}, \ldots, x_{n}\right\}$, sse existe uma valoração $v:\left\{y_{1}, \ldots, y_{k}\right\} \cup$ $\left\{x_{1}, \ldots, x_{n}\right\} \rightarrow\{0,1\}$ que satisfaz $\Gamma$, tal que $v\left(y_{i}\right)=v^{\prime}\left(y_{i}\right), 1 \leq i \leq k$. O resultado a seguir mostra que, quando uma instância PSAT $\langle\Gamma, \Psi\rangle$ na forma normal atômica é satisfazível, a probabilidade é distribuída apenas sobre valorações que satisfazem $\Gamma$.

Lema 2.5.3. Seja $\langle\Gamma, \Psi\rangle$ uma instância do problema PSAT na forma normal atômica, onde $\Psi=$ $\left\{p\left(y_{i}\right)=p_{i}, 1 \leq i \leq k\right\}$, e $\Gamma$, uma instância do SAT sobre as variáveis $\left\{x_{1}, \ldots, x_{n}\right\} \cup\left\{y_{1}, \ldots, y_{k}\right\}$. Se $\langle\Gamma, \Psi\rangle$ é satisfeito pela distribuição de probabilidade $\pi$, então toda valoração $v:\left\{x_{1}, \ldots, x_{n}\right\} \cup$ $\left\{y_{1}, \ldots, y_{k}\right\} \rightarrow\{0,1\}$, tal que $\pi(v)>0$, estende uma valoração $v^{\prime}:\left\{y_{1}, \ldots, y_{k}\right\} \rightarrow\{0,1\}$, com $v\left(y_{i}\right)=v^{\prime}\left(y_{i}\right), 1 \leq i \leq k$, tal que $v^{\prime}$ é consistente com $\Gamma$.

Demonstração. Para toda fórmula $s_{i} \in \Gamma$, tem-se $p_{\pi}\left(s_{i}\right)=1$. Logo, para qualquer distibuição $\pi$ que satisfaça $\langle\Gamma, \Psi\rangle$, se uma valoração $v:\left\{x_{1}, \ldots, x_{n}\right\} \cup\left\{y_{1}, \ldots, y_{k}\right\} \rightarrow\{0,1\}$ é tal que $\pi(v)>0, v$ deve satisfazer todas fórmulas $s_{i} \in \Gamma$, pois se $v$ não satisfizesse algum $s_{i} \in \Gamma$, teríamos $p_{\pi}\left(s_{i}\right)<1$, não satisfazendo $\Gamma$, o que é uma contradição. Construindo uma valoração $v^{\prime}:\left\{y_{1}, \ldots, y_{k}\right\} \rightarrow\{0,1\}$, $\operatorname{com} v^{\prime}\left(y_{i}\right)=v\left(y_{i}\right), 1 \leq i \leq k, v^{\prime}$ deve ser consistente com $\Gamma$ por definição, já que $v$ satisfaz $\Gamma$. 
Agora podemos enunciar o resultado que limita o tamanho da matriz da matriz $A$ na formulação de programação linear (2.1) de uma instância $\operatorname{PSAT}\langle\Gamma, \Psi\rangle$ na forma normal atômica a $|\Psi|+1$, onde $|\Psi|=k$ é o número de probabilidades atômicas atribuídas. Esse resultado é essencial para o desenvolvimento de algoritmos voltados a instâncias na forma normal atômica apresentados nos Capítulos 4 e 5 .

Teorema 2.5.4. Seja $\Psi=\left\{p\left(y_{i}\right)=p_{i} \mid 1 \leq i \leq k\right\}$. Uma instância PSAT na forma normal atômica $\langle\Gamma, \Psi\rangle$ é satisfazivel sse existe uma matriz $A_{\Psi}$, com $k$ linhas e até $k+1$ colunas que, junto de um vetor $\pi$, atende às restrições (2.1-2.3), tal que cada coluna de $A_{\Psi}$ corresponde a uma valoração sobre $\left\{y_{1}, \ldots, y_{k}\right\}$ consistente com $\Gamma$.

Demonstração. Suponha que $\Gamma$ contém $m$ fórmulas sobre as variáveis $x_{1}, \ldots, x_{n}$. Se $\langle\Gamma, \Psi\rangle$ é satisfazível, existe uma matriz $A,(m+k) \times\left(2^{n+k}\right)$, e uma distribuição de probabilidade $\pi$, sobre as $2^{n+k}$ valorações, que satisfazem as restrições (2.1-2.3). Construímos $A^{\prime}$ retirando de $A$ todas as colunas referentes a valorações $v_{j}$, tal que $\pi\left(v_{j}\right)=0$, e construímos $\pi^{\prime}$ eliminando os $\pi_{j}$ nulos, referentes a $\pi\left(v_{j}\right)=0$. Claramente, $A^{\prime}$ e $\pi^{\prime}$ satisfazem (2.1-2.3). Para toda fórmula $s_{i} \in \Gamma$, temos $p_{\pi^{\prime}}\left(s_{i}\right)=1$. As linhas que representam as fórmulas $s_{i}$ são compostas de 1's, sendo redundantes com a condição (2.3), e podem ser excluídas de $A^{\prime}$, juntamente com os $p_{i}$ 's correspondentes. Assim obtemos a matriz $A^{\prime \prime}$, com $k$ linhas, que com $\pi^{\prime}$ satisfaz (2.1-2.3). Então, pelo Lema de Carathéodory, existe uma matriz $A_{\Psi}$ com $k$ linhas e até $k+1$ colunas (linearmente independentes) que, juntamente com uma distribuição de probabilidade, satisfaz (2.1-2.3). E, pelo Lema 2.5.3, as valorações correspondentes às colunas de $A_{\Psi}$ devem ser consistentes com $\Gamma$.

Agora suponha que existe uma matriz $A_{\Psi}$, com $k$ linhas e $k^{\prime} \leq k+1$ colunas, que, juntamente com uma distribuição de probabilidade $\pi$, atende às restrições (2.1-2.3), e suas colunas representam valorações sobre $y_{1}, \ldots, y_{k}$ consistentes com $\Gamma$. Construímos $A^{\prime}$ adicionando $m$ linhas com $1^{\prime} s$, correspondendo às formulas de $\Gamma$, e adicionamos a $p$ os $m$ 1's correspondentes. Assim, cada coluna de $A^{\prime}$ representa uma valoração que satisfaz $\Gamma$. Claramente, $A^{\prime}$ e $\pi$ satisfazem as restrições (2.1-2.3), logo $\langle\Gamma, \Psi\rangle$ é satisfazível.

\subsection{Variações do PSAT}

O problema PSAT possui extensões e variações normalmente desenvolvidas conforme a necessidade prática de se resolver problemas semelhantes. Nesta seção nos atemos a problemas numéricos, de decisão e otimização, com 3 variações do PSAT de maior interesse. Note que neste trabalho não abordaremos estas variações do problema, apenas apresentando-as. Uma lista mais completa das variações do PSAT pode ser vista em [HJ00].

\subsubsection{PSAT na Forma de Otimização}

Quando Nilsson redescobriu a lógica probabilítica em [Nil86], distinguiu dois problemas: o PSAT sobre fórmulas da lógica de primeira ordem, tratando da consistência das probabilidades atribuídas, e a sua versão de otimização, extensão denominada então de Acarretamento Probabilístico (Probabilistic Entailment). Georgakopoulos, Kavvadias e Papadimitriou limitaram os problemas a lógica proposicional e batizaram o primeiro de Satisfazibilidade Probabilística (PSAT) [GKP88], 
por ser uma extensão da satisfazibilidade clássica (SAT); e Kavvadias e Papadimitriou denotaram o segundo por OPSAT [KP90], por ser a versão de otimização do PSAT.

Formalmente, temos uma instância PSAT $\Delta=\left\{p\left(s_{i}\right)=p_{i} \mid 1 \leq i \leq m\right\}$, e nos é dada mais uma fórmula $s_{m+1}$. O OPSAT pergunta qual é a maior (ou menor) probabilidade $p_{m+1}$ que podemos atribuir a $s_{m+1}$ de tal forma que $\Delta^{\prime}=\left\{p\left(s_{i}\right)=p_{i} \mid 1 \leq i \leq m+1\right\}$ seja probabilisticamente satisfazível. Claro que, se $\Delta$ já é probabilisticamente insatisfazível, então o OPSAT não tem solução. Resgatando a formulação de programação linear do PSAT (2.1-2.3), podemos ver o OPSAT como o seguinte problema de programação linear:

$$
\min / \max A_{m+1} \pi
$$

sujeito a:

$$
\begin{gathered}
A \pi=p \\
\pi \geq 0 \\
\sum \pi=1
\end{gathered}
$$

onde os elementos de $A_{m+1}$ representam o valor verdade de $s_{m+1}$ para cada valoração.

Por não ser um problema de decisão, OPSAT não está em NP, mas continua NP-difícil, já que este contém o PSAT embutido. Segundo Georgakopoulos, Kavvadias e Papadimitriou, o OPSAT pode ser trivialmente reduzido ao PSAT [GKP88], o que justifica nosso foco no problema de decisão. Além disso, as técnicas de programação linear apresentadas no Capítulo 3 para a solução do PSAT podem ser facilmente adaptadas para a solução do OPSAT, como vemos em [KP90].

\subsubsection{PSAT com Probabilidades Imprecisas}

O PSAT com Probabilidades Imprecisas (PSAT-PI) é um problema de decisão, onde se pergunta sobre a consistência de intervalos de probabilidades atribuídos a fórmulas da lógica proposicional clássica. Na prática, quando um especialista atribui uma probabilidade subjetivamente, é comum que isso ocorra através de limites superiores e inferiores, definindo intervalos de probabilidades, que correspondem à confiança do especialista na atribuição. O PSAT-PI é então a generalização do PSAT, onde temos atribuições da forma $\underline{p}_{i} \leq p\left(s_{i}\right) \leq \bar{p}_{i}$; logo o PSAT seria apenas um caso especial, onde $\underline{p}=\bar{p}$.

Formalmente, definimos uma instância do PSAT-PI $\Delta=\left\{\underline{p}_{i} \leq p\left(s_{i}\right) \leq \bar{p}_{i} \mid 1 \leq i \leq k\right\}$, onde $S=$ $\left\{s_{1}, \ldots, s_{k}\right\}$ é um conjunto de fórmulas da lógica proposicional sobre as variáveis $X=\left\{x_{1}, \ldots, x_{n}\right\}$, e $\underline{p}_{i}$ e $\bar{p}_{i}, 1 \leq i \leq k$, são probabilidades entre 0 e 1 . A instância $\Delta$ será probabilisticamente satisfazível sse existir uma distribuição de probabilidades $\pi$, sobre as valorações $v: X \rightarrow\{0,1\}$, que satisfaça $\underline{p}_{i} \leq p_{\pi}\left(s_{i}\right) \leq \bar{p}_{i}$, para $1 \leq i \leq k$. A probabilidade $p_{\pi}\left(s_{i}\right)$ de uma fórmula $s_{i}$ de acordo com uma distribuição de probabilidade $\pi$ está definida na Seção 2.2.

Sabemos que o PSAT é um caso específico do PSAT-PI, pois a atribuição de probabilidade $p(y)=p$ é equivalente a $p \leq p(y) \leq p$. O teorema seguinte mostra que os problemas são de fato equivalentes, apresentando um caminho para reduzir, em tempo polinomial, qualquer instância PSAT-PI a uma instância PSAT na forma normal atômica. Notemos que uma instância PSAT-PI pode ser escrita usando apenas atribuções de probabilidade da forma $p\left(s_{i}\right) \leq \bar{p}_{i}$, pois $p\left(s_{i}\right) \geq \underline{p}_{i}$ é o mesmo que $p\left(\neg s_{i}\right) \leq 1-\underline{p}_{i}$. 
Teorema 2.6.1. Seja $\Delta=\left\{p\left(s_{i}\right) \leq \bar{p}_{i} \mid 1 \leq i \leq k\right\}$ uma instância PSAT-PI . Existe uma instância PSAT $\Delta^{\prime}$ na forma normal atômica, construída em tempo linear com relação ao tamanho de $\Delta$, tal que $\Delta$ é probabilisticamente satisfazível sse $\Delta^{\prime}$ o for.

Demonstração. Primeiramente construímos a instância PSAT $\Delta^{\prime}=\langle\Gamma, \Psi\rangle$ na forma normal atômica. Seja $S=\left\{s_{1}, \ldots, s_{k}\right\}$ um conjunto de fórmulas sobre $x_{1}, \ldots, x_{n}$. Adicionando novas variáveis, $y_{1}, \ldots, y_{k}$, fazemos $\Gamma=\left\{s_{i} \rightarrow y_{i} \mid 1 \leq i \leq k\right\}$, o que pode ser feito em tempo linear sobre o tamanho de $\Delta$. Fazemos então $\Psi=\left\{p\left(y_{i}\right)=\bar{p}_{i} \mid 1 \leq i \leq k\right\}$, o que também toma tempo linear.

Para simplificar a demonstração, consideramos $S$ artificialmente sobre $x_{1}, \ldots, x_{n}, y_{1}, \ldots, y_{k}^{\prime}$, sendo que as variáveis $y_{i}$ não aparecem de fato em $S$, o que não muda a satisfazibilidade da instância $\Delta$. A instância $\Delta^{\prime}$ é probabilisticamente satisfazível sse existe uma distribuição de probabilidades $\pi$ que satisfaz $\langle\Gamma, \Psi\rangle$. Temos que $\pi$ satisfaz $\Psi$ sse $p_{\pi}\left(y_{i}\right)=\bar{p}_{i}$, para $1 \leq i \leq k$. Por outro lado, se $\pi$ satisfaz $\Gamma$, então $\pi$ é tal que $p_{\pi}\left(s_{i}\right) \leq p_{\pi}\left(y_{i}\right)$, para $1 \leq i \leq k$. Segue que, se $\pi$ satisfaz $\Delta^{\prime}$, então $\pi$ satisfaz $\Delta$.

Agora suponha que existe uma distribuição de probabilidade $\pi$ que satisfaz $\Delta$, tal que $p_{\pi}\left(s_{i}\right)=p_{i}$ e $p_{i} \leq \bar{p}_{i}$, para $1 \leq i \leq k$. Então, pelo Lema de Carathéodory, existe uma matriz $A$, com $k$ linhas e $k+1$ colunas, e uma distribuição de probabilidade $\pi$ tais que $A \pi=p$. Definimos $0 \leq \alpha_{i} \leq 1$ tal que $\bar{p}_{i}=p_{i}+\alpha_{i}\left(1-p_{i}\right), 1 \leq i \leq k$. Rearranjamos as sentenças $s_{i}$, e as correspondentes linhas em $A$, para que tenhamos $i<j \rightarrow \alpha_{i} \geq \alpha_{j}$. Replicamos cada coluna $A^{j}$, de $A$, um número de vezes igual a sua quantidade de zeros, $z(j)$, formando $A^{\prime}$. Assim, cada coluna $A^{j}$ de $A$ possui $z(j)+1$ colunas correspondentes em $A^{\prime}, A^{j, 0}, \ldots, A^{j, z(j)}$. Para cada coluna $A^{j, i}, 1 \leq i \leq z(j)$, trocamos os primeiros $i$ zeros, de cima para baixo, por 1. Por exemplo:

$$
A=\left[\begin{array}{l|l|l}
0 & 1 & 1 \\
0 & 0 & 1
\end{array}\right] ; \quad A^{\prime}=\left[\begin{array}{lll|ll|l}
0 & 1 & 1 & 1 & 1 & 1 \\
0 & 0 & 1 & 0 & 1 & 1
\end{array}\right]
$$

Note que $A^{j, 0}$ não se altera. Agora as linhas de $A^{\prime}$ representam valorações sobre $y_{1}, \ldots, y_{k}$ consistentes com $\Gamma$. Seja $\pi\left(A^{j}\right)$ a probabilidade associada a valoração correspondente à coluna $A^{j}$. Inicialmente temos $\pi\left(A^{j, 0}\right)=\pi\left(A^{j}\right), 1 \leq j \leq k+1$, e $\operatorname{logo} p\left(y_{i}\right)=p\left(s_{i}\right), 1 \leq j \leq k$. A ideia é distribuir a probabilidade $\pi\left(A^{j, 0}\right)$ pelas colunas $A^{j, 0}, \ldots, A^{j, z(j)}$, para $1 \leq j \leq k+1$, aumentando $p\left(y_{i}\right)$ sem alterar $p\left(s_{i}\right)$. Seja $j_{i}$ a i-ésima linha nula em $A^{j}$. Começamos a distribuir a probabilidade $\operatorname{com} \pi\left(A^{j, z(j)}\right)=\alpha_{j_{z(j)}} \pi\left(A^{j}\right)$ e então fazemos $\pi\left(A^{j, i}\right)=\left(\alpha_{j_{i}}-\alpha_{j_{i+1}}\right) \pi\left(A^{j}\right)$, para $i=z(j)-1, \ldots, 1$. Finalmente, $\pi\left(A^{j, 0}\right)=\pi\left(A^{j}\right)-\sum_{i=1}^{z(j)} \pi\left(A^{j, i}\right)$, o que força $\sum_{i=0}^{z_{j}} \pi\left(A^{j, i}\right)=\pi\left(A^{j}\right)$. Para cada coluna $A^{j}$ de $A$, distribuímos as probabilidades nas colunas $A^{j, 0}, \ldots, A^{j, z(j)}$ de $A^{\prime}$ conforme o sistema:

$$
\begin{aligned}
& \pi\left(A^{j, 0}\right)+\pi\left(A^{j, 1}\right)+\cdots+\pi\left(A^{j, z(j)}\right)=\pi\left(A^{j}\right) \\
& \pi\left(A^{j, 1}\right)+\cdots+\pi\left(A^{j, z(j)}\right)=\alpha_{j_{1}} \pi\left(A^{j}\right) \\
& \ddots \quad \vdots \quad \vdots \quad \vdots \\
& \pi\left(A^{j, z(j)}\right)=\alpha_{j_{z(j)}} \pi\left(A^{j}\right)
\end{aligned}
$$

Devido ao rearranjo de $S$ segundo $\alpha$, todas as probabilidades atribuídas estão entre 0 e 1 . Para cada variável $y_{i}$, acrescentamos $\alpha_{i} \sum_{j \mid v_{j}\left(s_{i}\right)=0} \pi\left(v_{j}\right)$ sobre a probabilidade $p\left(s_{i}\right)$, então tem-se $p\left(y_{i}\right)=p_{i}+\alpha_{i}\left(1-p_{i}\right)=\bar{p}_{i}$.

Temos agora $k$ linhas em $A^{\prime}$, representando valorações sobre $y_{1}, \ldots, y_{k}$, e uma distribuição de probabilidade $\pi$ tais que $A^{\prime} \pi=\bar{p}$. Pelo Lema de Carathéodory, podemos ficar com no máximo $k+1$ 
colunas com probabilidade não nula, descartando as demais. Devido à construção de $A^{\prime}$, todas as valorações representadas pelas colunas são consistentes com $\Gamma$. Finalmente, pelo Teorema 2.5.4, a matriz $A^{\prime}$ e distribuição de probabilidade construída sobre suas colunas garante a satisfazibilidade de $\Delta^{\prime}=\langle\Gamma, \Psi\rangle$. Então, se $\Delta$ é probabilisticamente satisfazível, $\Delta^{\prime}$ também o é.

Hansen havia mostrado a semelhança entre PSAT e PSAT-PI, colocando o problema de programação linear proveniente do último no formato padrão (definido na Seção 3.2) e adicionando variáveis de folga [HJ00]. Porém, o problema de programação linear resultante não possui uma instância PSAT correspondente, apenas está no mesmo formato, possui a mesma complexidade e pode ser resolvido com as mesmas técnicas de programação linear. O teorema aqui demonstrado pode ser entendido como uma redução polinomial do PSAT-PI ao PSAT, já que leva uma instância PSAT-PI a uma instância PSAT propriamente dita.

Segue que o PSAT-PI é também um caso do PSAT, também NP-completo. Convencidos da equivalência, abordaremos neste trabalho o PSAT, como definido na Seção 2.2.

\subsubsection{PSAT com Probabilidades Condicionais}

Sistemas especialistas fazem uso de conhecimento probabilístico, proveniente normalmente de um especialista que atribui probabilidades. Uma precisão de tais probabilidades pode eventualmente estar limitada a algumas condições. Então uma extensão natural do PSAT é considerar também a atribuição de probabilidades condicionais. Jaumard, Hansen e Aragão mostram, em [JHPdA91], como o modelo de Nilsson [Nil86] pode ser adaptado para incluir probabilidades condicionais, o que aqui resumiremos.

Seja $S=\left\{s_{1}, \ldots, s_{m}\right\}$ um conjunto de fórmulas lógicas, com $q \leq m$ atribuições de probabilidades simples (não condicionais), $p\left(s_{i}\right)=p_{i}, 1 \leq i \leq q$. As $m-q$ fórmulas restantes são utilizadas em atribuições de probabilidades condicionais, possivelmente junto com as $q$ primeiras. Seja $M=$ $\{1,2, \ldots, m\}$. Definimos $T \subseteq M \times M$ como o conjunto de pares ordenados de índices para os quais temos as atribuições de probabilidades condicionais $p\left(s_{i} \mid s_{j}\right)=p_{i / j}$. Sejam $A_{i}$ e $A_{j}$ as linhas da matriz $A$ (de (2.1)) correspondentes às fórmulas $s_{i}$ e $s_{j}$. Pela definição clássica de probabilidade condicional, quando $p\left(s_{j}\right)>0$, temos:

$$
p_{i / j}=p\left(s_{i} \mid s_{j}\right)=p\left(s_{i} \cap s_{j}\right) / p\left(s_{j}\right)=\left(A_{i} \wedge A_{j}\right) \pi / p_{j}
$$

Onde cada coluna $k$ de $A_{i} \wedge A_{j}$ é 1 se $s_{i}$ e $s_{j}$ são satisfeitas pela valoração correspondente $v_{k}$; e 0 caso contrário.

Seja $Q=\{1,2, \ldots, q\}$ o conjunto dos índices das fórmulas de $S$ com probabilidade não condicional atribuída. Seja $C$ o conjunto dos índices das fórmulas de $S$ que aparecem como condições nas atribuições. Podemos agora definir o problema da Satisfazibilidade Probabilística com Probabilidades Condicionais (CONDSAT) como um problema de decisão, onde perguntamos se existe uma distribuição de probabilidade $\pi$ para a qual o problema de programação linear abaixo admite pelo menos uma solução: 


$$
\left\{\begin{array}{lll}
A_{i} \pi & =p_{i} & i \in Q \\
A_{j} \pi-p_{j} & =0 & j \in C \cap(M \backslash Q) \\
\left(A_{i} \wedge A_{j}\right) \pi-p_{i / j} p_{j} & =0 & (i, j) \in T \\
\sum \pi & =1 & \\
p_{j} \geq 0 & & j \in C \cap(M \backslash Q) \\
\pi \geq 0 & &
\end{array}\right.
$$

Dada a formulação do CONDSAT também como um problema de programação linear, este também é NP-completo [GKP88], pelas mesmas razões que o PSAT.

Outra abordagem da probabilidade condicional surge quando se permite atribuir probabilidades condicionais $p\left(s_{i} \mid s_{j}\right)$ sem a exigência de uma probabilidade incondicional estritamente positiva para $s_{j}$. Isso é possível quando a abordagem de Kolmogorov da probabilidade condicional (2.10) dá lugar à definição de de Finetti [dF49], e o problema da consistência de probabilidades condicioanis atribuídas não mais se reduz a (2.11). Coletti e Scozzafava estudaram o problema da consistência de probabilidades condicionais atribuídas em tal abordagem, chamado de coerência, e mostraram como este se reduz à compatibilidade de uma sequência de sistemas lineares [Col02]. Esta abordagem possui um estudo independente e se distancia do foco deste trabalho (o estudo deste problema da coerência pode ser visto em [CS96], [CS02] e [CV98]). 


\section{Capítulo 3}

\section{Solução do PSAT via Programação Linear}

Como vimos no Capítulo 2, o PSAT pode ser visto como um problema de programação linear, e, de fato, as soluções mais eficientes o resolvem como tal. Em 1986, Nilsson previu a dificuldade prática de resolver o problema de programação linear correspondente a grandes instâncias do PSAT devido ao número exponencial de colunas [Nil86]. Já em 1990, Kavvadias e Papadimitriou propuseram a utilização do método de geração de colunas no algoritmo Simplex para resolver o PSAT sem explicitar tal número de colunas [KP90]. Este capítulo apresenta brevemente o algoritmo Simplex para então mostrar como o método de geração de colunas pode ser usado na resolução do PSAT.

\subsection{O Algoritmo Simplex}

Esta seção mostra apenas conceitos básicos do algoritmo Simplex, necessários para o entendimento da aplicação do método de geração de colunas ao PSAT. Uma exposição mais completa pode ser vista em [PS98], principal fonte desta seção.

O Simplex é um algoritmo que resolve problemas de otimização em programação linear. A estratégia é caminhar pelas soluções viáveis sempre aumentando (ou reduzindo) a função objetivo, que se deseja maximizar (minimizar), até chegar ao ponto ótimo. Para apresentarmos o Simplex, é conveniente tomarmos um problema de programação linear, com $m$ equações e $n$ incógnitas (vetor x), no Formato Padrão:

$$
\min z=c^{\prime} x
$$

sujeito a:

$$
\begin{gathered}
A x=b \\
x \geq 0
\end{gathered}
$$

A função objetivo (ou custo) é $z, c$ é o vetor custo, e $c^{\prime}$, sua transposta. Sem perda de generalidade, supomos que $b \geq 0$. Também supomos que a matriz $A$ possui $m$ colunas linearmente independentes.

Chamamos de Base da matriz $A$ um conjunto com $m$ colunas suas linearmente independentes, $\beta=\left\{A_{j_{1}}, \ldots, A_{j_{m}}\right\}$. Chamaremos de $B$ a matriz formada por tais colunas. As variáveis correspondentes às colunas que estão na base são chamadas de variáveis básicas, e as demais, não básicas. 
Uma base $\beta$ de $A$ implica uma Solução Básica para o problema (3.1), fazendo $x_{j}=0$, para toda coluna $A_{j} \notin \beta$, e $x_{B}=B^{-1} b$, onde $x_{B}$ é o vetor com as variáveis básicas.

Quando uma solução básica obedece a todas restrições do problema, dizemos que ela é uma Solução Básica Viável (SBV). No problema (3.1), um solução básica será viável se $x_{B} \geq 0$, implicando $x \geq 0$. Cada base, logo cada SBV, possui um custo correspondente, calculado pela aplicação da função objetivo a suas variáveis básicas, $z=c_{B}^{\prime} x_{B}$, onde $c_{B}$ é formado a partir de $c$, descartando os coeficientes correspondentes às variáveis não básicas, que, sendo nulas, não colaboram com o custo. Chamaremos tal custo de custo da base.

Encontrar uma base com solução viável pode não ser trivial, mas a Seção 3.2 explicará como abordar o problema. De posse de uma base com uma SBV, sempre podemos inserir uma nova coluna e, retirando a coluna certa, chegar a outra SBV - esse processo é chamado de Pivoteamento. Seja $\beta=\left\{A_{B(1)}, \ldots, A_{B(m)}\right\}$ uma base de $A$, e $x_{0}=\left\{x_{10}, \ldots, x_{m 0}\right\}$, a SBV correspondente, tal que $\sum_{i=1}^{m} x_{i 0} A_{B(i)}=b$. Sendo a matriz $B$ não singular, qualquer coluna $A_{j}$ de $A$ pode ser escrita como combinação linear das colunas da base, $A_{j}=\sum_{i=1}^{m} x_{i j} B(i)=A_{j}$. Sendo $l$ o valor de $i$ que minimiza a expressão $x_{i 0} / x_{i j}$, para $1 \leq i \leq m$ e $x_{i j}>0$, podemos substituir $A_{l}$ por $A_{j}$ na base, obtendo uma nova solução também viável.

A ideia do algoritmo Simplex é alterar a base $\beta$ de modo iterativo, partindo de uma SBV, substituindo uma coluna da base a cada iteração (pelo pivoteamento), obtendo novas SBVs e minimizando (ou maximizando) a função objetivo até que não haja substituição na base que diminua (ou aumente) tal função. Quando encontrarmos a base cuja a SBV minimiza (ou maximiza) a função objetivo, teremos encontrado a solução desejada. Agora precisamos de um método para encontrar tais colunas que, quando entram na base, diminuam (ou aumentem) o seu custo.

Suponha que tenhamos uma base $\beta$ com uma SBV $x_{0}$ para (3.1). Se inserirmos uma nova coluna $A_{j}$ na base, retirando $A_{l}$ pelo processo de pivoteamento, essa coluna será responsável por uma parcela do custo da base, $c_{j} x_{j 1}$, onde $x_{j 1}$ é a componente correspondente à coluna $A_{j}$ da nova SBV $x_{1}$. Porém, cada coluna $A_{i}$ que estava na base contribuirão diferentemente com o custo total, descontando $x_{j 1} x_{i j} c_{B(i)}$ de sua parcela no custo. Então, para cada unidade de $x_{j 1}$, a entrada de $A_{j}$ na base deve colaborar no custo total com $\bar{c}_{j}=c_{j}-\sum_{i=1}^{m} x_{i j} c_{B(i)}$, o que denotamos por custo reduzido. Os coeficientes $x_{i j}$ podem ser obtidos pelo produto $x_{i}=B^{-1} A_{j}$, então podemos reescrever o custo reduzido como $\bar{c}_{j}=c_{j}-c_{B}^{\prime} B^{-1} A_{j}$. Ao escolher uma coluna com custo reduzido negativo para entrar na base, garantimos que o custo desta decresça, a menos de casos degenerados. Quando não encontrarmos mais colunas com custo reduzido negativo, teremos encontrado uma solução ótima para (3.1). Em um problema de maximização, procuramos por colunas com custo reduzido positivo, mas aqui trataremos da minimização, sem perda de generalidade.

Em uma dada iteração do Simplex, podemos encontrar mais de uma coluna com custo reduzido negativo, o que sugere o uso de um critério para selecionar qual coluna queremos inserir na base. Qualquer coluna com custo reduzido negativo faz a SBV caminhar em direção ao ponto ótimo (a menos dos casos degenerados), porém certamente algumas o fazem de modo mais rápido. Poderíamos testar a inserção de cada uma das colunas fora da base e escolher aquela que mais diminui o custo da base, mas isso acarreta um grande esforço computacional, o que queremos evitar. Das heurísticas propostas, o Critério da Otimalidade é o mais intuitivo, onde escolhemos a coluna com menor custo reduzido para entrar na base, o que não garante o maior decréscimo no custo. Outra heurística utilizada sugere que escolhamos a coluna $A_{j}$ com menor $\bar{c}_{j} /\left(1+\sum_{i=1}^{m} x_{i j}^{2}\right)^{1 / 2}$, que corresponde à 
derivada do custo da base com respeito a todas suas variáveis.

Por fim, ignorando o problema de matrizes degeneradas, temos um algoritmo finito, pois o custo decresce monotonamente a cada iteração, não repetindo SBVs $^{1}$. Embora o número de iterações do Simplex seja exponencial no pior caso, com relação ao tamanho da entrada, o caso médio é polinomial, e na prática ele acaba sendo largamente usado para resolver problemas de programação linear, mesmo existindo um algoritmo polinomial no pior caso - o Algoritmo Elipsoidal.

\subsection{Simplex e PSAT}

Para aplicar o algoritmo Simplex a uma instância PSAT, primeiramente reproduzimos aqui a formulação desta como problema de programação linear, como apresentado no Capítulo 2:

$$
\begin{aligned}
A \pi & =p \\
\pi & \geq 0 \\
\sum \pi & =1
\end{aligned}
$$

Aqui $A$ possui $k$ linhas e $2^{k}$ colunas. Notamos logo que falta uma função objetivo, que pode ser acrescida artificialmente como $z=0 x$, para minimizar ou maximizar, já que qualquer solução viável nos serve. Podemos adicionar a condição (3.4) ao sistema (3.2), adicionando uma linha de 1 's à matriz $A$ e fazendo $p_{k+1}=1$. Temos agora um problema de programação linear no formato padrão:

$$
\min z=0 \pi
$$

sujeito a:

$$
\begin{gathered}
A \pi=p \\
\pi \geq 0
\end{gathered}
$$

Como mencionamos na Seção 3.1, encontrar uma primeira SBV para começar a execução do Simplex pode não ser trivial. Para isso, existe o Método Simplex de Duas Fases, onde na primeira fase encontramos uma SBV, para então otimizar a função objetivo na segunda fase. Como aqui nos interessa apenas a viabilidade, executaremos somente a primeira fase em busca de uma SBV, e, se não houver solução viável, a instância PSAT correspondente ao problema de programação linear será probabilisticamente insatisfazível.

Para encontrar uma solução viável, se esta existir, introduzimos $k+1$ variáveis artificiais, $\pi_{1}^{a}, \ldots, \pi_{k+1}^{a}$, a serem adicionadas em cada equação representada pelas linhas de $A: \sum_{j=1}^{k+1} a_{i, j} \pi_{j}+$ $\pi_{i}^{a}=p_{i}, \pi_{i}^{a} \geq 0$, para $1 \leq i \leq k+1$. Para cada variável artificial $\pi_{i}^{a}$, concatenamos a $A$ uma coluna composta de 0 's, a menos do i-ésimo elemento, igual a 1 , formando a matriz $[A \mid I]$. Assim, as colunas referentes às variáveis artificiais $\pi^{a}$ formam a matriz identidade, possibilitando uma base que fornece uma SBV, já que $p \geq 0$. Ao fim, queremos uma SBV com variáveis artificiais tendo probabilidade nula, então temos uma nova função objetivo artificial $\overrightarrow{1} \pi^{a}$, e a SBV só será solução

\footnotetext{
${ }^{1}$ Para casos degenarados, a regra de Bland, por exemplo, pode garantir o término do algoritmo [PS98].
} 
para a instância PSAT em questão quando a função objetivo se anular. Considerando $\pi^{a}$ dentro do vetor $\pi$, temos:

$$
\min z=\overrightarrow{1} \pi^{a}
$$

sujeito a:

$$
\begin{gathered}
{[A \mid I] \pi=p} \\
\pi \geq 0
\end{gathered}
$$

Agora podemos aplicar o algoritmo Simplex, incluindo na base inicialmente as $k+1$ colunas correspondentes às variáveis incluídas artificialmente. Como mencionamos, a matriz $B$ dessa base é a própria matriz identidade, logo as colunas são linearmente independentes e a solução é viável, com $\pi_{i}^{a}=p_{i} \geq 0$, para $1 \leq i \leq k+1$. Armazenamos então apenas a base $B$, sua inversa $B^{-1}$, o valor das variáveis básicas $\pi^{a}$ e o vetor $p$. Para procurar a coluna não básica a ser inserida na base sem precisar explicitá-las, aplicamos o método de geração de colunas.

\subsection{Método de Geração de Colunas e PSAT}

No Simplex tradicional aplicado ao PSAT, a cada iteração calcularíamos o custo reduzido de cada coluna não básica para escolher, utilizando algum dos critérios mencionados, aquela que entraria na base. Como o número de colunas é exponencial, isso é praticamente inviável para grandes instâncias PSAT. Podemos então adotar uma estratégia gulosa, gerando as colunas não básicas até encontrarmos uma com custo reduzido negativo. Porém, essas podem ser escassas, ou ainda não existirem, o que leva novamente à visitação de um número exponencial de colunas.

O custo reduzido de uma coluna $A_{j}$ pode ser calculado como $\bar{c}_{j}=c_{j}-c_{B}^{\prime} B^{-1} A_{j}$, e, como as colunas de $A$ fora da base inicial tem custo $c_{j}$ nulo no PSAT, podemos reescrevê-lo como $\overline{c_{j}}=$ $-c_{B}^{\prime} B^{-1} A_{j}$. Queremos encontrar colunas de $A$ com custo reduzido negativo, o que significa achar colunas $A_{j}$ tal que $c_{B}^{\prime} B^{-1} A_{j}>0$. O Método de Geração de Colunas consiste em encontrar tal coluna sem ter de listar explicitamente as colunas de $A$, o que é possível quando estas colunas possuem uma estrutura especial. No caso do PSAT, cada elemento $a_{i j}$ da matriz $A$ corresponde ao valor da fórmula $s_{i}$ na valoração $v_{j}$, ou $a_{i j}=v_{j}\left(s_{i}\right)$. Logo, podemos encontrar tal coluna $A_{j}$ que satisfaz $c_{B}^{\prime} B^{-1} A_{j}>0$ procurando no espaço de valorações, sem explicitar as colunas propriamente. Chamaremos esse problema de Problema Auxiliar, que deve ser resolvido a cada iteração do Simplex. Kavvadias e Papadimitriou mostraram que o problema auxiliar é NP-completo, no caso do PSAT, quando as fórmulas são dadas no formato clausal [KP90]. Se quisermos encontrar a coluna com menor custo reduzido, temos um problema de otimização NP-difícil.

O Algoritmo 3.1 mostra como o Simplex com geração de colunas pode ser usado para resolver uma instância PSAT. A função Pivoteamento $\left(B, A_{j}, \pi\right)$ insere a coluna $A_{j}$ na matriz $B$ eliminando outra coluna de maneira que mantenha a solução básica viável. O vetor custo da base $c_{B}$ possui 1 para as variáveis artificiais na base e 0 para as demais, sendo este atualizado pela função Pivoteamento a cada iteração. A função ProblemaAuxiliar $(S, w)$ recebe um conjunto de sentenças $S$, e um vetor $w$ com pesos para essas sentenças, e devolve a coluna que representa a valoração que satisfaz o problema auxiliar correspondente ou $\emptyset$ se este for insatisfazível. Enquanto o custo $c_{B}^{\prime} \pi_{B}$ 
for positivo, não teremos encontrado uma solução; se este se anular, teremos uma solução e o algoritmo para. Consideramos ainda que a última sentença, $s_{k+1}$, é uma tautologia e que $p_{k+1}=1$ para representar a restrição (3.4).

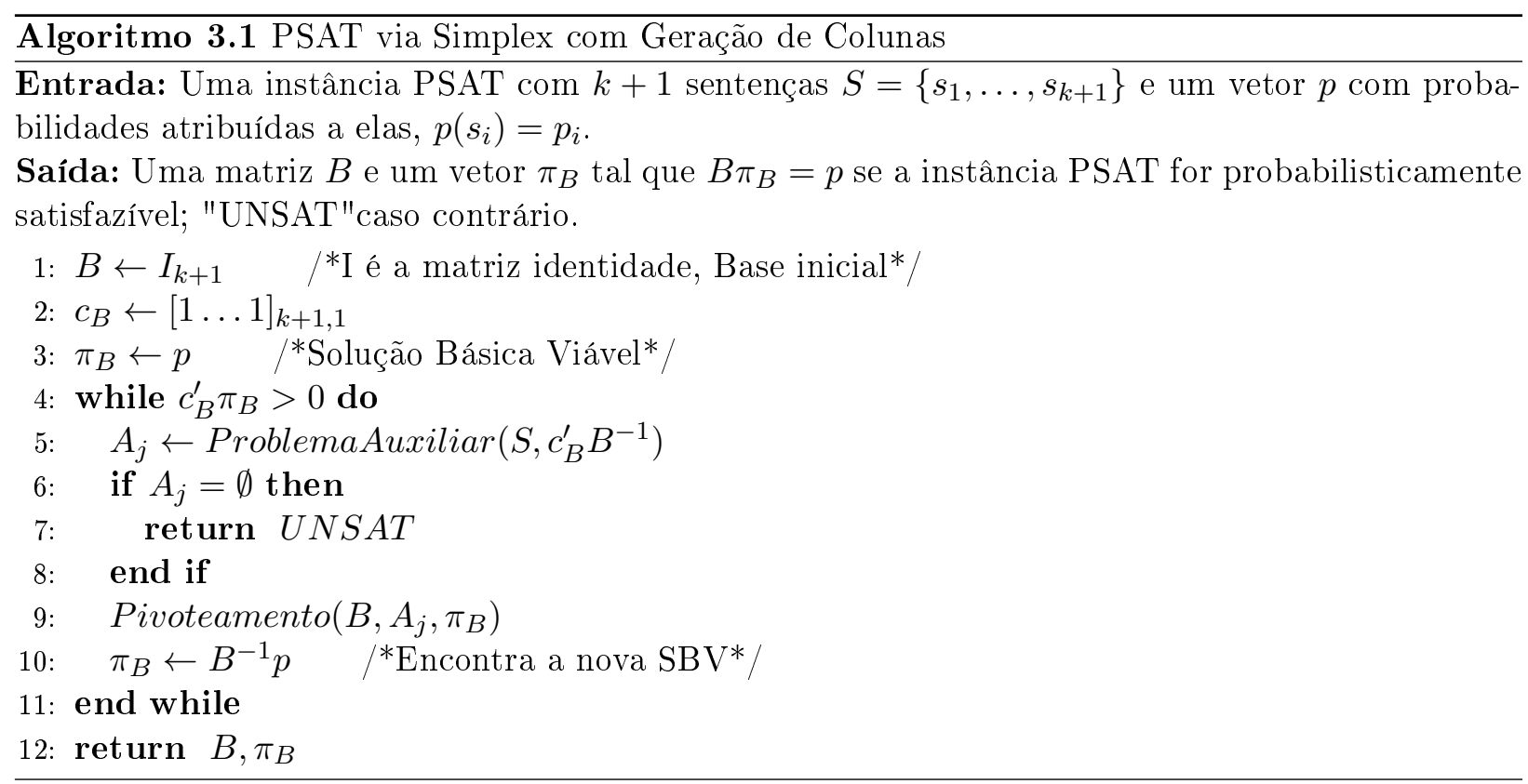

No Capítulo 5, propomos modificações no Algoritmo 3.1 para explorar a forma normal atômica, mas aqui vamos analisar os componentes desta solução.

\subsection{O Problema Auxiliar}

A menos dos processos de pivoteamento, inversão e multiplicação de matrizes, todos problemas polinomiais em tempo, decidir a satisfazibilidade probabilística se reduz a uma sequência de instâncias do problema auxiliar, em número exponencial no pior caso. Sendo $u_{i}$ a i-ésima componente do vetor-linha $c_{B}^{\prime} B^{-1}$, reescrevemos o custo reduzido de uma coluna não básica $A_{j}$ como:

$$
\bar{c}_{j}=-\sum_{i=1}^{k+1} u_{i} v_{j}\left(s_{i}\right)
$$

A expressão $v_{j}\left(s_{i}\right)$ tem valor 1 se $s_{i}$ é verdadeiro para valoração $v_{j}$, e 0 caso contrário. A fórmula $s_{i}$ é formada por variáveis lógicas $x_{1}, \ldots, x_{n}$ e conectivos da lógica proposicional clássica. Pela semântica desta lógica, podemos reescrever $v_{j}\left(s_{i}\right)$, para uma dada fórmula $s_{i}$, como função das valorações sobre as variáveis, $v_{j}\left(x_{1}\right), \ldots, v_{j}\left(x_{n}\right)$, substituindo os conectivos lógicos por operações aritméticas:

$$
\begin{aligned}
v_{j}\left(s_{a} \vee s_{b}\right) & =v_{j}\left(s_{a}\right)+v_{j}\left(s_{b}\right)-v_{j}\left(s_{a}\right) v_{j}\left(s_{b}\right) \\
v_{j}\left(s_{a} \wedge s_{b}\right) & =v_{j}\left(s_{a}\right) v_{j}\left(s_{b}\right) \\
v_{j}\left(\neg s_{a}\right) & =1-v_{j}\left(s_{a}\right)
\end{aligned}
$$

Assim podemos considerar a expressão (3.11) uma função pseudo-Booleana sobre as variáveis $x_{i}^{j}=v_{j}\left(x_{i}\right), 1 \leq i \leq n$, pois a cada iteração do Simplex $u_{i}$ são números racionais obtidos polino- 
mialmente. Como há uma valoração $v_{j}$ para cada uma das $2^{n}$ atribuições possíveis de valor verdade sobre $x_{1}, \ldots, x_{n}$, as variáveis $x_{i}^{j} \in\{0,1\}$ podem assumir valores independentemente uma das outras. Então, podemos fazer uma busca sobre $x_{i}^{j}, 1 \leq i \leq n$, para encontrar a valoração que leva à coluna com custo reduzido negativo, o que se torna a minimização de uma função pseudo-Booleana se quisermos encontrar a coluna com menor custo reduzido.

Kavvadias e Papadimitriou observaram que, se as fórmulas são dadas no formato clausal, o problema auxiliar pode ser visto como um caso especial do MAXSAT Pivô Ponderado (com $W=0$ ), já que uma coluna $A_{j}$ representa uma valoração $v_{j}$, e $c_{B}^{\prime} B^{-1} A_{j}$ é a soma dos pesos $c_{B}^{\prime} B^{-1}$ das cláusulas satisfeitas pela valoração $v_{j}$ [KP90]. Pergunta-se então se existe uma valoração $v_{j}$ tal que a soma dos pesos das fórmulas satisfeitas seja positivo, ou $c_{B}^{\prime} B^{-1} A_{j}>0$. O último elemento de cada coluna, sempre 1 , pode ser representado como a valoração sobre a cláusula vazia, satisfeita por todas valorações. Este caso especial do MAXSAT foi demonstrado NP-completo no mesmo trabalho. O problema de otimização correspondente, o MAXSAT Ponderado, busca a valoração que maximiza a soma dos pesos das cláusulas satisfeitas, minimizando o custo reduzido da coluna correspondente, o que possibilita a aplicação do critério da otimalidade. Sabe-se que este problema é NP-difícil.

Quando o conjunto de fórmulas $S$ da instância PSAT não vem no formato clausal, a cada iteração do Simplex podemos adicionar a $S$ novas variáveis e cláusulas, em quantidade linear, para gerar uma instância do MAXSAT Pivô Ponderado Parcial que será satisfazível sse o problema auxiliar for satisfazível. O MAXSAT Pivô Ponderado Parcial é versão de decisão do MAXSAT Ponderado Parcial, cujas instâncias são instância MAXSAT Ponderado que possuem um conjunto de cláusulas cuja satisfação é obrigatória. Logo, o MAXSAT (Pivô) Ponderado Parcial pode ser reduzido ao MAXSAT (Pivô) Ponderado atribuindo-se pesos "infinitos"a tais cláusulas. Estas cláusulas com peso "infinito"provavelmente interferirão na eficiência dos algoritmos propostos a seguir.

Devido à complexidade do MAXSAT Pivô Ponderado, heurísticas foram apresentadas para buscar soluções para o problema auxiliar. Quando a heurística não encontra valoração correspondente a uma coluna com custo reduzido negativo, um método exato deve ser aplicado para verificar se tal valoração não existe de fato. Esta seção apresenta diferentes heurísticas para o problema auxiliar, considerando as fórmulas no formato clausal, e referencia algoritmos para a solução exata. Embora muitas sejam as heurísticas propostas para o MAXSAT Ponderado (veja [MLLP07]), já que este problema possui interesse independentemente do PSAT, aqui apresentaremos 2 introduzidas em trabalhos que investigam a aplicação do método de geração de colunas para solução do PSAT.

\subsubsection{Busca Local com Profundidade Variável}

Esta heurística foi proposta por Kavvadias e Papadimitriou em [KP90], os primeiros a propor o método de geração de colunas para o PSAT e abordar o problema auxiliar. A heurística se propõe não só a procurar uma solução para o problema de decisão MAXSAT Pivô Ponderado, encontrando uma valoração correspondente a uma coluna com custo reduzido negativo, mas também a alterar tal valoração procurando por um custo reduzido ainda menor, visando o critério da otimalidade sendo assim uma heurística para o problema de decisão MAXSAT Ponderado.

A busca local ocorre sobre o espaço das valorações sobre as variáveis $x_{1}, \ldots, x_{n}$, que formam as cláusulas $C_{1}, \ldots, C_{m}$, com os pesos $w_{1}, \ldots, w_{m}$ associados. Começando com uma candidata a solução (uma valoração), o algoritmo busca melhorá-la localmente enquanto possível. Cada candidata a solução com sua busca por melhoria é chamada de estágio. A cada estágio, uma sequência de 
pequenas mudanças locais é explorada, cada mudança agindo sobre o valor de uma das variáveis Booleanas, e então se escolhe a subsequência inicial que leva à melhor solução, para iniciar um novo estágio. Cada mudança no valor de uma variável, nessa sequência, é chamada de subestágio. Como cada variável é alterada no máximo uma vez por estágio, temos até $n$ subestágios por estágio.

Para cada variável $x_{j}$, em um subestágio $i$, calcula-se o potencial $p_{i j}$, correspondente à diferença na soma do peso das cláusulas satisfeitas provocada pela alteração do valor de $x_{j}$. A cada subestágio é alterado o valor da variável com maior potencial $p_{i j}$ cujo valor não tenha sido alterado no estágio presente, resolvendo empates de maneira aleatória. A variável $\Delta_{i}$ mantém registro da mudança da soma dos pesos das cláusulas satisfeitas até o subestágio $i$, com $\Delta_{0}=0$ e $\Delta_{i}=\Delta_{i-1}+p_{i j}$, onde $x_{j}$ é a variável com maior potencial no subestágio $i$. Um estágio para quando passou por todos os $n$ subestágios ou quando $\Delta_{i}$ deixar de ser positivo, indicando que um próximo subestágio levaria a uma solução pior que a original do estágio. Ao final de cada estágio, escolhe-se a valoração correspondente ao subestágio $i *$ que corresponde à maior melhoria na solução, $\Delta_{i *}=\max _{i}\left\{\Delta_{i}\right\}$, para iniciar o próximo estágio. O algoritmo termina quando em algum estágio todo $\Delta_{i} \leq 0$, significando que não se obteve nenhuma melhoria nos $n$ subestágios.

Tal algoritmo pode ser implementado em tempo linear em relação a soma do tamanho das cláusulas envolvidas, como mostram os autores em [KP90]. A ideia básica é manter um contador $c_{k}$, para cada cláusula $C_{k}$, de quantas variáveis estão satisfazendo aquela cláusula.

Para cada instância do MAXSAT Pivô Ponderado, a heurística é repetida várias vezes para valorações iniciais diferentes, escolhidas para otimizar a busca. Como se busca uma soma positiva para o peso das cláusulas satisfeitas, a ideia é iniciar a busca local com valorações que não satisfaçam as cláusulas com menor peso negativo. Escolhe-se a cláusula com menor peso negativo e atribui-se valor as suas variáveis de modo a falsificá-la. Este processo é repetido até que todas as cláusulas com peso negativo sejam falsificadas, ou haja um conflito que exija a satisfação de uma para a falsificação de outra. Feito isso, as demais variáveis tem um valor atribuído aleatoriamente, com 1 e 0 equiprováveis.

\subsubsection{Busca Tabu}

Jaumard, Hansen e Poggi de Aragão propuseram independentemente outra heurística para resolver o problema auxiliar, usando uma busca tabu para procurar uma solução para o MAXSAT Ponderado, também supondo que as fórmulas são dadas no formato clausal [JHPdA91]. Como não se pode garantir que a solução encontrada é ótima, se a coluna correspondente a valoração encontrada possuir custo reduzido não negativo, um algoritmo exato é necessário para verificar a inviabilidade do problema auxiliar, que implicaria a insatisfazibilidade da instância PSAT correspondente.

A busca local utiliza uma política de Subida mais Íngreme Descida mais Branda (com acrônimo SAMD, do inglês Steepest Ascent Mildest Descent). Seja $f\left(x^{j}\right)$ a função que leva uma valoração, representada por $x^{j}=\left[x_{1}^{j}, \ldots, x_{n}^{j}\right]$, à soma dos pesos das cláusulas por ela satisfeita. Para minimizar o custo reduzido $c_{j}$, devemos maximizar $f$. Dada uma solução $x^{0}$, correspondente a uma valoração, a vizinhança $N\left(x^{0}\right)$ é definida como o conjunto de soluções $x^{1}, \ldots, x^{n}$ tal que $x^{j}$ difere de $x^{0}$ apenas no valor de $x_{j}^{0}$. Partindo de uma solução inicial, a cada iteração a heurística sai de uma solução $x^{0}$ para o seu vizinho $x^{j}$ que mais aumenta a função $f$ que se quer otimizar (subida mais íngreme). Uma vez encontrado um máximo local, deixa-se este na direção do vizinho que menos decresça a função $f$ (descida mais branda). Movimentos de subida opostos a movimentos de descida já realizados 
são proibidos para evitar ciclos. O critério de parada utilizado é número de iterações. Ao final, o algoritmo retorna a solução $x^{\text {opt }}$ para a qual $f\left(x^{\text {opt }}\right)$ foi o maior encontrado.

Hansen e Jaumard explicitam tal algoritmo para o caso da minimização de $f$ [HJ00], que reproduzimos no Algoritmo 3.2, levemente alterado para adequar a nossa notação, onde a função $f$ é o oposto do custo reduzido e deve ser maximizada.

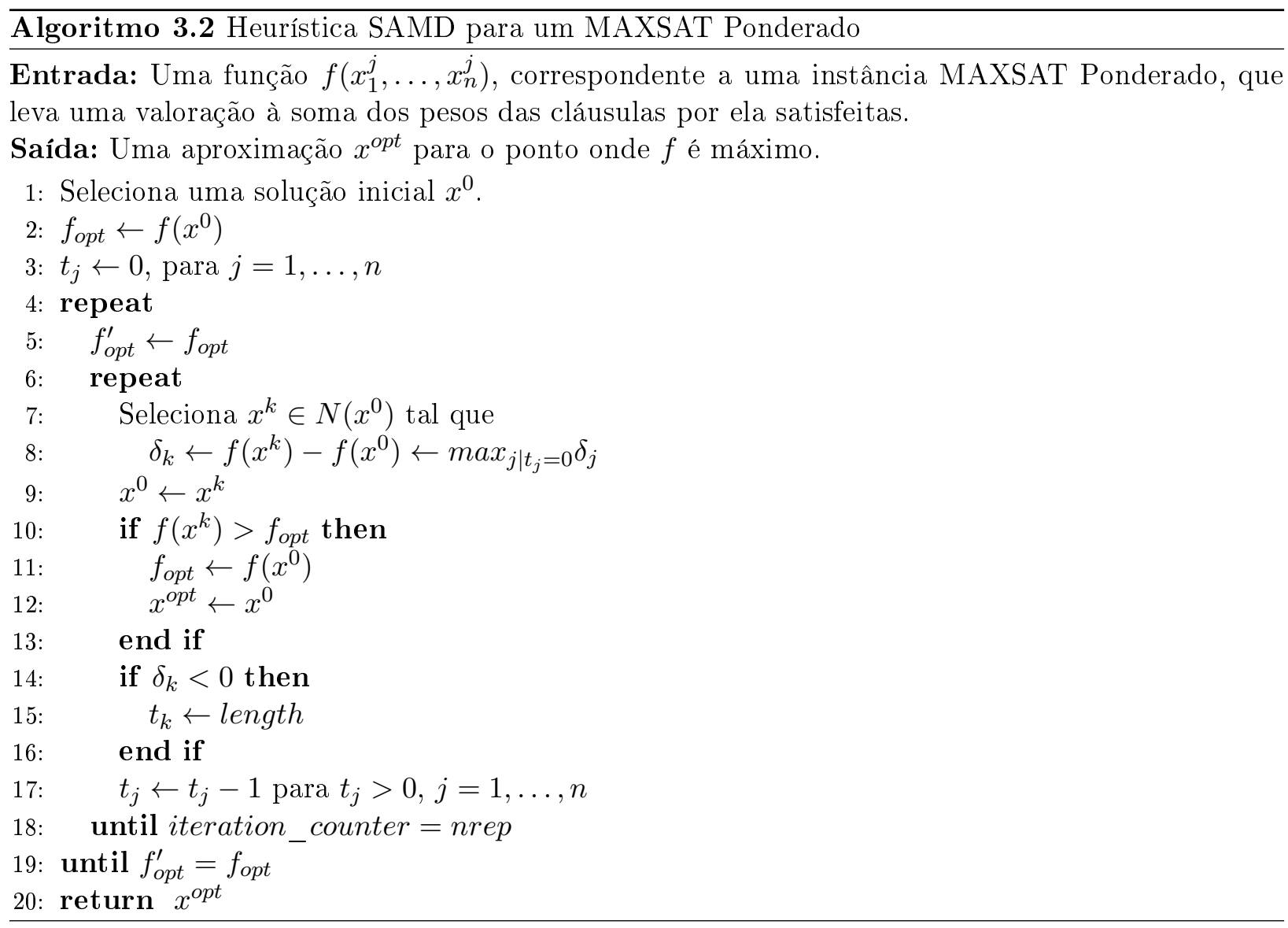

O parâmetro $t_{j}$ denota o número de iterações em que uma mudança na variável $x_{j}$ fica proibida após um movimento de descida através da modificação desta variável. O algoritmo executa a busca em blocos de nrep iterações, até que a solução não melhore ao fim de um bloco.

Jaumard, Hansen e Poggi de Aragão esboçam uma implementação que possibilita que cada iteração tenha tempo de pior caso da ordem do número total de literais [JHPdA91]. Os autores da heurística alegam que esta explora mais o espaço de soluções do que aquela apresentada na Seção 3.4.1. Isso se deveria a um critério de parada menos rígido, já que tipicamente $n r e p>n$, permitindo um maior número de iterações enquanto se procura uma solução melhor - e essa maior exploração do espaço de soluções acarreta de um maior custo computacional.

\subsubsection{Soluções Exatas}

Limitaremo-nos aqui a referenciar algoritmos para a solução exata do problema auxiliar, já que tais abordagens se distanciam do escopo deste trabalho. Como mencionado no início desta seção, o problema auxiliar pode ser abordado como um MAXSAT Pivô Ponderado (MAXSAT Ponderado para usar o critério de otimalidade) ou como a otimização de uma função pseudo-Booleana, que também pode ser vista como um problema de satisfação de restrições (CSP, do inglês). 
Alsinet, Manya e Planes notaram que a comunidade de programação linear já estudava intensamente o CSP enquanto que, na comunidade da satisfazibilidade, o interesse pelo MAXSAT Ponderado era bem mais recente [AMP05]. Nos últimos quatro anos, os programas que resolvem o MAXSAT têm sido testado anualmente em evento afiliado a Conferência Internacional em Teoria e Aplicações do Teste de Satisfazibilidade. As duas primeiras edições do evento são sumarizadas em [ALMP08], onde se pode encontrar uma lista de algoritmos exatos que resolvem o MAXSAT Ponderado, bem como a comparação entre seu desempenho.

Hansen e Jaumard apresentaram soluções exatas para o problema auxiliar visto como a maximização de uma função pseudo-Booleana, usando métodos de linearização e manipulação Booleana [HJ00]. De Givry et al. mostraram como o MAXSAT Ponderado pode ser modelado como um problema pseudo-Booleano, um problema de programação linear com números inteiros misto (Mixed ILP) ou um CSP Ponderado; uma comparação entre o então estado da arte dos algoritmos que resolvem os últimos dois também foi apresentada [DGLMS03]. 


\section{Capítulo 4}

\section{Redução Canônica do PSAT ao SAT}

Sendo o PSAT um problema NP, e o SAT, NP-completo, o Teorema de Cook [Coo71] garante a existência de uma redução polinomial do primeiro ao segundo. A busca por tal redução tem motivações teóricas e práticas: por um lado, abordar o PSAT com ferramentas lógicas, para melhor entender a conexão entre probabilidade, álgebra linear e lógica; por outro lado, explorar a eficiência de SAT Solvers (programas que resolvem o SAT) para implementar a redução e estudar o perfil de complexidade do PSAT em busca do fenômeno de transição de fase.

Sejam $A$ e $B$ problemas de decisão, e sejam $I_{A}$ e $I_{B}$ o conjunto das instâncias desses problemas, respectivamente. Instâncias de problemas de decisão podem ser separadas em negativas e positivas, estas obtém "Sim"como resposta de um algoritmo que resolva o problema, e aquelas, "Não". Evitando detalhes formais, podemos dizer que uma redução muitos-para-um de $A$ para $B$ é uma função $f$ (um algoritmo) que leva toda instância $x \in I_{A}$ a um instância $f(x) \in I_{B}$ tal que $x$ é uma instância positiva de $A$ sse $f(x)$ é uma instância positiva de $B$; se $f$ é computada em tempo polinomial em relação ao tamanho de sua entrada, dizemos que é uma redução muitos-para-um polinomial. Queremos o algoritmo que corresponde a tal função $f$, que leve instâncias PSAT a instâncias SAT em tempo polinomial. Neste trabalho, o termo redução polinomial se refere à redução muitos-para-um polinomial, em oposição a redução de Turing polinomial, apresentada na Seção 7.2. Definições mais formais pode ser encontrada em [GJ79].

Cook mostrou como qualquer problema da classe NP, logo incluindo o PSAT, pode ser reduzido polinomialmente ao SAT [Coo71]. Se um problema pertence a classe NP, então existe uma Máquina de Turing Não-Determinística que o resolve em tempo polinomial. Cook parte de tal máquina para construir uma instância do SAT. Assim, uma redução óbvia do PSAT ao SAT seria proveniente da Máquina de Turing Não-Determinística que resolve o PSAT, mas tal máquina, embora tenha a existência garantida, é de engenhosidade desnecessária para resolver o problema; e, embora polinomial, a redução apresentada por Cook tem complexidade cúbica em relação ao tempo de verificação de uma solução - quadrático no PSAT. Buscamos então outros algoritmos que façam a redução desejada.

Este capítulo apresenta o que chamamos de Redução Canônica, que é uma redução muitos-paraum polinomial do PSAT ao SAT baseada no Teorema 2.5.4. 


\subsection{Esboço da Redução}

Seja $\Delta=\langle\Gamma, \Psi\rangle$ uma instância PSAT na forma normal atômica, onde $\Gamma=\left\{s_{1}, \ldots, s_{m}\right\}$ é um conjunto com $m$ cláusulas da lógica proposicional clássica sobre $n+k$ variáveis Booleanas, $\left\{y_{1}, \ldots, y_{k}\right\} \cup\left\{x_{1}, \ldots, x_{n}\right\}$, e $\Psi$ é uma atribuição de probabilidades a átomos, $\Psi=\left\{p\left(y_{i}\right)=p_{i} \mid 1 \leq\right.$ $i \leq k\}$. Mostramos no Teorema 2.5.4 que, se $\Delta$ é probabilisticamente satisfazível, então existe uma matriz $A, \operatorname{com} k$ linhas e até $k+1$ colunas, que, junto com um vetor $\pi$, atende as restrições (2.1-2.3), de tal maneira que as colunas de $A$ representam valorações sobre $y_{1}, \ldots, y_{k}$ consistentes com $\Gamma$. Se quisermos que tal matriz $A$ tenha exatamente $k+1$ colunas, podemos eventualmente completá-la com colunas referentes a valorações consistentes $\operatorname{com} \Gamma$, que terão probabilidade nula. Podemos também incluir a restrição $\sum \pi=1$ no sistema $A \pi=p$, inserindo uma linha de 1's na matriz $A$ e fazendo $p_{k+1}=1$, o que faremos no restante deste capítulo.

Sendo $\Delta$ probabilisticamente satisfazível, há então uma matriz $A_{(k+1) \times(k+1)}$ e um vetor $\pi \geq 0$ (distribuição de probabilidade) que formam um NP-certificado, de tamanho polinomial, desde que os elementos de $\pi$ sejam representados em tamanho polinomial, com relação ao tamanho de $\Delta$. De posse desses certificados, poderíamos constatar a satisfazibilidade probabilística da instância $\Delta$ pela verificação de um sistema de equações lineares, o que pode ser feito em tempo polinomial sobre o tamanho do sistema. A ideia da redução canônica é representar esta matriz certificado $A_{(k+1) \times(k+1)}$ juntamente com o vetor $\pi \geq 0$ usando variáveis lógicas (como bits) e codificar a verificação das relações $A \pi=p$ em fórmulas lógicas sobre estas variáveis, que formarão uma instância do problema SAT. Para garantir a correção da redução, tais operações devem ser codificadas em uma aritmética racional, sem arredondamentos.

Cada elemento da matriz certificado procurada, $A$, será representado por uma variável Booleana, já que $a_{i j} \in\{0,1\}$. Cada elemento do vetor $\pi$ procurado é a razão entre dois inteiros, que serão representados no sistema posicional binário com $b_{\pi}$ bits no numerador e $b_{\text {det }}$ no denominador, cada bit sendo uma variável Booleana. Analogamente, representaremos os elementos do vetor $p$ por bits, como uma razão de inteiros. Podemos agora codificar, em uma instância SAT, a verificação do sistema de equações lineares, o que corresponde a uma série de somas e multiplicações, todas com reduções ao SAT polinomiais em relação ao tamanho da instância PSAT $\Delta$. Assim, se a instância SAT construída for satisfazível, teremos encontrado a matriz $A$ e o vetor $\pi$, codificado em bits, que satisfazem a instância PSAT, caso contrário, não existe tal par $A$ e $\pi$, e, pelo Teorema 2.5.4, a instância PSAT será probabilisticamente insatisfazível.

Para que tal redução seja de fato polinomial, precisamos garantir que o número de bits com que representaremos numerador e denominador dos elementos de $\pi$ seja polinomial em relação ao tamanho da instância PSAT. Para encontrar tal precisão mínima que garanta a correção da nossa redução, recorreremos a um argumento da álgebra linear.

\subsection{Cálculo da Precisão Necessária}

Primeiramente tomamos a instância PSAT $\Delta$ acima introduzida, na sua formulação de programação linear, e a levamos para o domínio dos inteiros. Cada elemento $p_{i}$ de $p$ é a razão entre dois inteiros, $n\left(p_{i}\right) / d\left(p_{i}\right)$. Seja $M M C_{d}$ o mínimo múltiplo comum dos denominadores $d\left(p_{i}\right), 1 \leq i \leq k$, seja $M A X_{d}$ o maior entre tais denominadores, ou $\operatorname{MAX}_{d}=\operatorname{Max}_{i}\left\{d\left(p_{i}\right), 1 \leq i \leq k\right\}$. O número máximo de bits necessários para armazenar $M M C_{d}$ será $k$ multiplicado pelo número de bits de 
$M A X_{d}$, ou $k \cdot \operatorname{bits}\left(M A X_{d}\right)$, onde bits $(x)=\left(\left\lfloor\log _{2}(x)\right\rfloor+1\right)$. Se multiplicarmos o vetor $p$ por $M M C_{d}$, obtendo $p^{\prime}$ inteiro, teremos um novo problema de programação linear, $\Delta^{\prime}$, que será viável sse $\Delta$ o for, tal que, se $A \pi^{\prime}=p^{\prime}$, então $\pi=\pi^{\prime} / M M C_{d}$. Então estamos interessados na precisão necessária para solução exata de $\Delta^{\prime}$, mesma de $\Delta$. Podemos representar cada elemento da solução exata $\pi^{\prime}$ como uma fração, onde cada denominador é no máximo o determinante de $A$, pela regra de Crammer, supondo que tal determinante seja positivo, sem perda de generalidade. Como a matriz $A$ é composta por 0's e 1's, e uma de suas linhas somente por 1's, pela desigualdade de Hadamard (veja [FS71], problema 523), limitamos tal determinante a $(k+1)^{(k+3) / 2} / 2^{k}$. Seja $b_{\text {det }}$ o número de bits necessários para armazenar o determinante de $A$ exatamente, tal que $b_{d e t}=b i t s\left((k+1)^{(k+3) / 2} / 2^{k}\right)$. Como $\pi_{i}^{\prime} \leq M M C_{d}$, pois $\pi \leq 1$, o número de bits necessários para armazenar os numeradores de $\pi_{i}^{\prime}$ será $b_{\pi}=k \cdot\left(b i t s\left(M A X_{d}\right)\right)+b_{\text {det }}$. Finalmente, como $\pi=\pi^{\prime} / M M C_{d}$, o numerador e o denominador de cada elemento de $\pi$ podem ser representados pelo mesmo número de bits, $b_{\pi}$. Como $b_{\text {det }}=O\left(k \cdot \log _{2} k\right)$, e bits $\left(M A X_{d}\right)$ é polinomial em relação ao tamanho de $\Delta$, concluímos que o número de bits necessários para armazenar os elementos de $\pi$ é polinomial em relação ao tamanho da instância $\Delta$.

No algoritmo apresentado adiante, consideraremos que as probabilidades $p_{i}$ vêm representadas em frações com um mesmo denominador $M A X_{d}$, assim $M M C_{d}=M A X_{d}$ e bits $\left(M M C_{d}\right)=$ bits $\left(M A X_{d}\right)=b_{p}$, resultando em $b_{\pi}=b_{p}+b_{d e t}$, possibilitando uma grande economia de variáveis.

\subsection{Construção da Instância SAT}

Seja $\Delta=\langle\Gamma, \Psi\rangle$ uma instância PSAT na forma normal atômica, onde $\Gamma=\left\{s_{1}, \ldots, s_{m}\right\}$ é um conjunto de cláusulas da lógica proposicional clássica sobre as variáveis $\left\{y_{1}, \ldots, y_{k}\right\} \cup\left\{x_{1}, \ldots, x_{n}\right\}$, e $\Psi=\left\{p\left(y_{i}\right)=p_{i} \mid 1 \leq i \leq k\right\}$ é uma atribuição de probabilidades atômica. Desejamos construir, em tempo polinomial, uma instância SAT $\Lambda$ que seja satisfazível sse $\Delta$ for probabilisticamente satisfazível.

Para simplificar, consideramos que as razões que representam os elementos de $p$ já possuam um mesmo denominador $d$, o que poderia ser feito em um pré-processamento, extraindo-se o mínimo múltiplo comum dos denominadores em tempo polinomial. Na prática, os racionais de $p$ podem vir representados como uma expansão binária finita. Também consideramos a solução procurada $\pi$ com um denominador comum, que será um divisor positivo do determinante da matriz certificado (denotado por det), multiplicado por $d$. Como $d$ também é denominador comum em $p$, não precisamos considerá-lo em ambos os lados da igualdade. Então, vamos verificar a viabilidade do problema de programação linear $\Delta^{\prime}: A\left(\pi^{\prime} /\right.$ det $)=p^{\prime}=p \cdot d, \pi^{\prime} \geq 0$ e $\sum \pi^{\prime} /$ det $=d$. Claro que $\Delta$ é probabilisticamente satisfazível sse $\Delta^{\prime}$ é viável. Se $\pi^{\prime} /$ det é uma solução para $\Delta^{\prime}$, então $\pi=\pi^{\prime} /(\operatorname{det} \cdot d)$ é uma solução para $\Delta$.

Antes de mostrar o algoritmo da redução polinomial do PSAT para o SAT, apresentaremos as variáveis e cláusulas de $\Lambda$, explicando sua origem em $\Delta$.

\subsubsection{Variáveis}

As variáveis da instância SAT a ser construída podem ser divididas em três grandes grupos: aquelas com correspondentes diretos na instância PSAT; aquelas auxiliares, necessárias para codificar a verificação do sistema de equações lineares; e as variáveis adicionadas para implementar 
soma e multiplicação bit a bit, bem como as variáveis extras provenientes da passagem da fórmula para a forma normal conjuntiva (formato clausal). O último grupo não será listado completamente, mas será contabilizado no total de variáveis.

Primeiramente, precisamos de 5 grupos de variáveis primárias:

- $x_{i}^{j}, 1 \leq i \leq n$ e $1 \leq j \leq k+1$ : variáveis Booleanas de $\Gamma$ sem probabilidade atribuída, replicadas para cada uma das valorações correspondentes às colunas da matriz certificado;

- $y_{i}^{j}, 1 \leq i \leq k+1$ e $1 \leq j \leq k+1$ : átomos de $\Psi$, replicados para cada uma das valorações correspondentes às colunas da matriz certificado procurada, já acrescidos da linha artificial $y_{k+1}$, que representará a condição $\sum \pi=1\left(\sum \pi^{\prime} /\right.$ det $\left.=d\right)$; chamaremos de $Y$ a matriz correspondente ao conjunto dessas variáveis.

- $p_{i, j}^{\prime}, 1 \leq i \leq k+1$ e $1 \leq j \leq b_{p}$ : $b_{p}$ variáveis (bits) para cada elemento de $p^{\prime}$, numeradores de $p$, acrescido de $p_{k+1}$, correspondente à condição $\sum \pi=1=p_{k+1}\left(\sum \pi^{\prime} / \operatorname{det}=d=p_{k+1}^{\prime}\right)$; denotamos por $p_{i}^{\prime}$ o inteiro correspondente aos bits $p_{i, j}^{\prime}, 1 \leq j \leq b_{p}$;

- $\pi_{i}^{\prime j}, 1 \leq j \leq k+1$ e $1 \leq i \leq b_{\pi}$ : $b_{\pi}$ variáveis (bits) para cada elemento do vetor $\pi^{\prime}$, numeradores de $\pi$, tal que $A \pi^{\prime} /$ det $=p^{\prime}$; denotamos por $\pi^{\prime j}$ o inteiro correspondente aos bits $\pi_{i}^{\prime j}, 1 \leq i \leq b_{\pi}$;

- $\operatorname{det}_{i}, 1 \leq i \leq b_{\text {det }}$ : $b_{\text {det }}$ variáveis (bits) para um fator do denominador comum dos elementos de $\pi$ (outro fator do denominador comum seria $d$, que pode ser omitido aqui por estar nos dois lados da igualdade); denotamos por det o inteiro correspondente aos bits $\operatorname{det}_{i}, 1 \leq i \leq b_{\text {det }}$; pela regra de Crammer, det deve ser um divisor do determinante da matriz certificado.

Os dois primeiros itens mostram que precisamos replicar $k+1$ vezes as variáveis originais de $\Gamma$, isso porque precisamos simultaneamente de $k+1$ valorações diferentes que satisfaçam $\Gamma$ para formar a matriz certificado, o que ficará mais claro adiante. Notemos também que $b_{\pi}=b_{p}+b_{d e t}$.

Como o Teorema 2.5.4 mostra, a matriz certificado procurada representa valorações sobre os átomos $y$, que devem ser consistentes com $\Gamma$. Assim, cada conjunto de variáveis $y_{1}^{j}, \ldots, y_{k}^{j}$ pode ser entendido como uma valoração sobre $y_{1}, \ldots, y_{k}$, compondo uma coluna da matriz certificado $Y$, a menos da última linha. O sistema abaixo mostra o papel que as variáveis primárias terão na redução a ser construída:

$$
\left[\begin{array}{ccc}
y_{1}^{1} & \cdots & y_{1}^{k+1} \\
\vdots & \ddots & \vdots \\
y_{k}^{1} & \cdots & y_{k}^{k+1} \\
y_{k+1}^{1} & \cdots & y_{k+1}^{k+1}
\end{array}\right] \cdot\left[\begin{array}{c}
\pi^{\prime 1} / \operatorname{det} \\
\pi^{\prime 2} / \operatorname{det} \\
\vdots \\
\pi^{\prime k+1} / \operatorname{det}
\end{array}\right]=\left[\begin{array}{c}
p_{1}^{\prime} \\
\vdots \\
p_{k}^{\prime} \\
p_{k+1}^{\prime}
\end{array}\right]
$$

Note que a última linha corresponde à condição $\sum \pi^{\prime} /$ det $=d$, logo $y_{k+1}^{j}=1,1 \leq j \leq k+1$, e $p_{k+1}=d$. Lembramos ainda que a codificação em bits dos números presentes em (4.1) os considera sempre não negativos.

Para corresponderem a uma solução, as variáveis primárias devem respeitar as restrições (4.1), e, para reduzirmos isso ao SAT, precisaremos de 3 grupos de variáveis secundárias, oriundas da manipulação das variáveis primárias: 
- $z_{i, h}^{j}, 1 \leq j \leq k+1,1 \leq i \leq k+1$ e $1 \leq h \leq b_{\pi}$ : multiplicamos cada coluna $y^{j}$ por $\pi^{\prime j}$, obtendo $(k+1)^{2}$ elementos com $b_{\pi}$ bits cada; denotamos por $z_{i}^{j}$ o inteiro correspondente aos bits $z_{i, h}^{j}$, $1 \leq h \leq b_{\pi}$

- $z_{i, h}^{\prime j}, 1 \leq j \leq k, 1 \leq i \leq k+1$ e $1 \leq h \leq b_{\pi}$ : variáveis para armazenar somas parciais das linhas $z_{i}^{1}, \ldots, z_{i}^{k+1}, 1 \leq i \leq k+1$; denotamos por $z_{i}^{\prime j}$ o inteiro correspondente aos bits $z_{i, h}^{\prime j}$, $1 \leq h \leq b_{\pi}$

- $r h s_{i, j}, 1 \leq i \leq k+1$ e $1 \leq j \leq b_{\pi}$ : variáveis que armazenam em $b_{\pi}=b_{p}+b_{\text {det }}$ bits os números finais ao lado direito da igualdade, $\operatorname{det} \cdot p_{i}^{\prime}$; denotamos por $r h s_{i}$ o inteiro correspondente aos bits $r h s_{i, j}, 1 \leq j \leq b_{\pi}$.

\subsubsection{Fórmulas}

As cláusulas da instância SAT $\Lambda$ desejada também podem ser separadas em dois grupos: aquelas que fazem com que as valorações representadas pela matriz certificado $Y$ sejam consistentes com $\Gamma$; e as cláusulas que codificam a verificação das restrições (4.1). Aqui apresentaremos fórmulas não necessariamente no formato clausal, mas sabendo que tal transformação é linear no tempo com a adição de novas variáveis.

Sendo $X=\left\{x_{1}, \ldots, x_{n}\right\}$ o conjunto original de variáveis de $\Gamma$ que não estão em $\Psi$, definimos $x^{1}, \ldots, x^{k+1}$ como conjuntos disjuntos de variáveis Booleanas, tal que $x^{j}=\left\{x_{1}^{j}, \ldots, x_{n}^{j}\right\}$. Analogamente, definimos $y^{j}=\left\{y_{1}^{j}, \ldots, y_{k}^{j}\right\}, 1 \leq j \leq k+1$. Sendo $\Gamma=\left\{s_{1}, \ldots, s_{m}\right\}$ um conjunto de cláusulas sobre as variáveis $\left\{y_{1}, \ldots, y_{k}\right\} \cup\left\{x_{1}, \ldots, x_{n}\right\}$, definimos $\Gamma\left(y^{j} ; x^{j}\right)$ como o conjunto de cláusulas $\Gamma$ substituindo $y_{i}$ por $y_{i}^{j}$, para $1 \leq i \leq k$, e substituindo $x_{i}$ por $x_{i}^{j}$, para $1 \leq i \leq n$. Começamos a nossa instância SAT $\Lambda$ então pela inclusão das cláusulas relativas a $\Gamma\left(y^{j} ; x^{j}\right), 1 \leq j \leq k+1$, para garantir que cada coluna $y^{j}$ de $Y$ denote uma valoração consistente com $\Gamma$. Para gerar tais fórmulas, supomos que existe uma função Replica $\left(y^{j}, x^{j}, \Sigma\right)$, polinomial no tempo, que retorne o conjunto de fórmulas $\Sigma$ aplicado sobre os conjuntos de variáveis $y^{j}$ e $x^{j}$. Impomos ainda que a última linha seja composta de 1 's, adicionando a $\Lambda$ os fatos $y_{k+1}^{j}$, para $1 \leq j \leq k+1$. Até aqui temos uma instância SAT $\Lambda$ com $(m+1)(k+1)$ fórmulas, que levam a $\Theta(m \cdot k)$ cláusulas e $\Theta(k(k+n))$ variáveis.

O restante das cláusulas de $\Lambda$ virão da verificação das restrições (4.1). Primeiramente representamos os numeradores e o denominador do vetor $p$, dados em $\Psi$, no sistema binário posicional, o que pode ser feito em tempo polinomial. Então forçamos os bits de cada $p_{i}^{\prime}$ a corresponderem a tal representação, lembrando que $p_{k+1}^{\prime}=d$. Fazemos isso acrescentando a $\Lambda$ fatos $p_{i, j}^{\prime}$ ou $\neg p_{i, j}^{\prime}$, para $1 \leq i \leq k+1$ e $1 \leq j \leq b_{p}$. O número de bits $b_{p}$ usado será o mínimo necessário para representar binariamente $p_{k+1}^{\prime}=d$. Vamos supor a existência de uma função paraBinario $(x, n, b)$, que recebe um vetor de variáveis Booleanas $x$, um inteiro $n$ e uma precisão $b$, para gerar essas fórmulas que associam os $b$ elementos de $x$ à representação binária de $n$. Nesta etapa, teremos $\Theta\left(b_{p} \cdot k\right)$ cláusulas, e variáveis, acrescentadas a $\Lambda$.

As variáveis do tipo $z_{i}^{j}$, que representam a multiplicação do elemento $y_{i}^{j}$ da matriz $Y$ pelo $\pi^{\prime j}$ correspondente, terão cada bit equivalente a conjunção dos bits de $\pi^{\prime j}$ com $y_{i}^{j}$, isso para todo $1 \leq i, j \leq k+1$. Então, acrescentamos a $\Lambda$ as fórmulas $z_{i, h}^{j} \leftrightarrow\left(y_{i}^{j} \wedge \pi_{h}^{\prime j}\right)$, para $1 \leq i, j \leq k+1$ e $1 \leq h \leq b_{\pi}$. Fórmulas com a mesma utilidade podem ser geradas pela função Produto, que será apresentada em breve. O número de bits $b_{\pi}=b_{\text {det }}+b_{p}$ pode ser calculado pela desigualdade de Hadamard, para dar a precisão necessária à exatidão, e será $b_{\pi}=\Theta(k \cdot \log k)+b_{p}$. Logo o número 
de cláusulas introduzidas a $\Lambda$ nessa etapa será $\Theta\left(k^{2} \cdot b_{\pi}\right)=\Theta\left(k^{2}\left(k \log k+b_{p}\right)\right.$, assim como o número de variáveis.

O esquema abaixo ilustra o papel das variáveis $z$ no andamento de nossa redução:

$$
\begin{array}{ccccc}
\left(z_{1}^{1}+\right. & \cdots & \left.+z_{1}^{k+1}\right) / \operatorname{det} & = & p_{1}^{\prime} \\
\vdots & \ddots & \vdots & \vdots & \vdots \\
\left(z_{k}^{1}+\right. & \cdots & \left.+z_{k}^{k+1}\right) / \operatorname{det} & = & p_{k}^{\prime} \\
\left(z_{k+1}^{1}+\right. & \cdots & \left.+z_{k+1}^{k+1}\right) / \operatorname{det} & = & p_{k+1}^{\prime}
\end{array}
$$

Para codificar as somas, supomos a existência de uma função $\operatorname{Soma}\left(p_{1}, p_{2}\right.$, sum, b), onde $p_{1}, p_{2}$, e sum são conjuntos ordenados, com $b$ variáveis cada, que representam inteiros. Tal função deve retornar uma fórmula lógica que é verdadeira sse a soma das parcelas representadas por $p_{1}$ e $p_{2}$ for igual ao inteiro representado por sum. A função Soma pode ser construída tendo tempo de pior caso $\Theta(b)$. Então acrescentamos a $\Lambda$ as fórmulas $\operatorname{Soma}\left(z_{i}^{1}, z_{i}^{2}, z_{i}^{\prime 1}, b_{\pi}\right)$ e $\operatorname{Soma}\left(z_{i}^{\prime j-1}, z_{i}^{j+1}, z_{i}^{\prime j}, b_{\pi}\right)$, para $1 \leq i \leq k+1$ e $2 \leq j \leq k$. Nessa etapa, são representadas $\Theta\left(k^{2}\right)$ somas, cada uma codificada em $\Theta\left(b_{\pi}\right)$ cláusulas, o que leva a $\Theta\left(k^{2} \cdot b_{\pi}\right)=\Theta\left(k^{2}\left(k \log k+b_{p}\right)\right.$ cláusulas e variáveis, adicionadas a $\Lambda$, para garantirmos a correção da redução.

Após poucas transformações algébricas, a situação da redução pode ser visualizada no esquema abaixo:

$$
\begin{array}{ccc}
z_{1}^{\prime k} & = & p_{1}^{\prime} \cdot \operatorname{det} \\
\vdots & \vdots & \vdots \\
z_{k}^{\prime k} & = & p_{k}^{\prime} \cdot \operatorname{det} \\
z_{k+1}^{\prime k} & = & p_{k+1}^{\prime} \cdot \operatorname{det}
\end{array}
$$

Antes de prosseguir, é importante lembrar que queremos evitar que det seja nulo. Já mencionamos que det deve ser um divisor da matriz certificado $Y$, pela regra de Crammer, porém pode acontecer de não haver $Y$ singular. Nesse caso, se a instância PSAT em questão for satisfazível, precisamos garantir que existe um valor para det que possibilite a satisfação de $\Lambda$. Se a matriz certificado encontrada $Y$ for singular, certamente esta possui colunas com probabilidade zero. Nesse caso, existe uma matriz binária não singular $Y^{\prime}$, cujas colunas representam valorações não necessariamente consistentes com $\Gamma$, que coincide com $Y$ nas colunas com probabilidade não nula. Seja $\pi^{\prime \prime}$ um vetor de números naturais, e det', um natural não nulo, tais que $Y \pi^{\prime \prime} / \operatorname{det}^{\prime}=p^{\prime}$. Claro que $Y^{\prime} \pi^{\prime \prime} / \operatorname{det}^{\prime}=$ $Y \pi^{\prime} /$ det $=p^{\prime}$, então o determinante de $Y^{\prime}$, multiplo de $d e t^{\prime}$, é um valor possível para det. Incluímos em $\Lambda$ uma cláusula com $b_{\text {det }}$ variáveis garantindo que pelo menos um bit de det seja diferente de zero e, para gerá-la, usaremos a função naoNulo $\left(n_{1}, b\right)$, que garante que o número $n_{1}$, representado pelo conjunto de $b$ variáveis (bits), seja diferente de zero.

Para codificar as multiplicações, supomos a existência da função Produto $\left(f_{1}, f_{2}, \operatorname{Pro}, b_{1}, b_{2}\right)$, análoga a função Soma. Assim, a função Produto retorna uma fórmula lógica que é verdadeira sse o produto dos inteiros representados pelos conjunto ordenados $f_{1}$, com $b_{1}$ bits, e $f_{2}$, com $b_{2}$ bits, for igual ao inteiro representado por Pro, $\operatorname{com} b_{1}+b_{2}$ bits. A função Produto pode ser construída tendo tempo de pior caso $\Theta\left(b_{1} \cdot b_{2}\right)$. Acrescentamos a $\Lambda$ as fórmulas Produto $\left(d e t, p_{i}^{\prime}, r h s_{i}, b_{\text {det }}, b_{p}\right)$, para $1 \leq i \leq k+1$. As $\Theta(k)$ multiplicações realizadas implicam $\Theta\left(k \cdot \min \left(b_{\text {det }}, b_{p}\right)\right)$ somas com $b_{\text {det }}+b_{p}$ bits, acrescentando um total de $\Theta\left(k \cdot b_{p} \cdot b_{d e t}\right)$ cláusulas e variáveis a $\Lambda$. Se tomarmos $b_{d e t}=\Theta(k \log k)$, para garantir a correção da redução, então serão $\Theta\left(b_{p} k^{2} \log k\right)$ cláusulas e variáveis acrescentadas. 
Finalmente, precisamos codificar as relações abaixo, para verificar as restrições do sistema (4.1):

$$
\begin{array}{ccc}
z_{1}^{\prime k} & = & r h s_{1} \\
\vdots & \vdots & \vdots \\
z_{k}^{\prime k} & = & r h s_{k} \\
z_{k+1}^{\prime k} & = & r h s_{k+1}
\end{array}
$$

Para codificar as igualdades, basta acrescentar a $\Lambda$ fórmulas correspondentes à equivalência bit a bit de cada $z_{i}^{\prime k}$ e $r h s_{i}: z_{i, j}^{\prime k} \leftrightarrow r h s_{i, j}$, para $1 \leq i \leq k+1$ e $1 \leq j \leq b_{\pi}$. Para construir tais fórmulas, supomos que existe uma função $E q\left(n_{1}, n_{2}, b\right)$ que gera as cláusulas de equivalência entre os $b$ bits de $n_{1}$ e $n_{2}$. Tal função podem ser construída tendo tempo de pior caso $\Theta(b)$. Acrescentamos finalmente a $\Lambda$ as fórmulas $E q\left(z_{i}^{\prime k}, r h s_{i}, b_{\pi}\right)$, para $1 \leq i \leq k+1$. Nesta etapa são acrescidas $\Theta\left(k \cdot b_{\pi}\right)$ cláusulas e variáveis.

\subsection{Algoritmo da Redução Canônica}

Agora podemos explicitar a redução no formato algorítmico, usando a notação desenvolvida neste capítulo. Antes deixaremos claro as hipóteses assumidas sobre o formato da entrada do algoritmo.

Cada probabilidade $p_{i}$, da entrada do algoritmo $\Delta=\langle\Gamma, \Psi\rangle$, é um número racional não negativo representado por seu numerador $n p[i]$ e o denominador comum $d p$. Os numeradores devem ser não negativos e menores do que $d p$. Nos laços do algoritmo, consideramos que os contadores $(i$ e $j$ ) são incrementados a cada iteração, o que deixamos implícito para uma melhor visualização.

O Algoritmo 4.1 mostra como construir a instância SAT $\Lambda$ a partir de uma instância PSAT $\Delta$, acrescentando as fórmulas como explicado na Seção 4.3.2. Tal algoritmo computa a função que é uma redução muitos-para-um do PSAT para o SAT, e a Seção 4.5 mostra que tal redução é polinomial.

\subsection{Análise da Complexidade Computacional}

Duas análises são de interesse para investigarmos a eficiência da redução apresentada. Primeiramente, a análise do tempo de pior caso do Algoritmo 4.1 proposto, que limita o espaço utilizado no pior caso. Precisamos provar um tempo polinomial para o pior caso do algoritmo para que este de fato seja uma redução polinomial. Porém, a análise do tamanho da instância $\Lambda$ retornada pelo algoritmo é de maior relevância, já que um SAT Solver deve requerer, no pior caso, tempo superpolinomial em relação ao número de variáveis em $\Lambda$ para decidir sua satisfazibilidade, a menos que $P=N P$.

\subsubsection{Análise do Algoritmo}

Aqui nos preocuparemos apenas com a polinomialidade no tempo do Algoritmo 4.1, já que, para o tamanho das instâncias PSAT na prática, isso deve garantir a eficiência desejada. Para investigar se o tempo de pior caso é polinomial, focamos nas funções definidas para geração de cláusulas na Seção 4.3, chamadas até $O\left(k^{2}\right)$ vezes no algoritmo. Para justificar tal abordagem, observamos que as demais operações aritméticas realizadas, bem como as atribuições $(\leftarrow)$ são todas polinomiais no tempo. As operações de união $(\Lambda \cup \Phi)$, sempre sobre conjuntos disjuntos, são implementadas junto 


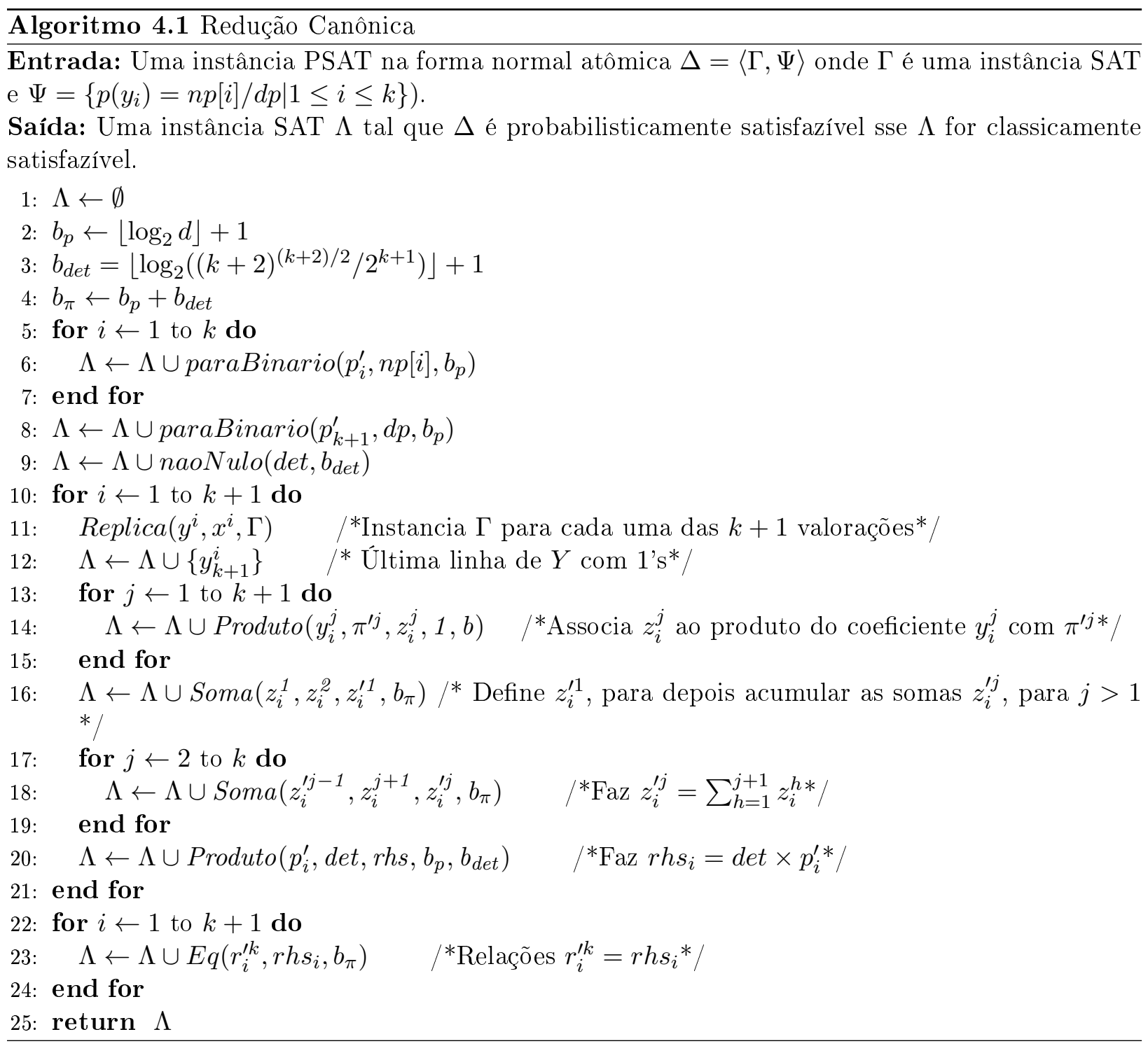


das atribuições correspondentes e são polinomiais em relação ao tamanho do conjunto de fórmulas $\Phi$, limitado pela complexidade de tempo de sua função geradora.

A Tabela 4.1 lista as funções utilizadas, o seu número de chamadas e seu tempo de pior caso. A segunda coluna mostra o tempo de pior caso em função dos parâmetros formais, e a terceira, em função dos parâmetros reais passados no algoritmo. Aqui $|\Gamma|$ é o tamanho da instância $\Gamma$.

Tabela 4.1: Complexidade das Funções Geradoras de Fórmulas

\begin{tabular}{|c|c|c|c|}
\hline Nome da função & Tempo de pior caso & Tempo no algoritmo & num. de chamadas \\
\hline paraBinario $(x, n, b)$ & $\Theta(b)$ & $\Theta\left(b_{p}\right)$ & $\Theta(k)$ \\
\hline naoNulo $\left(n_{1}, b\right)$ & $\Theta(b)$ & $\Theta\left(b_{\text {det }}\right)$ & $\Theta(1)$ \\
\hline Replica $\left(x^{j}, y^{j}, \Sigma\right)$ & $\Theta(|\Sigma|)$ & $\Theta(|\Gamma|)$ & $\Theta(k)$ \\
\hline Produto $\left(f_{1}, f_{2}\right.$, Pro, $\left., b_{1}, b_{2}\right)$ & $\Theta\left(b_{1} \cdot b_{2}\right)$ & $\Theta\left(b_{p} \cdot b_{\text {det }}\right)$ & $\Theta(k)$ \\
\hline Produto $\left(f_{1}, f_{2}\right.$, Pro, $\left.b_{1}, b_{2}\right)$ & $\Theta\left(b_{1} \cdot b_{2}\right)$ & $\Theta\left(b_{\pi}\right)=\Theta\left(b_{p}+b_{\text {det }}\right)$ & $\Theta\left(k^{2}\right)$ \\
\hline Soma $\left(p_{1}, p_{2}\right.$, Sum,$\left.b\right)$ & $\Theta(b)$ & $\Theta\left(b_{\pi}\right)=\Theta\left(b_{p}+b_{\text {det }}\right)$ & $\Theta\left(k^{2}\right)$ \\
\hline$E q\left(n_{1}, n_{2}, b\right)$ & $\Theta(b)$ & $\Theta\left(b_{\pi}\right)$ & $\Theta(1)$ \\
\hline
\end{tabular}

Separamos as duas ocorrências da função Produto, pois para parâmetros diferentes ela ocorreu diferentes vezes. As complexidade apresentadas são suportadas pela implementação de tais funções, listadas no Apêndice A.

Agregando os tempos das funções da Tabela 4.1 e seus números de ocorrências, temos um tempo de pior caso resultante de $\Theta\left(k\left(|\Gamma|+k\left(b_{\text {det }}+b_{p}\right)+b_{\text {det }} \cdot b_{p}\right)\right)$. Da linha 3 do Algoritmo 4.1 vemos que $b_{d e t}=\Theta(k \log k)$. Notamos o tamanho da instância PSAT $\Delta$, entrada do algoritmo, é $\Theta\left(|\Gamma|+k b_{p}\right)$, onde $b_{p}$ é o número de bits necessário para representar o denominador comum dos elementos de $p$. Finalmente, a soma do tempo de pior caso das funções utilizadas no algoritmo é $\Theta\left(k\left(|\Gamma|+k \log k\left(k+b_{p}\right)\right)\right.$, e logo polinomial em relação ao tamanho da entrada. Como as demais operações utilizadas também são polinomiais, concluímos que o algoritmo tem tempo polinomial em relação ao tamanho da entrada, e, logo, a redução apresentada é polinomial.

Note que há um fator $k^{3}$ no tempo do algoritmo, que acarreta uma complexidade ao menos cúbica para a redução, e seu impacto será analisado com mais detalhe na próxima seção.

\subsubsection{Análise do Tamanho da Saída}

Da teoria da complexidade computacional, sabemos que a complexidade do tamanho das fórmulas geradas pelas funções da Tabela 4.1 não pode exceder a complexidade no tempo das funções. Assim, como a instância $\Lambda$ é formada pela união dos conjuntos disjuntos de fórmulas retornados por tais funções, concluímos que $|\Lambda|=O\left(k\left(|\Gamma|+b_{\pi}\left(k+b_{p}\right)\right)\right)=O\left(k\left(|\Gamma|+k \log k\left(k+b_{p}\right)\right)\right)$.

Até a presente data, qualquer algoritmo que decida a satisfazibilidade de $\Lambda$ deve ter um tempo de pior caso $\Theta\left(2^{N}\right)=O\left(2^{|\Lambda|}\right)$, onde $N$ é o número de variáveis em $\Lambda$. Da Seção 4.3.2, totalizamos o número de variáveis de $\Lambda$ em $N=\Theta\left(k\left(n+k \cdot b_{\pi}+b_{p} \cdot b_{\text {det }}\right)\right)=\Theta\left(k\left(n+k \log k\left(k+b_{p}\right)\right)\right)$. Assim, se quisermos decidir a satisfazibilidade probabilística da instância PSAT $\Delta$ decidindo a satisfazibilidade clássica de sua redução ao SAT, $\Lambda$, temos um tempo de pior caso $\Theta\left(2^{k\left(n+k \log k\left(k+b_{p}\right)\right)}\right)$ se $P \neq N P$. O fator $k^{3} \log k$ no expoente, aliado às altas constantes omitidas na notação assintótica, dificulta tal estratégia na prática para $k$ 's muito pequenos, que não alcançam um dezena. Para se ter uma ideia, os melhores SAT Solvers são exponenciais sobre uma base próxima a $2^{0,4}$ no pior caso [Sch99], e $2^{\left(0,4 \cdot 10^{3} \log _{2} 10\right)} \geq 10^{300}$. Ainda assim, devido ao perfil de complexidade do SAT, onde 
os casos realmente difíceis se concentram em uma faixa estreita, a redução pode ser usada para resolver pequenas instâncias PSAT oriundas de casos práticos. Entretanto, para investigar o perfil de complexidade do PSAT, precisamos resolver as instâncias mais difíceis, a fim de procurar sua localização.

Essa dificuldade prática de se utilizar da redução apresentada para decidir o problema PSAT nos motiva a buscar modificações no algoritmo que diminuam sua complexidade, mesmo que em detrimento da precisão.

\subsection{Redução Canônica de Precisão Limitada}

Observando a expressão $N=\Theta\left(k\left(n+k \cdot b_{\pi}+b_{p} \cdot b_{\text {det }}\right)\right)$, notamos que $n, k$ e $b_{p}$ são parâmetros dados na entrada do algoritmo, característicos da instância PSAT $\Delta$ em questão. Se impusermos uma limitação para $n$, pouco se ganha em eficiência, e restringir $k$ não faz sentido, já que queremos justamente resolver instâncias com $k$ maiores. Assim, limitar a precisão $b_{p}$ na entrada é uma opção para diminuir o tempo do algoritmo, mas ainda pouco impactante.

Outra possibilidade é limitar a variável $b_{d e t}$, que leva a precisão em bits da solução que procuramos, $b_{\pi}=b_{d e t}+b_{p}$. Na Seção 4.2, argumentamos que, para mantermos a correção da redução, a precisão da solução deveria ser de $b_{\pi}=b_{p}+\Theta(k \log k)$ bits. Assim, essa garantia por correção é, em boa parte, responsável pela complexidade de $|\Lambda|$. Se limitamos $b_{\text {det }}$, a redução deixa de ser exata, e logo não se faz mais necessária a aritmética racional. Então, em vez de utilizar racionais, representaremos cada número de $\pi$ com uma sequência finita de bits, $0, b_{1}, \ldots, b_{\pi}$. A entrada $p$ será um vetor de probabilidades, não mais representadas por frações, e truncaremos cada elemento $p[i]$ de $p$ em seu $b_{p}$-ésimo bit mais significativo. Ao fixarmos $b_{\pi}$, artificialmente fixamos também $b_{p}$, pois $b_{p}>b_{\pi}$ não faz sentido.

Para modificarmos o Algoritmo 4.1 apresentado, a fim de limitar a precisão $b_{\pi}$, primeiramente eliminamos as linhas do algoritmo que calculam as precisões $b_{d e t}$ e $b_{\pi}$ e acrescentarmos a última à entrada do algoritmo, deixando por conta do usuário escolher o $b_{\pi}$ que lhe convenha. Supomos então que a função paraBinario $\left(p_{i}^{\prime}, p[i], b_{\pi}\right)$ toma apenas os $b_{\pi}$ primeiros bits de cada elemento de $p$, completando com 0's se necessário. O divisor comum det das soluções e as variáveis rhs deixam de ser necessárias, bem como as multiplicações $r h s_{i}=\operatorname{det} \cdot p_{i}$. O Algoritmo 4.2 implementa a redução canônica com precisão limitada.

O Apêndice B mostra um exemplo da execução de tal algoritmo, construindo cláusula por cláusula a instância SAT oriunda da redução e submentendo esta a um SAT Solver para decidir a satisfazibilidade probabilística da instância PSAT correspondente.

Ao eliminar as $k$ multiplicações de tempo $\Theta\left(b_{p} \cdot b_{\text {det }}\right)$, e fazer $b_{\pi}=b_{p}$, diminuímos o tamanho da instância SAT $\Lambda$ retornada pelo algoritmo para $|\Lambda|=\Theta\left(k\left(|\Gamma|+k \cdot b_{p}\right)\right)$, com um número de variáveis $N=\Theta\left(k\left(n+k \cdot b_{p}\right)\right)$.

Na prática, essa limitação da precisão pouco deve interferir nos resultados, já que os erros devem se concentrar em torno do ponto de transição de fase, onde a precisão se faz mais necessária.

Na transição de fase do PSAT, metade das instâncias é satisfazível, e a outra metade não o é. Se conjecturarmos que a probabilidade de ocorrer um falso negativo, em uma instância positiva, é igual a probabilidade de ocorrer um falso positivo, em uma instância negativa, a transição de fase deve se centrar no mesmo ponto, apenas se alargando, suavizando a transição. Condicionado a tal 


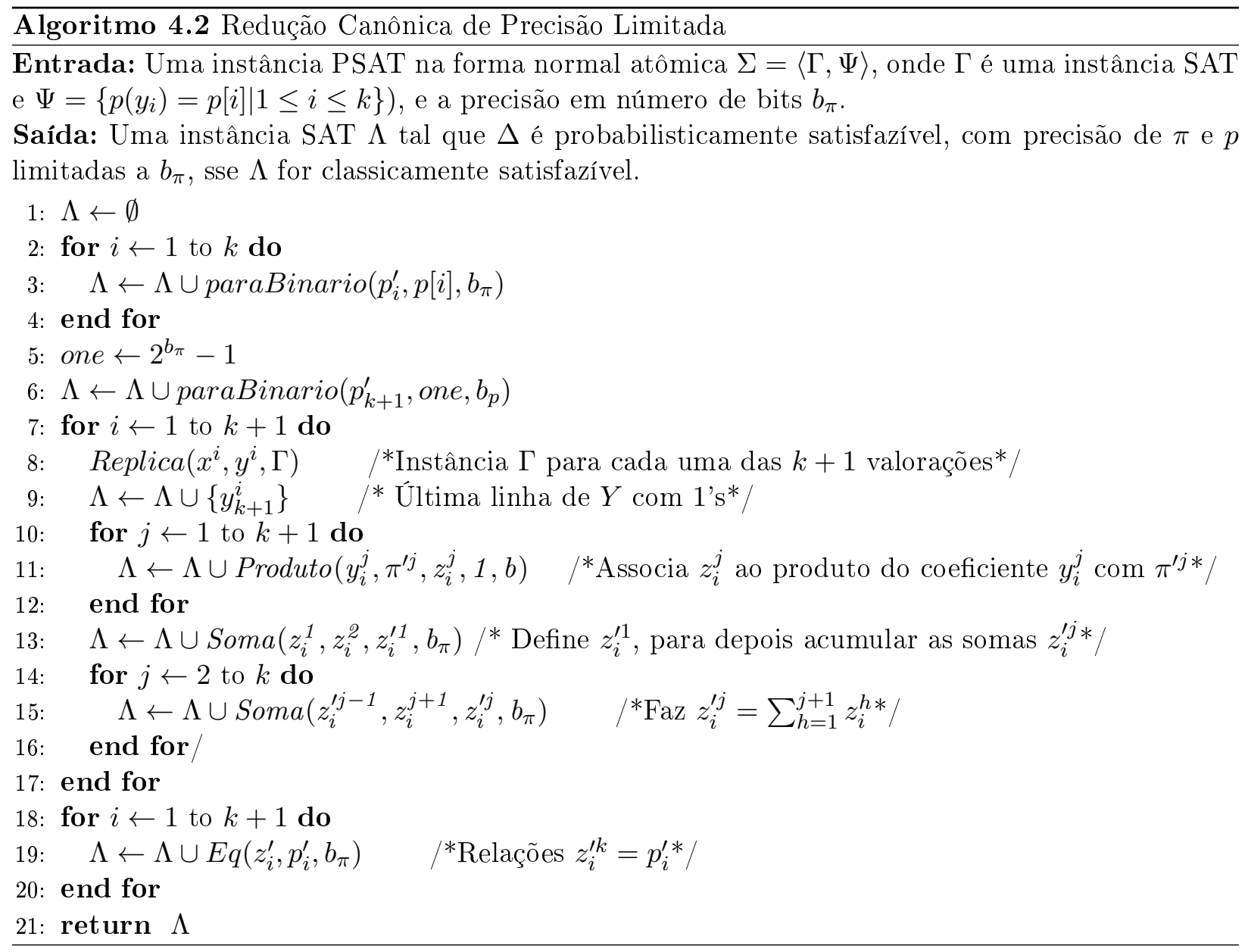


hipótese, mesmo com uma precisão limitada, o algoritmo mantém sua utilidade na investigação do fenômeno de transição de fase no PSAT.

De fato, o Algoritmo 4.2 foi implementado (disponível em "http://sourceforge.net/projects/psat/"), e experimentos com tal implementação para investigar o perfil de complexidade do PSAT são relatados no Capítulo 6. 


\section{Capítulo 5}

\section{Redução de Turing do PSAT para o SAT}

Tendo em vista a complexidade computacional observada na Redução Canônica do PSAT ao SAT, investigada nas Seções 4.5 e 4.6, procuramos outras reduções em busca da eficiência necessária para a solução de grandes instâncias PSAT. O algoritmo a ser apresentado usa um SAT Solver como oráculo para decidir o PSAT, o que é conhecido como Redução de Turing do PSAT ao SAT (sobre Redução de Turing, veja [Dav]). Se, considerando o oráculo com tempo constante, o algoritmo for polinomial no tempo, dizemos que é uma Redução de Turing polinomial. Ao deixar a precisão limitada pela implementação de ponto flutuante da máquina que executa o algoritmo, não podemos mais garantir a completude deste, mas claro que, para fins práticos, tal limitação pouco deve interferir.

As implementações dos algoritmos apresentados neste capítulo e seu desempenho serão discutidos apenas no Capítulo 6.

\subsection{Esboço do Algoritmo}

Nossa ideia é partir da abordagem do PSAT como problema de programação linear, pelo emprego do algoritmo Simplex apresentado no Capítulo 3, adaptando-o para entradas na forma normal atômica. Explorando o Teorema 2.5.4, chega-se a um problema auxiliar diferente, que será reduzido ao SAT. Assim como no Algoritmo 3.1, partiremos de uma solução básica viável (SBV) para a seguinte inserindo uma coluna, pelo pivoteamento, que não aumente nossa função objetivo.

Primeiramente, retomemos a apresentação de uma instância PSAT na forma de um problema de programação linear, já no formato padrão, com a primeira linha de A representando a condição $\sum \pi=1$ :

$$
\min z=0 \pi
$$

sujeito a:

$$
\begin{gathered}
A \pi=p \\
\pi \geq 0
\end{gathered}
$$

Para uma instância PSAT $\Delta=\langle\Gamma, \Psi\rangle$ na forma normal atômica, com $m$ cláusulas em $\Gamma$ e $\Psi=\left\{p\left(y_{i}\right)=p_{i} \mid 1 \leq i \leq k\right\}$, a aplicação direta da primera fase do algoritmo Simplex levaria a uma 
base com $m+k+1$ linhas e colunas, já que cada cláusula $\alpha \in \Gamma$ corresponde a uma atribuição de probabilidade $p(\alpha)=1$. Por outro lado, podemos modificar o Teorema 2.5.4, acrescentando uma linha acima de $A$ composta por 1's e uma probabilidade correspondente $p_{0}=1$ para representar a condição $\sum \pi=1$, e completando $k+1$ colunas, que não necessariamente representam valorações consistentes com $\Gamma$, de modo a obter uma matriz $A_{(k+1) \times(k+1)}$ não singular, chegando ao seguinte resultado:

Corolário 5.1.1. Seja $\Psi=\left\{p\left(y_{i}\right)=p_{i} \mid 1 \leq i \leq k\right\}$. Uma instância PSAT na forma normal atômica $\langle\Gamma, \Psi\rangle$ é satisfazível sse existe uma matriz binária não singular $A_{\Psi}$, com $k+1$ linhas e colunas e um vetor $\pi_{(k+1) \times 1}$ tais que $A_{\Psi} \pi=\left[1 \mid p_{1} \ldots p_{k}\right]^{\prime}$, e que cada coluna de $A_{\Psi}$ com probabilidade não nula corresponde a uma valoração sobre $\left\{y_{1}, \ldots, y_{k}\right\}$ consistente com $\Gamma$, a menos da primeira linha, composta por 1's.

Isso nos sugere que, para instâncias PSAT $\Delta=\langle\Gamma, \Psi\rangle$ na forma normal atômica, temos um problema de programaçao linear no mesmo formato de (5.1), porém $A$ pode ser uma matriz com apenas $k+1$ linhas e colunas representando apenas valorações consistentes com $\Gamma$. Podemos então aplicar o Simplex com uma base de tamanho $k+1$, considerando apenas as $k$ probabilidades atribuídas em $\Psi$, com a restrição de, a cada iteração, adicionarmos a base apenas colunas que representem valorações consistentes com $\Gamma$ (chamaremos simplesmente de colunas $\Gamma$-consistentes).

A cada iteração queremos uma matriz $B_{k+1, k+1}$ (base) e um vetor $\pi$ tais que $B \pi=p$ e $\sum \pi=1$, com algumas colunas eventualmente $\Gamma$-inconsistentes tendo probabilidade não nula. Se $\Gamma$ for vazio, todas as valorações são consistentes com $\Gamma$, e qualquer matriz $B_{k+1, k+1}$ e vetor $\pi$ tais que $A \pi=p$ nos dão uma solução, desde que as colunas de $B$ representem valorações, a menos da primeira linha composta pos 1's. Daí, nos convém a seguinte definição:

Definição 5.1.2. Para toda instância PSAT $\langle\Gamma, \Psi\rangle$, definimos a instância PSAT relaxada como $\langle\emptyset, \Psi\rangle$, ignorando a instância SAT $\Gamma$.

A cada iteração teremos então uma solução para a instâncias PSAT relaxada. Se anularmos a soma das probabilidades das colunas $\Gamma$-inconsistentes, ou encontrarmos uma matriz $B$ apenas com colunas $\Gamma$-consistentes, teremos encontrado uma solução para a instância não relaxada.

Antes de usarmos o algoritmo Simplex, precisamos de base inicial. A primeira fase do Simplex com duas fases sugere o uso da matriz identidade como base inicial, com a adição de variáveis artificiais. Entretanto, tal matriz não nos leva a uma solução para a instância PSAT relaxada, uma vez que a primeira linha não é composta apenas de 1's, e a SBV correspondente não será uma distribuição de probabilidade. O resultado a seguir nos oferece uma alternativa:

Lema 5.1.3. Toda instância PSAT relaxada é satisfazível.

Demonstração. Considere uma instância relaxada $\left(\emptyset,\left\{P\left(y_{i}\right)=p_{i} \mid 1 \leq i \leq k\right\}\right.$; supomos que os elementos de $p=\left[p_{1}, \ldots, p_{k}\right]$ são dados em ordem decrescente. Considere a matriz $I^{*}=\left[a_{i, j}\right]$, onde:

$$
a_{i, j}= \begin{cases}1, & i \leq j \\ 0, & i>j\end{cases}
$$

Então o sistema $I^{*} \cdot \pi=[1 \mid p]^{\prime}$, sempre admite uma solução $\pi_{1}=1-p_{1} \geq 0 ; \pi_{i}=p_{i-1}-p_{i} \geq 0$, $2 \leq i \leq k$; and $\pi_{k+1}=p_{k} \geq 0$. Pelo Corolário 5.1.1, a instância relaxada é satisfazível. 
A prova do Lema 5.1.3 nos sugere uma base inicial $I^{*}$ para nosso algoritmo, com uma clara vantagem em relação a matriz identidade: suas colunas podem representar valorações, já que seu primeiro elemento é 1, e então podem ser $\Gamma$-consistentes. Assim, a função objetivo a ser minimizada será a soma das probabilidades referentes às colunas de $I^{*}$ não consistentes com $\Gamma$, já que as demais poderão compor a solução final.

Agora podemos apresentar o problema de programação linear modificado para instâncias PSAT na forma normal atômica, onde a base inicial é $I^{*}$ em vez de $I$, as probabilidades das colunas $\Gamma$-consistentes de $I^{*}$ não entram no custo e a matriz $A$ contém apenas colunas $\Gamma$-consistentes. Denotamos por $J$ o conjunto dos índices das colunas em $I^{*}$ que não são $\Gamma$-consistentes.

$$
\begin{array}{ll}
\min _{\text {sujeito a }} & f=\sum_{j \in J} \pi_{j} \\
& {\left[A \mid I^{*}\right] \pi=p} \\
& \pi \geq 0
\end{array}
$$

O Algoritmo 5.1 é resultado da aplicação do Simplex com o método de geração de colunas no problema (5.4), oriundo de uma instância PSAT na forma normal atômica. Lembremos que agora a função ProblemaAuxiliar deve retornar colunas com custo reduzido negativo que sejam $\Gamma$-consistentes.

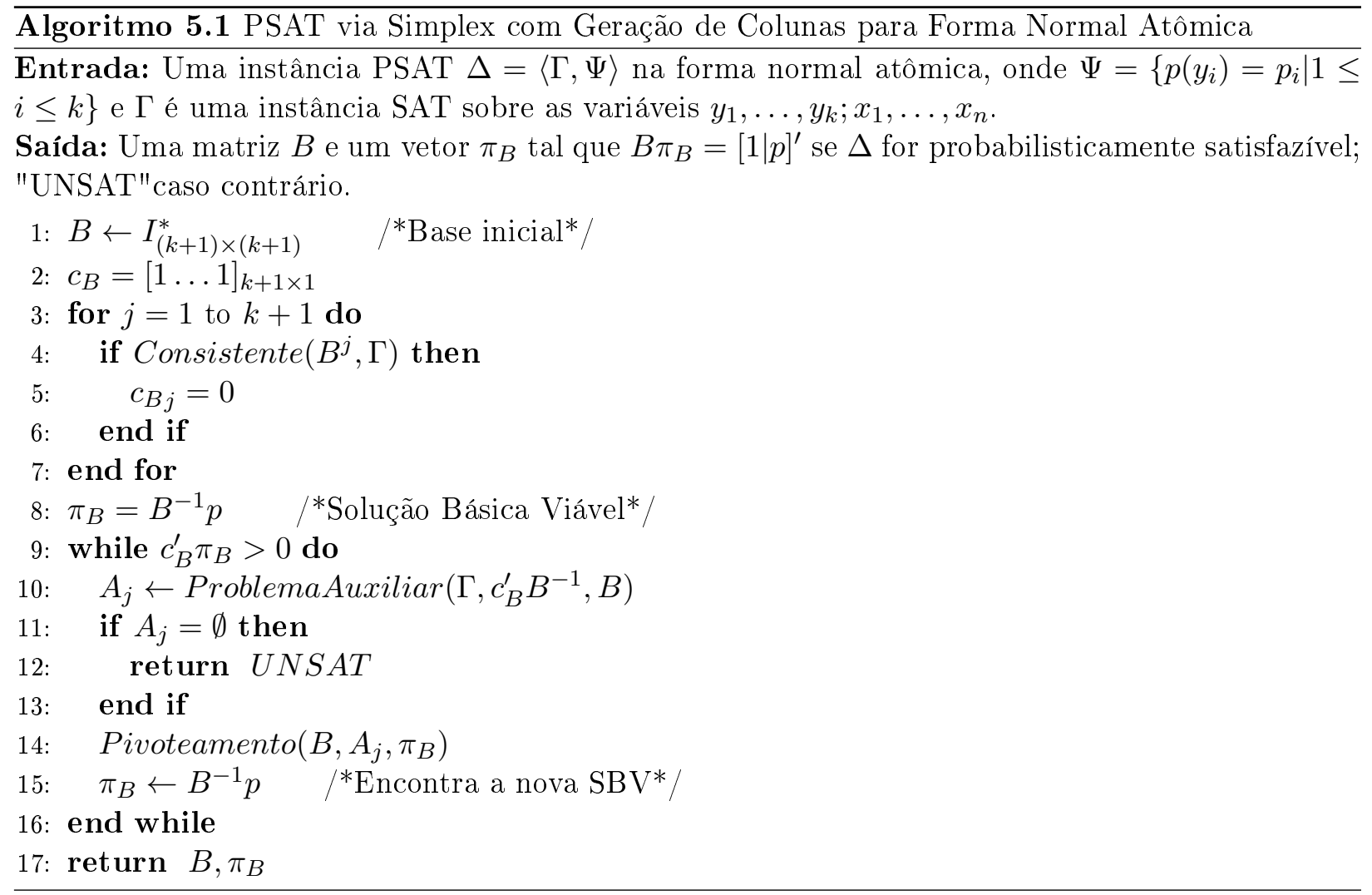

A função pivoteamento aqui também atualiza o vetor $c_{B}$, que conterá 0 para cada coluna $\Gamma$ consistente que entrar na base, além de inserir uma coluna na base mantendo a viabilidade da solução, como mostramos na Seção 3.1. A função Consistente $\left(B^{j}, \Gamma\right)$ retorna $T R U E$ sse a coluna $B^{j}$ representa uma valoração sobre $y_{1}, \ldots, y_{k}$ consistente com $\Gamma$, a menos da primeira linha. Tal função pode ser implementada simplesmente chamando a um SAT Solver para $\Gamma$, com uma valoração 
parcial sobre $y_{1}, \ldots, y_{k}$ correspondente à coluna $B^{j}$. A função ProblemaAuxiliar retorna uma coluna $\Gamma$-consistente com custo reduzido negativo, ou $\emptyset$ se não houver tal coluna. $O$ parâmetro extra $B$ terá seu uso justificado na próxima seção. Lembremos que as colunas retornadas devem conter 1 na primeira linha, representando a condição $\sum \pi=1$.

Comparado ao Algoritmo 3.1, o Algoritmo 5.1 apresenta 3 principais modificações:

- a entrada é uma instância PSAT na forma normal atômica, o que nos permite utilizar o Simplex com uma base de tamanho $k+1$, independentemente do tamanho de $\Gamma$;

- a base inicial é $I^{*}$, que, diferentemente da matriz identidade, possui colunas que podem representar valorações consistentes com $\Gamma$ - que são procuradas no laço das linhas 3-7;

- o problema auxiliar deve retornar colunas $\Gamma$-consistentes.

Dada a nova caracterização do problema auxiliar, é natural que este seja reduzido a uma instância SAT, já que procuramos valorações que satisfaçam $\Gamma$. Assim, teremos uma Redução de Turing do PSAT ao SAT, onde aplicamos o Simplex ao PSAT e, a cada iteração, chamamos um SAT Solver para gerar uma nova coluna a ser inserida na base. Como sabemos do Simplex, se não existir uma nova coluna com custo reduzido negativo, em alguma iteração onde o custo da base é positivo, então a instância PSAT em questão é insatisfazível. Do contrário, a menos de casos degenerados, o custo sempre decresce e o algoritmo termina em um número finito de passos. Para garantir o término do algoritmo em casos degenados, quando colunas básicas tem probabilidade nula, podemos, por exemplo, resolver aleatoriamente empates na escolha da coluna que sai da base a cada iteração ou usar a regra de Bland. [PS98].

O Exemplo 5.1.4 ilustra o funcionamento do Algoritmo 5.1, a menos da função ProblemaAuxiliar, que será discutida na próxima seção.

Exemplo 5.1.4. Seja $\langle\Gamma, \Psi\rangle$ uma instância PSAT na forma normal atômica, tal que $\Gamma=\left\{\neg y_{1} \vee\right.$ $\left.y_{2} \vee y_{3}\right\}$ e $\Psi=\left\{p\left(y_{1}\right)=0,7, p\left(y_{2}\right)=0,6, p\left(y_{3}\right)=0,2\right\}$. Como temos $k=3$ probabilidades atribuídas em $\Psi$, ao submetermos $\langle\Gamma, \Psi\rangle$ ao Algoritmo 5.1 obtemos $I_{4 \times 4}^{*}$ como base inicial:

$$
B=\left[\begin{array}{llll}
1 & 1 & 1 & 1 \\
0 & 1 & 1 & 1 \\
0 & 0 & 1 & 1 \\
0 & 0 & 0 & 1
\end{array}\right]
$$

Inicialmente, $c_{B}^{\prime}=\left[\begin{array}{llll}1 & 1 & 1 & 1\end{array}\right]$, mas do laço das linhas 3-7 resulta que apenas a valoração correspondente à segunda coluna de $B, v(y 1)=1$ e $v\left(y_{2}\right)=v\left(y_{3}\right)=0$, não é consistente com $\Gamma$. Logo, o vetor custo é atualizado para $c_{B}^{\prime}=\left[\begin{array}{llll}0 & 1 & 0 & 0\end{array}\right]$.

Na linha 8 , a solução básica inicial é obtida utilizando a matriz inversa da base $B$ :

$$
\pi_{B}=B^{-1} p=\left[\begin{array}{cccc}
1 & -1 & 0 & 0 \\
0 & 1 & -1 & 0 \\
0 & 0 & 1 & -1 \\
0 & 0 & 0 & 1
\end{array}\right] \cdot\left[\begin{array}{c}
1 \\
0,7 \\
0,6 \\
0,2
\end{array}\right]=\left[\begin{array}{c}
0,3 \\
0,1 \\
0,4 \\
0,2
\end{array}\right]
$$

Como $c_{B}^{\prime} \pi_{B}=0,1>0$, ainda não temos uma solução e entramos no laço das linhas 9-16. A função ProblemaAuxiliar $\left(\Gamma, c_{B}^{\prime} B^{-1}, B\right)$ deve retornar uma coluna $\Gamma$-consistente com custo reduzido 
negativo e será detalhada na próxima seção. Aqui supomos que ela retorna $A_{j}=\left[\begin{array}{llll}1 & 1 & 0 & 1\end{array}\right]$, que é $\Gamma$-consistente e tem como custo reduzido $-c_{B}^{\prime} B^{-1} A_{j}=-1<0$.

Na linha 14 do algoritmo, inserimos $A_{j}$ na base, procurando qual coluna deve sair para manter a solução básica viável. Para escolhe tal coluna, conforme explicado na Seção 3.1, primeiramene calculamos os coeficientes $\alpha_{j i}$ tais que $A_{j}=\sum_{i=1}^{4} \alpha_{j i} B(i)=A_{j}$, onde $B(i)$ denota a $i$-ésima coluna da base:

$$
\alpha_{j}=B^{-1} A_{j}=\left[\begin{array}{cccc}
1 & -1 & 0 & 0 \\
0 & 1 & -1 & 0 \\
0 & 0 & 1 & -1 \\
0 & 0 & 0 & 1
\end{array}\right] \cdot\left[\begin{array}{l}
1 \\
1 \\
0 \\
1
\end{array}\right]=\left[\begin{array}{c}
0 \\
1 \\
-1 \\
1
\end{array}\right]
$$

Como temos $\alpha_{j 1}, \alpha_{j 3} \leq 0$, comparamos $\pi_{B 2} / \alpha_{j 2}=0,1$ com $\pi_{B 4} / \alpha_{j 4}=0,2$ e escolhemos a segunda coluna $(j=2)$ para deixar a base, a fim de manter a solução viável. Ainda na linha 14, o vetor custo é atualizado, e, como inserimos uma coluna $\Gamma$-consistente, temos $c_{B}^{\prime}=\left[\begin{array}{llll}0 & 0 & 0 & 0\end{array}\right]$. Eis a base $B$ atualizada:

$$
B=\left[\begin{array}{llll}
1 & 1 & 1 & 1 \\
0 & 1 & 1 & 1 \\
0 & 0 & 1 & 1 \\
0 & 1 & 0 & 1
\end{array}\right]
$$

Na linha 15 do algoritmo, atualizamos a solução básica para a nova base:

$$
\pi_{B}=B^{-1} p=\left[\begin{array}{cccc}
1 & -1 & 0 & 0 \\
0 & 1 & -1 & 0 \\
0 & 1 & 0 & -1 \\
0 & -1 & 1 & 1
\end{array}\right] \cdot\left[\begin{array}{c}
1 \\
0,7 \\
0,6 \\
0,2
\end{array}\right]=\left[\begin{array}{c}
0,3 \\
0,1 \\
0,5 \\
0,1
\end{array}\right]
$$

Como $c_{B}^{\prime} \pi_{B}=0$, a condição de entrada no laço na linha 7 é falsa, e a solução $\pi_{B}$ é retornada na linha 17 juntamente com a base $B$, indicando que a instância PSAT $\langle\Gamma, \Psi\rangle$ é satisfazível.

\subsection{O Problema Auxiliar para Instâncias na Forma Normal Atômica}

O problema auxiliar consiste em encontrar uma valoração $v_{j}$ que corresponda a uma coluna $\Gamma$-consistente $A_{j}$ com custo reduzido negativo. Sendo $u_{i}$ a i-ésima componente do vetor $c_{B}^{\prime} B^{-1}$, relembramos a expressão do custo reduzido de uma coluna candidata a entrar na base, da Seção 3.4, ressaltando aqui que o primeiro elemento da coluna é sempre 1:

$$
\bar{c}_{j}=-u_{0}-\sum_{i=1}^{k} u_{i} v_{j}\left(y_{i}\right)
$$

Ignorando o critério da otimalidade, onde buscaríamos uma coluna com o menor custo reduzido, contentaremo-nos com uma coluna com custo reduzido negativo, ficando com um problema de decisão, que pode ser reduzido a uma instância SAT. Denotando $v_{j}\left(y_{i}\right)$ simplesmente por $y_{i}$, chegamos a uma inequação:

$$
u_{0}+\sum_{i=1}^{k} u_{i} y_{i}=u\left[1 \mid y_{1} \ldots y_{k}\right]^{\prime}>0
$$


A coluna a ser gerada deve respeitar tal inequação para que seu custo reduzido seja negativo. Partindo da inequação, queremos gerar uma instância SAT $\Lambda$ tal que uma valoração $v$ satisfaz $\Lambda$ sse a inequação (5.6) é verdadeira quando substituímos $y_{i}$ por $v\left(y_{i}\right)$. De posse de tal instância, podemos submeter $\Gamma \cup \Lambda$ a um SAT Solver para obter uma valoração sobre $\left\{y_{1}, \ldots, y_{k}\right\} \cup\left\{x_{1}, \ldots, x_{n}\right\}$ que satisfaça $\Gamma$, cuja valoração parcial sobre $y_{1}, \ldots, y_{k}$ corresponda a uma coluna com custo reduzido negativo.

\subsubsection{De Inequações para Instâncias SAT}

A transfomação de uma inequação linear em uma fórmula da lógica proposicional clássica no formato clausal pode ser feita em tempo linear sobre o número de variáveis e o número de bits usados para representar os coeficiente, como mostra [War98]. Mas para usar tal transformação, precisamos primeiramente reescrever nossa inequação no formato abaixo, garantindo coeficientes inteiros e não negativos, bem como o termo independente ao lado direto:

$$
a_{1} z_{1}+\cdots+a_{k} z_{k} \geq a_{0}
$$

Primeiramente, precisamos encontrar um número grande o suficiente que, multiplicado por $u=$ $c_{B}^{\prime} B^{-1}$, leve a $u^{\prime}$ inteiro. Lembremos que os elementos de $c_{B}^{\prime}$ são 0 ou 1 , então $u$ deve ser o resultado da soma de linhas de $B^{-1}$. Os elementos de $B^{-1}$, por sua vez, são os elementos da matriz adjunta de $B, \operatorname{Adj}(B)$, divididos pelo determinante de $B, \operatorname{det}(B)$. Os elementos de $\operatorname{Adj}(B)$, a menos do sinal, são determinantes de submatrizes de $B$ e, logo, inteiros. Assim, para garantirmos coeficientes inteiros na inequação (5.6), basta multiplicar ambos os lados da desiguladade por $\operatorname{det}(B)$, chegando aos coeficientes $u^{\prime}=u \cdot \operatorname{det}(B)$. Usando a desigualdade de Hadamard (veja [FS71], problema 523) limitamos tal determinante a $(k+1)^{(k+3) / 2} / 2^{k}$. Passamos o termo independente para a direita e o incrementamos, mudando relação para $\geq$, aproximando-nos do formato desejado:

$$
u_{1}^{\prime} y_{1}+\cdots+u_{k}^{\prime} y_{k} \geq-u_{0}^{\prime}+1
$$

Uma vez que os elementos de $u^{\prime}$ são inteiros, eliminamos então os coeficientes negativos. Para todo $y_{i}$ em (5.8) com $u_{i}^{\prime}$ negativo, subtraímos $u_{i}^{\prime}$ em ambos os lados da desigualdade, subsituindo $-u_{i}^{\prime}+u_{i}^{\prime} y_{i}$ por $-u_{i}^{\prime} \bar{y}_{i}$, onde $\bar{y}_{i}$ representa aqui $v\left(\neg y_{i}\right)$. Finalmente teremos uma inequação no formato de (5.7) com coeficientes inteiros e positivos, a menos de $a_{0}$; mas se só restar este negativo, nossa inequação é trivialmente verdadeira para qualquer valoração e pode ser reduzida à tautologia, uma instância SAT sem cláusulas. Por outro lado, se $a_{0}$ for maior que a soma dos coeficientes restantes, a inequação é trivialmente falsa para qualquer valoração, sendo transformada em uma contradição, uma cláusula vazia.

Quando finalmente obtemos todos os coeficientes inteiros e não negativos, representamo-los no sistema posicional binário, com $b_{a}$ bits. $\mathrm{O}$ inteiro $a_{i}$ será representado por $a_{i b_{a}}, \ldots, a_{i 1}$, sendo $a_{i 1}$ o bits menos significativo. Como precisaremos armazenar a soma $\sum_{i=1}^{k} a_{i}$, representamos cada coeficiente $a_{i}$ com um número de bits $b_{a}$ suficiente para armazenar a soma $\sum_{i=1}^{k} a_{i}$ a fim de facilitar a implementação. Para limitar $b_{a}$, precisamos estimar o tamanho máximo dos coeficientes $a_{1}, \ldots, a_{k}$ em (5.7), para limitar sua soma. Cada termo de $u=c_{B}^{\prime} B^{-1}$ é inicialmente a soma de até $k+$ 1 elementos de $B^{-1}$, igual a soma de $k+1$ cofatores de $B$ dividida pelo determinante de $B$. Usando novamente a desigualdade de Hadamard (veja [FS71], problema 523), limitamos o valor 
absoluto de cada cofator a $(k+1)^{(k+1) / 2} / 2^{k}$, e o valor absoluto de cada elemento de $u$ a $k(k+$ $1)^{(k+1) / 2} /\left(2^{k} \operatorname{det}(B)\right)$. Após multiplicarmos $u$ por $\operatorname{det}(B)$, obtemos um valor absoluto no máximo de $k(k+1)^{(k+1) / 2} / 2^{k}$. Este é o valor máximo possível para os coefcientes $a_{1}, \ldots, a_{k}$. Finalmente, limitamos $\sum_{i=1}^{k} a_{i}$ a $k^{2}(k+1)^{(k+1) / 2} / 2^{k}$ e $b_{a}$ será $O(k \log k)$.

Agora, de maneira completamente análoga à feita na Seção 4.3.2, codificamos as somas e multiplicações. Seja $b_{1}, \ldots, b_{k}$ o resultado das multiplicações $a_{i} z_{i}$, sendo cada bit de $b_{i}$ equivalente à conjunção entre $z_{i}$ e cada bit de $a_{i}$, ou seja, $b_{i j} \leftrightarrow a_{i j} \wedge z_{i}, 1 \leq i \leq k$ e $1 \leq j \leq b_{a}$. A essa altura, temos a inequação $b_{1}+\cdots+b_{k} \geq a_{0}$. Então codificamos em $c_{i}$ as somas parciais de $b_{i}$. Inicialmente, $c_{1}=b_{1}$ é implementado pela equivalência bit a bit, então fazemos $c_{i}=b_{i}+c_{i-1}$, para $2 \leq i \leq k$. Tal soma é codificada em tempo linear no número de bits e é implementada pela função Soma apresentada na Seção 4.3.2. Por fim, basta verificar a relação $c_{k} \geq a_{0}$, que também pode ser codificada em um fórmula lógica em tempo linear e é implementada pela função Geq no Apêndice A.

\subsubsection{Algoritmo para o Problema Auxiliar}

Podemos enfim apresentar um algoritmo que implementa a função ProblemaAuxiliar do Algoritmo 5.1 através de uma chamada a um SAT Solver. Note que precisamos do determinante de $B$ para obter os coeficientes inteiros, explicando o parâmetro adicional da função ProblemaAuxiliar em relação àquela apresentada no Algoritmo 3.1.

A função paraBinario, assim como no Algoritmo 4.1, força um conjunto $a_{i}$ de $b_{a}$ variáveis a corresponder a representação binária de um inteiro, $a[i]$. As funções Soma, Produto e Eq também são as mesmas do Algoritmo 4.1, codificando a soma, a multiplicação e a igualdade respectivamente. A função $\operatorname{Geq}\left(c_{k}, a_{0}, b_{a}\right)$ gera uma fórmula que é verdadeira sse o inteiro representado pelos bits $c_{k j}$ for maior ou igual ao inteiro representado pelos bits $a_{0 j}$, com $1 \leq j \leq b_{a}$. Por simplicidade na notação, consideramos que a função SATSolver retorna a coluna correspondente à valoração que satisfaz seu argumento, ou $\emptyset$ se seu argumento for insatisfazível.

O Exemplo 5.2.1 retoma o Exemplo 5.1.4, detalhando a chamada da função ProblemaAuxiliar do Algoritmo 5.1, ilustrando a execução do Algoritmo 5.2.

Exemplo 5.2.1. Durante o Exemplo 5.1.4, a função ProblemaAuxiliar $(\Gamma, u, B)$ é chamada para $\Gamma=\left\{\neg y_{1} \vee y_{2} \vee y_{3}\right\}, u=c_{B}^{\prime} B^{-1}=\left[\begin{array}{llll}0 & 1 & -1 & 0\end{array}\right]$ e $B=I_{4 \times 4}^{*}$, que são as entradas do Algoritmo 5.2, que implementa tal função. Queremos encontrar uma coluna $\Gamma$-consistente cujo o custo reduzido seja negativo.

Inicialmente, notemos que $\operatorname{det}(B)=1$, logo as linhas 1-3 não modificam os elementos de $u$, que já são inteiros. A essa altura, a inequação que força o custo reduzido da coluna a ser retornada a ser negativo é dada por $u\left[\begin{array}{llll}1 & y_{1} & y_{2} & y_{3}\end{array}\right]^{\prime}>0$.

Na linha 4, tem-se $a[0]=1$, necessário para chegar a uma inequação no formato de (5.7).

No laço das linhas 5-14, eliminamos o coeficiente negativo $u[2]=-1$ da inequação chegando a uma inequação da forma (5.7):

$$
\begin{array}{ccccc}
a[1] z_{1} & +a[2] z_{2} & +a[3] z_{3} & \geq & a[0] \\
1 y_{1} & +1\left(\neg y_{2}\right) & +0 y_{3} & \geq & 2
\end{array}
$$

Notemos que o coeficiente $a[0]$ é maior que zero mas menor ou igual a soma dos demais coeficientes, 


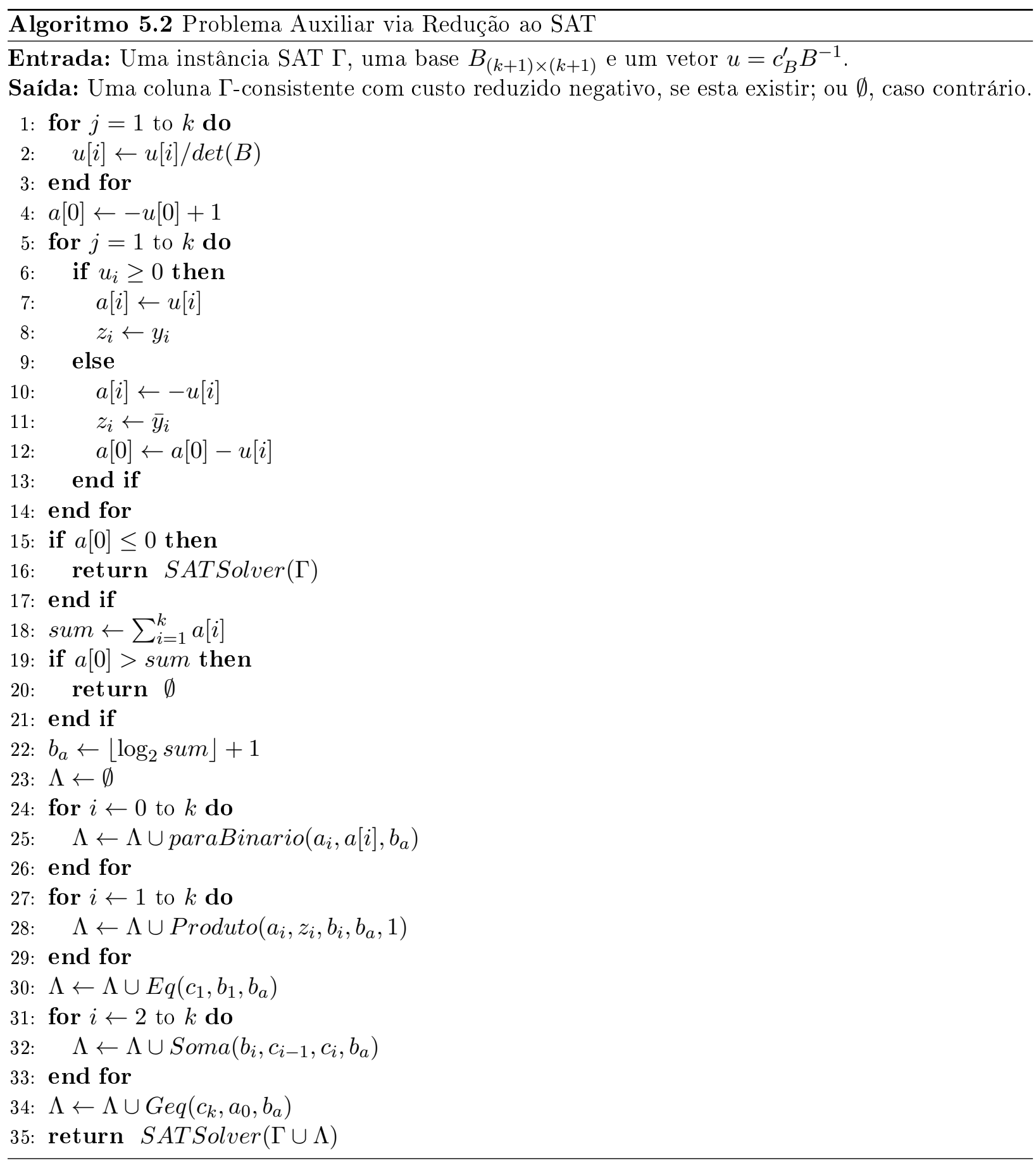


logo não caímos nos casos triviais:

$$
0<a[0]=2 \leq \sum_{i=1}^{3} a[i]=2
$$

O número de bits $b_{a}=2$ garante a precisão necessária, e podemos começar a construir a instância SAT $\Lambda$, inicialmente vazia, que codifica a inequação (5.9). Em todo este exemplo, não nos preocuparemos em construir $\Lambda$ no formato clausal, para simplificar a notação. Assim, quando dizemos acrescentar uma fórmula a $\Lambda$, entenda-se acrescentar cláusulas correspondentes a tais fórmulas, para $\Lambda$ ser uma instância SAT de fato. Logo, as fórmulas aqui listadas não corresponderão exatamente àquelas geradas pelas implementações listadas no Apêndice A.

Cada coeficiente $a[i]$ é representado por 2 bits: $a_{i 1}, a_{i 2}$, sendo $a_{i 1}$ o menos significativo. No laço das linhas 24-26, acrescentamos a $\Lambda$ cláusulas que forçam os bits que representam os coeficientes $a[0], \ldots, a[3]$ a corresponderem àqueles de $(5.9)$ :

$$
a_{02}, \neg a_{01}, \neg a_{12}, a_{11}, \neg a_{22}, a_{21}, \neg a_{32}, \neg a_{31},
$$

O resultado de cada multiplicação $b[i]=a[i] z_{i}, 1 \leq i \leq 3$, é analogamente representado por 2 bits, $b_{i 1}$ e $b_{i 2}$. No laço das linhas 27-29 adicionamos a $\Lambda$ as fórmulas:

$$
b_{i j} \leftrightarrow a_{i j} \wedge z_{i}, \quad[1 \leq i \leq 3,1 \leq j \leq 2]
$$

As somas parciais $c[i]=\sum_{j=1}^{i} b[j], 1 \leq i \leq 3$, são da mesma forma codificadas em 2 bits, $c_{i 1}$ e $c_{i 2}$. Para facilitar a notação, consideramos que $c[1]$ e $b[1]$ são equivalentes bit a bit e na linha 30 incluímos em $\Lambda$ as fórmulas:

$$
c_{11} \leftrightarrow b_{11}, \quad c_{12} \leftrightarrow b_{12}
$$

No laço das linhas 31-33, adicionamos a $\Lambda$ as fórmulas que codificam os bits de $c[i]=\sum_{j=1}^{i} b[j]$, $2 \leq i \leq 3$.

$$
\begin{aligned}
c_{i 1} & \leftrightarrow b_{i 1} \wedge \neg c_{i-1,1} \vee \neg b_{i 1} \wedge c_{i-1,1}, \quad[2 \leq i \leq 3] \\
c_{i 2} & \leftrightarrow b_{i 2} \vee c_{i-1,2} \vee b_{i 1} \wedge c_{i-1,1}
\end{aligned}
$$

A conjunção $b_{i 1} \wedge c_{i-1,1}$ corresponde ao "carry"do primeiro para o segundo bit. É importante ressaltar que, como o número de bits $b_{a}=2$ foi escolhido para evitar "overflow", apenas uma entre as três conjunções da disjunção $b_{i 2} \vee c_{i-1,2} \vee b_{i 1} \wedge c_{i-1,1}$ pode ser verdadeira para qualquer valoração que satisfaça $\Lambda$.

Finalmente, a construção da instância SAT termina quando o algoritmo adiciona a $\Lambda$, na linha 34 , a fómula equivalente a desigualdade $c[3] \geq a[0]$ :

$$
c_{22} \wedge \neg a_{02} \vee\left(c_{22} \vee \neg a_{02}\right) \wedge\left(c_{21} \wedge \neg a_{01}\right)
$$

A instância SAT $\Lambda$ que codifica em uma fórmula lógica a inequação (5.9), forçando a coluna correspondente a qualquer valoração que a satisfaça a ter um custo reduzido negativo, é formada pela união cláusulas provenientes das fórmulas (5.10-5.14). Observando a inequação (5.9), vemos que a instância SAT $\Lambda^{\prime}=\left\{y_{1}, \neg y_{2}\right\}$ cumpre o mesmo papel com apenas dois literais, mas aqui nos interessou ilustrar o Algoritmo 5.2, que constrói $\Lambda$ ainda em tempo linear sobre $k$ e $b_{a}$. 
Na linha 35, o algoritmo submete a um SAT Solver a instância $\Gamma \cup \Lambda$ para obter uma valoração correspondente à coluna a ser retornada. É devolvida a coluna $A_{j}=\left[\begin{array}{llll}1 & 1 & 0 & 1\end{array}\right]^{\prime}$, que é $\Gamma$-consistente e tem custo reduzido $-c_{B} B^{-1} \cdot A_{j}=-\left[\begin{array}{lllll}0 & 1 & -1 & 0\end{array}\right] \cdot\left[\begin{array}{llll}1 & 1 & 0 & 1\end{array}\right]^{\prime}=-1<0$.

\subsection{Análise da Complexidade Computacional}

Para que a redução de Turing implementada seja polinomial, é necessário que o tempo do Algoritmo 5.1 seja polinomial sobre o tamanho da entrada (uma instância PSAT) quando consideramos um SAT Solver com tempo constante, ou seja, um oráculo para o SAT. Outra análise, de fim prático, diz respeito ao tamanho da instância submetida ao SAT Solver a cada iteração, que será responsável por maior parte do tempo de execução do algoritmo como um todo. Assim, dividimos nossa análise entre o Algortimo 5.1, incluindo o Algoritmo 5.2, sua principal rotina, e o tamanho da instância SAT que esta gera. Por economia na escrita, denotamos simplesmente por polinomial a expressão mais formal "de tempo polinomial no pior caso em relação ao tamanho da entrada".

\subsubsection{Análise do Algoritmo 5.1}

Nesta seção consideramos a hipótese da existência de um SAT Solver de tempo constante, a fim de estudar sob que condições teríamos uma redução de Turing polinomial. analisando os passos do algoritmo, vemos que além da funções Pivoteamento, Consistente e ProblemaAuxiliar, restam operações de atribuição, inversão e multiplicação de matrizes, tipicamente polinomiais. O pivoteamento do Simplex, como apresentamos na Seção 3.1, consiste também em operações aritméticas polinomiais. A função Consistente, como mencionamos na Seção (5.1), é implementada diretamente com um SAT Solver, de tempo constante pela hipótese do oráculo. Resta-nos investigar a função ProblemaAuxiliar e o número de iterações esperado para o laço while das linhas 9-16.

A função ProblemaAuxiliar, por sua vez, é implementada pelo Algoritmo 5.2. Aqui nos preocuparemos apenas com a polinomialidade deste, na posse de oráculo para o SAT, e na Seção 5.3.2 analisaremos em maior detalhe seu tempo, que teoricamente limita o tamanho da instância SAT gerada. Nesta rotina também vemos apenas operações aritméticas polinomiais, a menos das funções que definimos. A polinomialidade das funções paraBinario, Produto, Soma, Eq e Geq já foi comentada nas Seções 4.5 e 5.2.1 e pode ser constatada por sua implementação no Apêndice A. Resta novamente uma chamada ao SAT Solver, de tempo constante por hipótese.

Finalmente, se o número de iterações for polinomial, teremos um redução de Turing polinomial do PSAT ao SAT, isto é, um algoritmo que decide o PSAT com um número polinomial de chamadas a um SAT Solver, mais um número polinomial de operações. Da análise do Simplex, sabemos que este é exponencial no pior caso, porém polinomial no caso médio, quando utilizamos o critério da otimalidade [PS98]. Como não utilizamos tal critério no algoritmo apresentado, contentandonos com uma coluna com custo reduzido negativo, não podemos prever um número polinomial de iterações nem no caso médio, antes de observar os resultados da implementação no Capítulo 6.

\subsubsection{Análise do Tamanho das Instâncias SAT}

Na ausência do hipotético oráculo para o SAT, acoplamos um SAT Solver real ao nosso algoritmo. Se $P !=N P$, então não deve existir algoritmo polinomial que decida o SAT. Na prática, as chamadas ao SAT Solver devem requerer, no pior caso, tempo exponencial em relação ao tamanho 
das instâncias SAT, mais especificamente, seu número de variáveis. Assim, faz-se necessária uma análise cuidadosa do tamanho destas instâncias, já que a decisão destas deve compor a maior parte do tempo de execução do Algoritmo 5.2, e, logo, do Algoritmo 5.1.

O tamanho das instâncias SAT geradas pela função Consistente tem o mesmo tamanho do $\Gamma$ da entrada do Algoritmo 5.1, com $n+k$ variáveis. Entretanto, na prática, $k$ variáveis já vem com valoração definida, o que deixa a instância menor, com $n$ variáveis. Além disso, essa função é chamada apenas $k+1$ vezes, não sendo grande responsável pela complexidade do algoritmo.

No Algoritmo 5.2, a instância SAT submetida ao SAT Solver é a união de $\Gamma$ com a instância $\Lambda$, que codifica a inequação oriunda do Simplex que força a coluna gerada a ter um custo reduzido negativo. Como baseamos a transformação de tal inequação em uma instância SAT $\Lambda$ no algoritmo proposto em [War98], sabemos que seu tempo, e logo o tamanho de $\Lambda$, é linear em relação ao número de variáveis na inequação, $k$, e ao número de bits usados para representar os coeficiente. Como mencionamos na Seção 5.2.1, a soma dos coeficientes não é maior que $k^{2}(k+1)^{(k+1) / 2} / 2^{k}$, podendo cada coeficiente então ser escrito com $O(k \log k)$ bits. Assim, $\Lambda$ terá $O\left(k^{2} \log k\right)$ variáveis.

Observando minuciosamente a redução da inequação linear para uma instância SAT, vemos que as variáveis correspondentes à codificação binária dos coeficientes $a_{0}, \ldots, a_{k}$ já vem com valoração definida pela linha 20 do Algoritmo 5.2. Além disso, uma valoração parcial sobre os átomos $z_{1}, \ldots, z_{k}$ força, por Propagação de Restrição Booleana (BCP), uma única valoração para as variáveis restantes de $\Lambda$. Isso porque as variáveis $b_{i j}$, que representam os números $b_{i}$, são resultantes da codificação da conjunção $a_{i j} \wedge z_{i}$, e as variáveis $c_{i j}$, da soma dos números $b_{i}$. Sendo assim, para decidir a satisfazibilidade da instância $\Lambda$, um SAT Solver precisa testar apenas valorações parciais sobre $k$ variáveis, que denotaremos por variáveis controláveis.

Naturalmente, a instância $\Gamma \cup \Lambda$, submetida ao SAT Solver, deve conter a soma do número de variáveis de $\Gamma$ e $\Lambda$, descontando variáveis repetidas. Cada variável $z_{i}$ de $\Lambda$ corresponde a uma variável $y_{i}$ em $\Gamma$, ou a sua negação, para $1 \leq i \leq k$. De qualquer forma, o número total de variáveis em $\Gamma \cup \Lambda$ será $O\left(n+k^{2} \log k\right)$. Porém, quando consideramos apenas as variáveis controláveis em $\Lambda$, chegamos a um total de $n+k$ variáveis. Claro que as variáveis não controláveis também acarretam custo computacional ao SAT Solver, especialmente durante a fase de BCP, mas tal custo deve crescer exponencialmente apenas em relação a $n+k$.

\subsection{Problema Auxiliar para Instâncias na Forma Normal Atômica Modificado}

Tendo em vista o possível número exponencial de iterações na redução de Turing proposta, buscamos alternativas que possam diminuir o número médio de iterações. Uma primeira ideia, detalhada nesta seção, seria modificar o problema auxiliar para instâncias na forma normal atômica de modo a procurar primeiramente por colunas que sejam $\Gamma$-consistentes. Uma outra abordagem, apresentada na próxima seção, seria implementar o critério da otimalidade, buscando colunas com o menor custo reduzido.

\subsubsection{Uma Nova Função Objetivo}

Sabemos que o Algoritmo 5.1 termina devolvendo uma solução quando a soma das probabilidades das colunas correspondentes a valorações inconsistentes com $\Gamma$ se anula. É claro que isso deve 
acontecer quando todas as colunas na base com probabilidade positiva forem $\Gamma$-consistentes. Logo, uma ideia natural seria tentar minimizar o número de colunas com probabilidade positiva que não forem $\Gamma$-consistentes, além de minimizar a soma de suas probabilidades. Se em toda iteração a função ProblemaAuxiliar retornar uma coluna que, pelo pivoteamento, substitui uma coluna que não seja $\Gamma$-consistente na base, o algoritmo para em no máximo $k+1$ iterações, devolvendo uma solução se a instância for probabilisticamente satisfazível. Um algoritmo baseado somente nessa ideia foi inicialmente proposto em [FDB10a], mas aqui apresentamos uma função objetivo composta.

Seja $f=c_{B}^{\prime} B$ a função a ser minimizada no Algoritmo 5.1, e $J$, o conjunto dos índices das colunas básicas $\Gamma$-inconsistentes com probabilidade positiva. Definimos uma nova função objetivo a ser minimizada, formada pelo par $\langle|J|, f\rangle$, com a seguinte ordem:

$$
\langle|J|, f\rangle \succ\left\langle\left|J^{\prime}\right|, f^{\prime}\right\rangle \text { sse }|J|>\left|J^{\prime}\right| \text { ou }\left(|J|=\left|J^{\prime}\right| \text { e } f>f^{\prime}\right) .
$$

Para minimizar tal função objetivo, primeiramente tentamos diminuir $|J|$, o número de colunas $\Gamma$-inconsistentes com probabilidade positiva; se isto não for possível, tentamos diminuir $f$, mantendo $|J|$ constante, já que as colunas que entram na base a cada iteração são sempre $\Gamma$-consistentes. Temos assim uma modificação do problema de programação linear (5.4), onde uma solução também é encontrada quando a função objetivo se anula:

$$
\begin{array}{ll}
\min & \langle|J|, f\rangle \\
\text { subjeito a } & \\
& {\left[A \mid I^{*}\right] \pi=p,} \\
& \pi \geq 0
\end{array}
$$

Na teoria, o problema (5.15) não é de programação linear, pois a sua função objetivo não é da forma $c^{\prime} \pi$, onde $c$ é um vetor custo. Mas na prática, o problema é o mesmo, e podemos ainda usar o Algoritmo 5.1 para resolvê-lo, apenas incrementando a função ProblemaAuxiliar (que renoameamos para ProblemaAuxiliar2) para considerar o novo custo $\langle|J|, f\rangle$. Isso acontece porque se conseguirmos minimizar $f$ até esta se anular, certamente teremos $|J|=0$. Em outras palavras, simplesmente implementaremos uma variação do Simplex, que permite eventualmente que o custo $f$ cresça em troca de um decréscimo em $|J|$; mas, se não for possível encontrar uma coluna que diminua $|J|$, a ausência de colunas com custo reduzido negativo continua atestando a insatisfazibilidade da instância PSAT em questão.

\subsubsection{O Algoritmo para o Problema Auxiliar Modificado}

Resta-nos então explicitar a nova implementação da função ProblemaAuxiliar do Algoritmo 5.1. A ideia é gerar instâncias SAT que retornem colunas que substituam colunas básicas $\Gamma$-inconsistentes com probabilidade positiva. Para isso, recorremos à algebra para construir uma inequação que impunha tais condições à nova coluna, e então reduzir esta para uma instância SAT, usando o método apresentado na Seção 5.2.1.

Relembremos da Seção 3.1 como escolhemos qual coluna retirar da base, ao inserirmos uma nova, para manter-se a viabilidade da solução básica. Seja $\beta=\left\{A_{B(1)}, \ldots, A_{B(k+1)}\right\}$ uma base de $A$, e $\pi_{B}=\left\{\pi_{B 1}, \ldots, \pi_{B, k+1}\right\}$, a SBV correspondente, tal que $\sum_{i=1}^{k+1} \pi_{B i} A_{B(i)}=p$. Sendo a matriz $B$ (da base) não singular, qualquer coluna $A_{j}$ pode ser escrita como combinação linear de suas colunas, 
$A_{j}=\sum_{i=1}^{k+1} \alpha_{j i} B(i)$. Sendo $s$ o valor de $i$ que minimiza a expressão $\pi_{B i} / \alpha_{j i}$, para $1 \leq i \leq k+1 \mathrm{e}$ $\alpha_{j i}>0$, podemos substituir $A_{s}$ por $A_{j}$ na base, obtendo uma nova solução também viável.

Queremos tirar da base uma coluna $A_{s} \Gamma$-inconsistente com probababilidade $\pi_{B s}>0$. Tal coluna deve ser tal que $\alpha_{j i}>0$ e $\pi_{B s} / \alpha_{j s} \leq \pi_{B i} / \alpha_{j i}$, para todo $1 \leq i \leq k+1$ tal que $\alpha_{j i}>0$. Podemos reescrever tais inequações como $\alpha_{j s} \pi_{B i}-\alpha_{j i} \pi_{B s} \geq 0$, sem nos preocuparmos com o sinal de $\alpha_{j i}$. Se denotarmos a coluna $A_{j}$ a entrar na base por $\left[1 \mid y_{1} \ldots y_{k}\right]^{\prime}$, podemos obter os coeficientes $\alpha_{j}$ usando a inversa da matriz da base: $\alpha_{j}=B^{-1}\left[1 \mid y_{1} \ldots y_{k}\right]^{\prime}$. Assim, para substituir a coluna $A_{s}$ na base, a coluna $A_{j}=\left[1 \mid y_{1} \ldots y_{k}\right]^{\prime}$ a entrar deve obdecer ao sistema de restrições lineares, onde $B_{i}^{-1}$ representa a $i$-ésima linha de $B^{-1}$ :

$$
\left(B_{s}^{-1} \pi_{B i}-B_{i}^{-1} \pi_{B s}\right)\left[1 \mid y_{1} \ldots y_{k}\right]^{\prime} \geq 0, \quad 1 \leq i \leq k+1
$$

Usando então o método apresentado na Seção 5.2.1, podemos codificar cada uma das inequações de (5.16) em uma instância SAT $\Lambda_{s, i}$. Para isso, precisamos encontrar um número que, multiplicado a cada desigualdade em (5.16), deixe os coeficientes inteiros. Como os elementos de $B$ são inteiros, multiplicando todas as linhas de $B^{-1}$ por $\operatorname{det}(B)$, obtemos elementos inteiros, sem afetar as desigualdades. Agora suponha que as probabilidades $p_{1}, \ldots, p_{k}$ são expressas usando no máximo $b_{p}$ bits no sistema binário usual. Pela Regra de Crammer, $\pi 2^{b_{p}} \operatorname{det}(B)$ é inteiro. Finalmente, os coeficientes $2^{b_{p}} \operatorname{det}(B)^{2}\left(B_{s}^{-1} \pi_{B} i-B_{i}^{-1} \pi_{B} s\right)$ serão inteiros.

Assim, podemos construir uma instância SAT $\Lambda_{s}=\Lambda_{s, 1} \cup \cdots \cup \Lambda_{s, k+1}$ que é satisfeita somente por valorações que correspondam a colunas que, quando entram na base, substituam a coluna $A_{s}$. Podemos então gerar instâncias $\Lambda_{i}$ e submeter $\Gamma \cup \Lambda_{i}$ ao SAT Solver, para cada $i \in J$, até encontrarmos uma coluna $\Gamma$-consistente que substitui uma coluna básica $\Gamma$-inconsistente com probabilidade positiva. Se não encontrarmos tal coluna, continuamos com o Algoritmo 5.2, procurando uma coluna $\Gamma$-consistente com custo reduzido negativo, para decrescer $f$.

Para ganhar eficiência, primeiramente executamos o Algoritmo 5.2; se este não retornar uma coluna, nossa instância PSAT já é insatisfazível. Se devolver uma coluna $b$, testamos se esta substitui uma coluna $\Gamma$-inconsistente na base com probabilidade positiva, diminuindo $|J|$. Se sim, inserimos $b$ na base; se não, procuramos por alguma coluna que decresça $|J|$ ao entrar na base. Encontrando tal coluna, a inserimos na base; caso contrário, inserimos $b$.

O Algoritmo 5.3 implementa a nova função ProblemaAuxiliar $2\left(\Gamma, c_{B}^{\prime} B^{-1}, B, \pi_{B}, b_{p}\right)$, que chama a antiga ProblemaAuxiliar $\left(\Gamma, c_{B}^{\prime} B^{-1}, B\right)$, buscando primeiramente uma coluna $\Gamma$-consistente com custo reduzido negativo. Observe que a função ProblemaAuxiliar2 possui dois novos parâmetro, $\pi_{B}$ e $b_{p}$, entradas do Algoritmo 5.3.

A função IneqParaSat $\left(a_{0}, \ldots, a_{k}\right)$ recebe como parâmetros os coeficientes de uma inequação linear $a_{0}+a_{1} y_{1}+\cdots+a_{k} y_{k} \geq 0$ e devolve uma instância SAT que é satisfeita apenas por valorações sobre $y_{1}, \ldots, y_{k}$ correspondetes ao conjunto solução da desigualdade. A sua implementação é explicada na Seção 5.2.1, e a conversão dos parâmetros para inteiros não negativos faz parte do seu corpo por hipótese, para simplificar a escrita.

\subsubsection{Análise do Algoritmo e da Instância SAT}

Nesta implementação do problema auxiliar modificada para acomodar a nova função objetivo, não apresentamos nem uma nova função, e o algoritmo continua polinomial, quando consideramos 


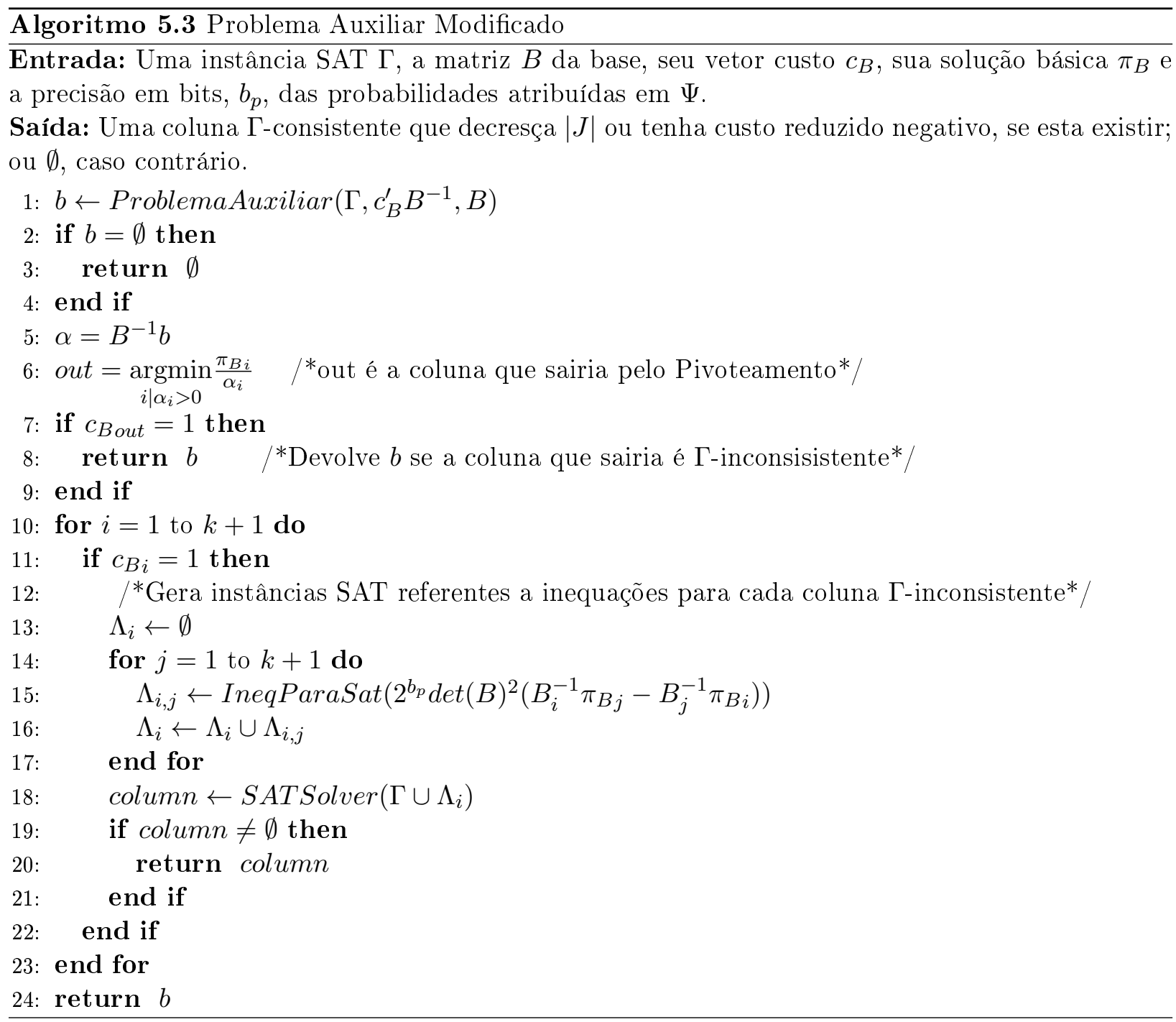


um SAT Solver hipotético de tempo constante. Esperamos que o número de iterações, equivalente ao número de chamadas à função ProbelmaAuxiliar2, decresça, mas não temos justificativa teórica para isso, precisando ver os resultados da implementação.

A maior diferença nesse algoritmo está nas $O(k)$ instâncias SAT geradas a mais por iteração, para tentar extrair cada uma das colunas $\Gamma$-inconsistentes na base com probabilidade positiva. Cada instância $\Lambda_{i}$ vem da união de $k+1$ instâncias $\Lambda_{i, j}$ geradas pela função IneqParaSat. Sabemos que cada $\Lambda_{i, j}$ tem complexidade linear em relação a $k$ e ao número de bits usados para representar cada coeficiente na inequação correspondente [War98]. De maneira análoga à mostrada na Seção 5.2.1, podemos limitar a soma dos coficiente da inequação, após trasformarmos todos em naturais, de maneira que esta deve demandar até $O\left(b_{p}+k \log k\right)$ bits para ser codificado no sistema binário. Sendo assim, cada instância $\Lambda_{i, j}$ terá $O\left(k\left(b_{p}+k \log k\right)\right)$ variáveis no pior caso; e cada instância $\Lambda_{i},\left(k^{2}\left(b_{p}+k \log k\right)\right)$. De qualquer forma, o número de variáveis controláveis continua $k$, pois uma valoração parcial sobre os átomos $y_{1}, \ldots, y_{k}$ força uma valoração às demais variáveis por propagação de restrição Booleana. Cada instância SAT $\Gamma \cup \Lambda_{i}$ conterá $O\left(n+k^{2}\left(b_{p}+k \log k\right)\right)$ variáveis, mas com $n+k$ controláveis. Conforme ressaltamos na Seção 5.3.2, as variáveis não controláveis também acarretam grande custo computacional, principalmente durante o BCP.

\subsection{Problema Auxiliar com Critério de Otimalidade}

Na Seção 5.2 explicitamos nosso contentamento em encontrar colunas cujo custo reduzido fosse simplesmente negativo, chegando a inequação:

$$
u_{0}+\sum_{i=1}^{k} u_{i} v_{j}\left(y_{i}\right)>0
$$

Como foi explicado na Seção 3.1, o critério da otimalidade no Simplex consiste em inserir na base, a cada iteração, a coluna com menor custo reduzido, quando este é negativo. Este critério deve acelerar a convegência do algoritmo para uma solução, e, de fato, o número de iterações do Simplex pode então ser considerado polinomial no caso médio [PS98]. Temos agora um novo problema auxiliar, onde queremos encontrar uma valoração $v_{j}$ que satisfaça $\Gamma$ e que corresponda a uma coluna que minimiza o custo reduzido:

$$
\underset{v_{j} \mid v_{j}(\Gamma)=1}{\operatorname{argmax}}\left(u_{0}+\sum_{i=1}^{k} u_{i} v_{j}\left(y_{i}\right)\right)
$$

A expressão (5.18) corresponde a uma instância MAXSAT Ponderado Parcial, definido na Seção 3.4. Não sendo um problema de decisão, não podemos reduzir tal instância a uma instância SAT, mas claro que poderíamos reduzi-la a um número polinomial de instâncias SAT. Seja $\Lambda(W)$ a redução da inequação $u_{0}+\sum_{i=1}^{k} u_{i} v_{j}\left(y_{i}\right) \geq W$ ao SAT. Submetemos $\Gamma \cup \Lambda(W)$ a um SAT Solver, variando $W$ com uma busca binária, até encontrarmos o maior $W$ para o qual $\Gamma \cup \Lambda(W)$ é satisfazível.

Como o número de chamadas ao SAT Solver continuaria polinomial a cada iteração, e com o critério de otimalidade temos um número polinomial de iteações no caso médio, finalmente teríamos uma Redução de Turing do PSAT ao SAT polinomial no caso médio, embora ainda exponencial no pior caso. Mas como o MAXSAT Ponderado Parcial já possui um estudo parte, com uma série de Solvers em contínuo desenvolvimento, avaliados metódica e regularmente (veja, p. ex., [ALMP08]), 
convém, por fins práticos, adotarmos um MAXSAT Solver para resolver a expressão (5.18), nosso novo problema auxiliar.

Para submeter a expressão (5.18) a um MAXSAT Solver, precisamos novamente garantir coeficientes naturais - e já ilustramos como fazê-lo na Seção 5.2.1. Então, podemos modificar o Algoritmo 5.2, criando o Algoritmo 5.4, para chamar um MAXSAT Solver em vez de um SAT Solver. A função MAXSATSolver $\left(\Gamma,\left\{z_{1}, \ldots, z_{k}\right\}, a, a_{0}\right)$ deve receber como argumentos o conjunto de cláusulas rígidas $\Gamma$, que devem sempre ser satisfeitas, e uma instância do MAXSAT Ponderado, com um conjunto de cláusulas $z$ e um vetor de pesos $a$ associados. Para simplificar a notação, incluimos um argumento extra $a_{0}$, que define o mínimo que esperamos da soma dos pesos das cláusulas satisfeitas, correspondendo ao custo reduzido negativo. Consideramos aqui que o MAXSAT Solver já devolve uma coluna, correspondente à valoração que satisfaz $\Gamma$, com o menor custo reduzido, se este for menor que zero; ou $\emptyset$ caso contrário.

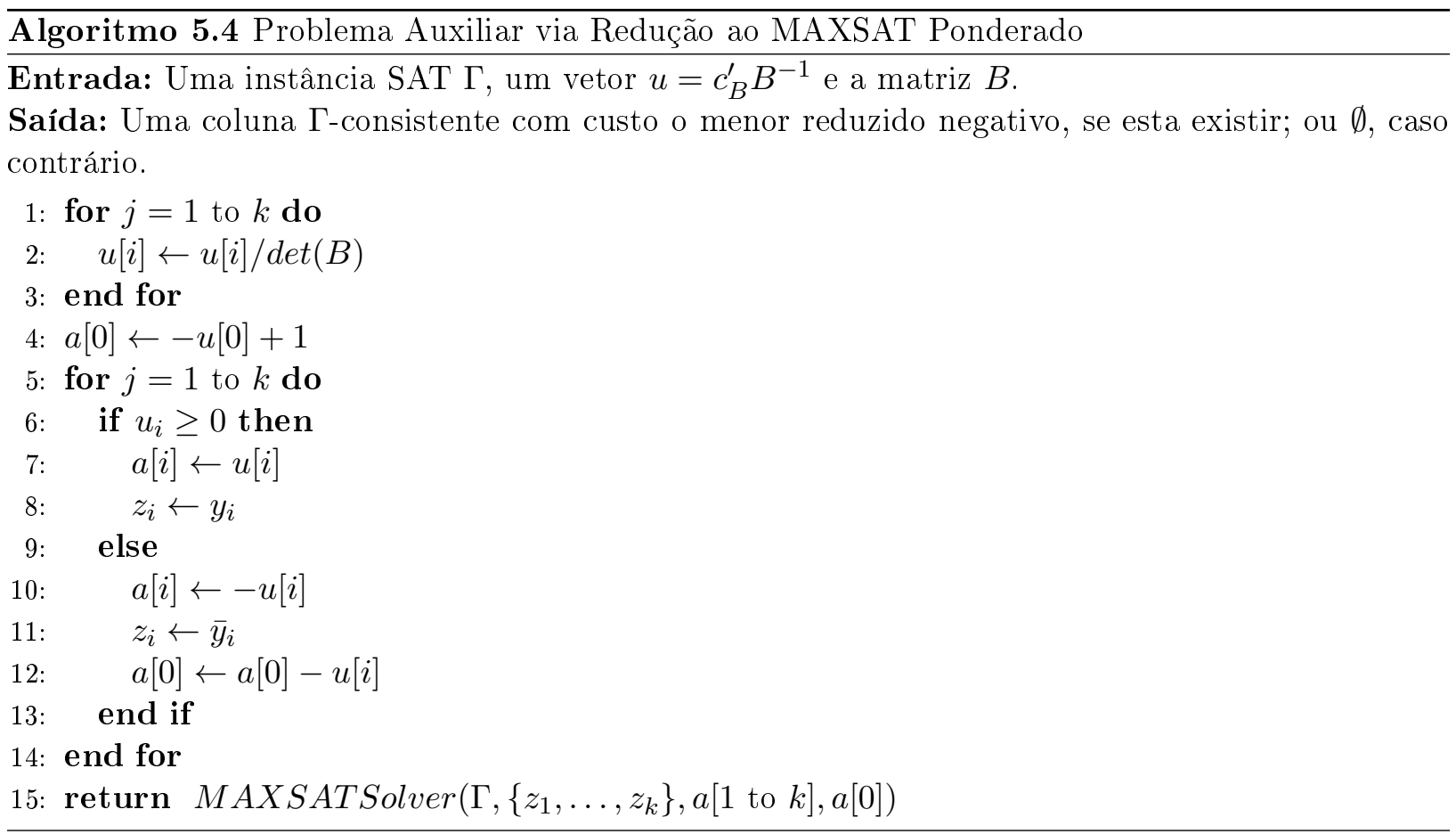

Embora a instância MAXSAT tenha apenas $k$ clásulas a mais que $\Gamma$ e o mesmo número de variáveis, o tempo de execução do MAXSAT Solver aqui deve ser naturalmente maior que o do SAT Solver no Algoritmo 5.2, já que aqui temos um problema de maximização NP-hard, referente àquele de decisão NP-completo. Porém, como já mencionamos, esta chamada a um MAXSAT Solver pode ser reduzida um número polinomial de chamadas ao SAT Solver para instâncias da forma $\Lambda$ do Algoritmo 5.2. Assim, acoplando um MAXSAT Solver eficiente, esperamos que na prática o Algoritmo 5.4 seja apenas pouco menos eficiente que o Algoritmo 5.2. 


\section{Capítulo 6}

\section{Resultados e Transição de Fase}

O fenômeno de transição de fase ainda é desconhecido no PSAT, e sua investigação é um dos objetivos deste trabalho. Este capítulo apresenta o desempenho da implementação dos algoritmos apresentados nos Capítulos 4 e 5. Levantamos o perfil de complexidade do PSAT e estudamos a presença do fenômeno de transição de fase, discutindo as condições para sua detecção e o seu comportamento.

\subsection{Implemetação dos Algoritmos e Geração dos Testes}

Do Capítulo 4, implementamos o Algoritmo 4.1, correspondente à Redução Canônica, e o Algoritmo 4.2, denotado por Redução Canônica de Precisão Limitada, acomplando-os a um SAT Solver, para decidir a satisfazibilidade probabilística de instâncias PSAT através da satisfazibilidade clássica de sua redução ao SAT. Do Capítulo 5, foram implementados o Algoritmo 5.1 com o Algoritmo 5.2, que chamaremos de Redução de Turing, bem como suas modifições, quando trocamos o Algoritmo 5.2 pelo 5.3 ou pelo 5.4, os quais denominamos Redução de Turing Modificada e Redução de Turing com Critério de Otimalidade, respectivamente.

Todas as implementações foram feitas em $\mathrm{C}++$, compiladas com $\mathrm{g}++$, a menos das rotinas de inverter matrizes e calcular determinantes. Estas foram implementadas em C, compiladas com gcc, para explorar a eficiência das bibliotecas BLAS e LAPACK, quando lidamos com grandes matrizes. Os programas foram compilados e testados em um computador com um processador de 32 bits de 1,6GHz, com 2GB de memória RAM e sistema operacional Ubuntu 10.4. Como SAT Solver, utilizamos o zChaff $\left[\mathrm{MMZ}^{+} 01\right]$ e, como MAXSAT Solver, o MAXSATz [LMMP09]. Todos os softwares aqui citados são de diponibilização gratuita para fins acadêmicos, e as implementações úteis resultantes deste trabalho estão sendo disponibilizadas na internet no endereço "http://sourceforge.net/projects/psat/", sob a licença GNU GPL 3. A príncipio, 2 implementações estão disponíveis: a Redução Canônica de Precisão Limitada, nomeada de PSATtoSAT; e a Redução de Turing Modificada, denotada por PsatColGen.

Para realização dos testes, utilizamos instâncas PSAT na forma normal atômica, apresentada na Seção 2.5, onde uma instância é um par $\langle\Gamma, \Psi\rangle$, com $\Gamma$ sendo uma instância SAT, e $\Psi$, uma atribuição atômica de probabilidades, da forma $p(y)=p$. Cada instância SAT $\Gamma$ foi construída com $m$ cláusulas aleatórias, cada uma com 3 literais escolhidos aleatoriamente de um total de $n$ variáveis (incluindo aqueles em $\Psi$ ) com probabilidade 0,5 de serem negados. As atribuições de probabilidade foram feitas sobre as $k \leq n$ variáveis de menor índice em $\Gamma$, sem perda de generalidade, distribuindo 
as probabilidades uniformemente entre 0 e 1 , com precisão de 2 decimais à direita da vírgula.

Para investigar o perfil de complexidade do PSAT, em cada experimento, fixamos o número total de variáveis $n$ e o número de variáveis $k$ com probabilidade atribuída. Variamos o número de cláusulas $m$ de modo a variar a razão $m / n$ com passo de 0,1 . Para cada ponto $m / n, 100$ a 200 instâncias foram geradas aleatoriamente. Então, para cada ponto $m / n$, foi calculado o tempo médio em segundos por instância da execução da implementação em questão e a porcentagem de instâncias retornadas como (probabilisticamente) satisfazíveis.

\subsection{Resultados}

Nesta seção, apresentamos os resultados dos experimentos com as diferentes implementações. Para cada implementação, apresentamos os resultados obtidos com o um $k$ (número de variáveis em $\Psi$ ) que permitiu o levantamento da curva de complexidade do PSAT em um tempo viável sob as condições citadas na Seção 6.1. A análise do fenômeno de transição de fase é feita na Seção 6.3.

A Redução Canônica sem a limitação na precisão não foi utilizada para investigar o perfil de complexidade do PSAT, porque os experimentos já se tornaram impraticáveis para $k=3$. Logo, utilizamos apenas a Redução Canônica de Precisão Limitada, nesse caso à 6 bits. O gráfico da Figura 6.1 mostra os resultados para tal implementação, quando fixamos $k=4$ e $n=40$.

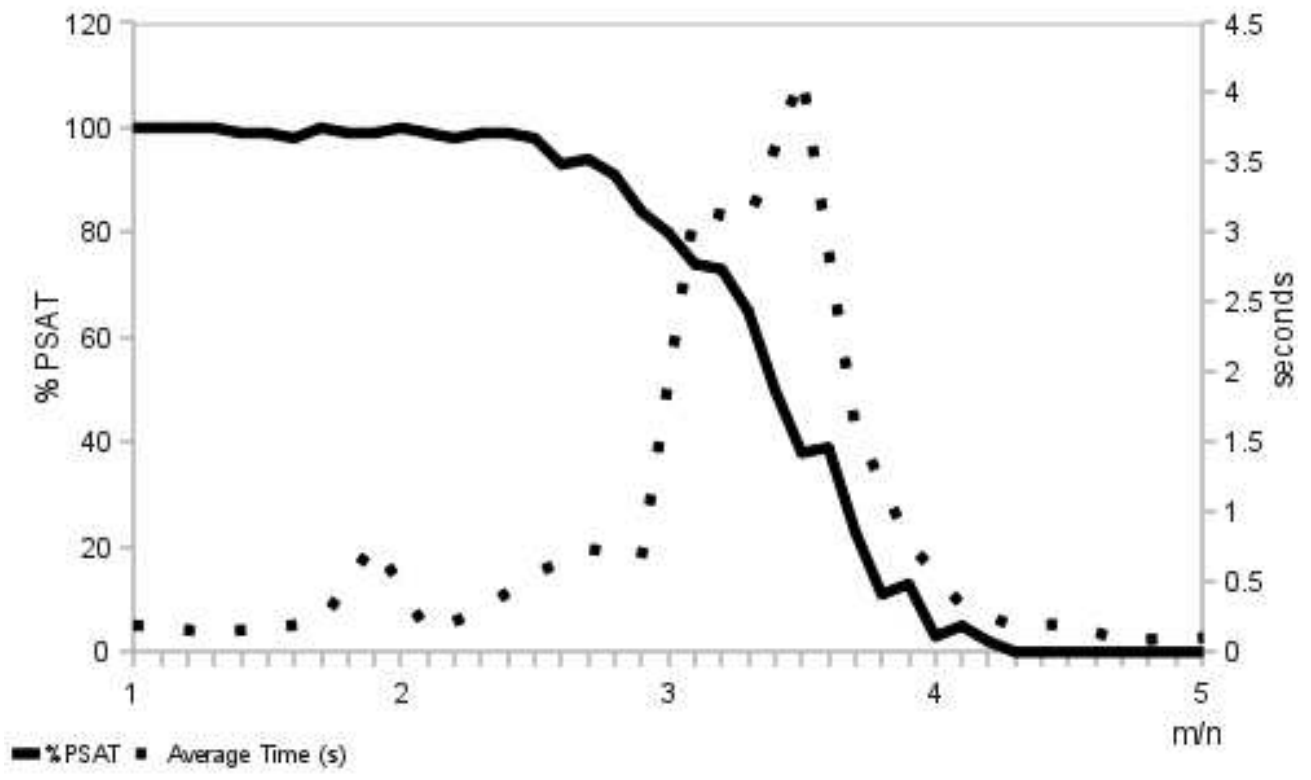

Figura 6.1: Perfil de complexidade do PSAT, com $n=40$ e $k=4$, levantado pela Redução Canôninca de Precisão Limitada.

Com a Redução de Turing, conseguimos realizar os experimentos desejados até com $k=15$. O gráfico da Figura 6.2 mostra tais resultados, com o número de variáveis $n=100$.

Na prática, a Redução de Turing Modificada se mostrou mais lenta que a Redução de Turing, e conseguimos levantar o perfil de complexidade do PSAT apenas até $k=12$. Em relação a Redução de Turing, o número de iterações praticamente não se alterou, e as instâncias SAT maiores oriundas do problema auxiliar acarretam um tempo maior por iteração. O gráfico da Figura 6.3 mostra os resultados desta implementação com $k=12$ e $n=150$. 


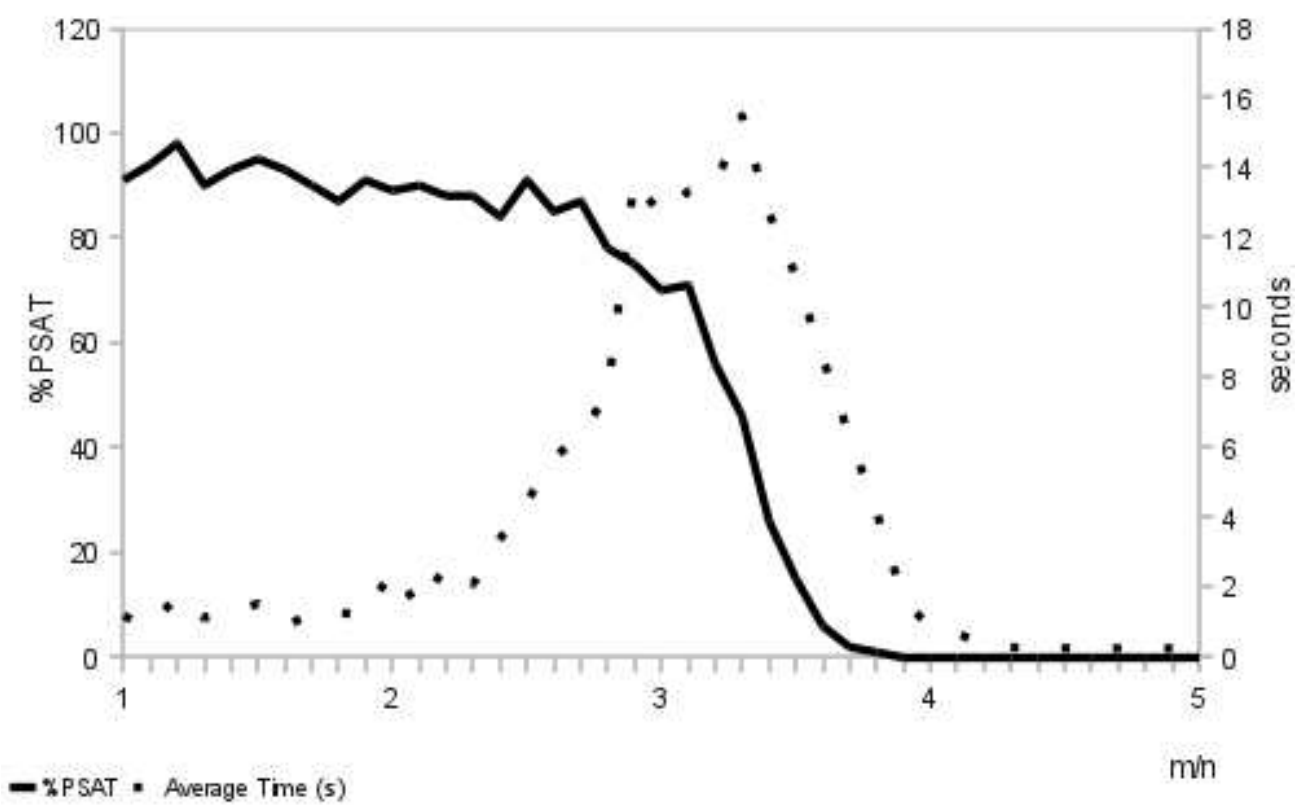

Figura 6.2: Perfil de complexidade do PSAT, para $n=100$ e $k=15$, levantado pela Redução de Turing.

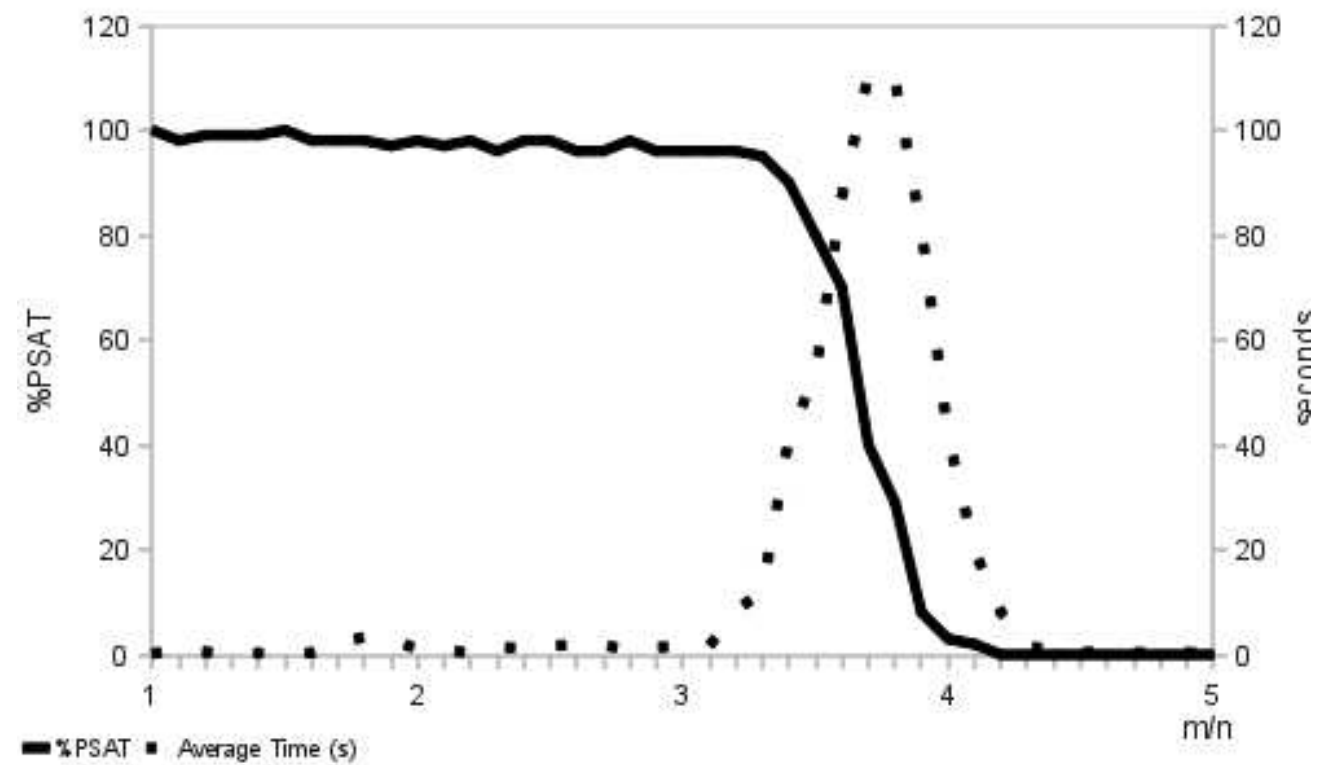

Figura 6.3: Perfil de complexidade do PSAT, para $n=150$ e $k=12$, levantado pela Redução de Turing Modificada.

A Redução de Turing com Critério de Otimalidade, na prática uma redução ao MAXSAT, nos permitiu levantar o perfil de complexidade do PSAT para $k$ até 25, como mostra o gráfico da Figura 6.4. Essa limitação no tamanho de $k$ que permitiu a investigação do perfil de complexidade do PSAT não foi causada pelo tempo inviável de experimentos com instâncias maiores. Para $k>25$, algumas instâncias levaram a implementação ao "overflow", quando passamos os pesos das da cláusulas para inteiros, ao montarmos a instância MAXSAT relativa ao problema auxiliar (veja Seção 5.5). Isso se deve principalmente ao crescimento exponencial do determinante da base em função de $k$. 
Testando a implementação para instâncias isoladas, resolvemos instâncias PSAT $\langle\Gamma, \Psi\rangle$ insatisfazíveis com $\Gamma$ satisfazível para $k=100$ em menos de um minuto. Quando $\Gamma$ é insatisfazível, a instância PSAT $\langle\Gamma, \Psi\rangle$ é trivialmente insatisfazível, e pode-se resolver instâncias com $k$ da ordem de centenas. Para instâncias trivialmente satisfazíveis, quando a base inicial $I *$ já nos dá uma solução, conseguimos resolver instâncias com $k=60$ em poucos segundos. Entretanto, instâncias satisfazíveis não triviais, quando são necessárias iterações, foram decididas por nossa implementação somente até $k$ 's próximos de 30 sem apresentar "overflow".

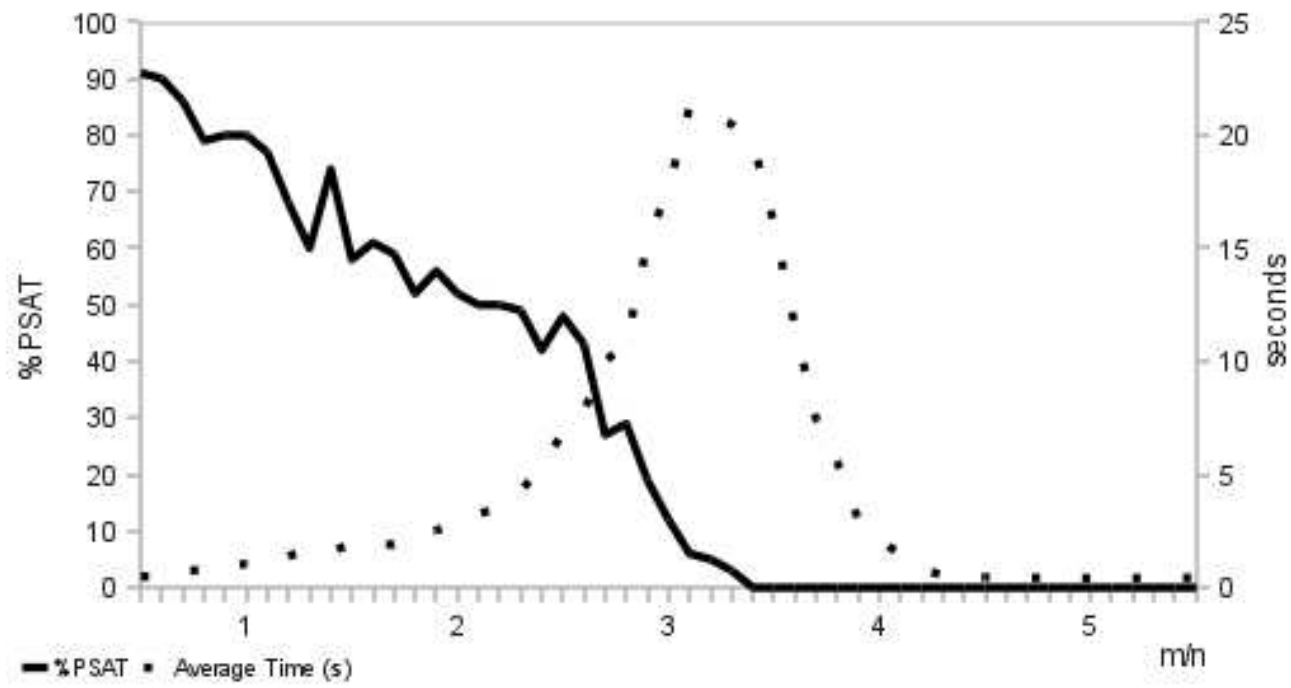

Figura 6.4: Perfil de complexidade do PSAT, para $n=100$ e $k=25$, levantado pela Redução de Turing com Critério de Otimalidade.

Para se ter uma ideia do ganho em eficiência proporcionado pelo critério de otimalidade, no gráfico da Figura 6.5 comparamos o tempo médio por instância obtido pela Redução de Turing com e sem o Critério de Otimalidade, para as mesmas instâncias do gráfico da Figura 6.2.

Ao resolvermos uma instância MAXSAT em vez de uma SAT, prevíamos que o tempo médio por iteração deveria crescer. De fato, nos experimentos do gráfico da Figura 6.5, o tempo médio por iteração da Redução de Turing com Critério de Otimalidade ficou em 90ms, enquanto o tempo médio por iteração da Redução de Turing ficou em 51ms. Como esperávamos, o critério de otimalidade reduz o número de iterações expressivamente, o que compensa um tempo eventualmente maior por iteração. O gráfico da Figura 6.6 mostra o número médio de iterações necessárias para decidir as mesmas instâncias PSAT do gráfico da Figura 6.5 para a Redução de Turing e a Redução de Turing com Critério de Otimalidade.

\subsection{A Transição de Fase}

Cheeseman, Kanefsky e Taylor apresentaram o fenômeno de transição de fase para alguns problemas NP-completos e conjecturaram que esta seria uma propriedade de todos os problemas dessa classe [CKT91]. Mitchell, Selman e Levesque detectaram tal transição no 3-SAT [MSL92], e Gent e Walsh estudaram detalhadamente este fenômeno no problema SAT [GW94]. Se parametrizarmos as instâncias do $L$-SAT (todas as cláusulas com $L$ literais ) pela razão $m / n$, onde $m$ é o número de 


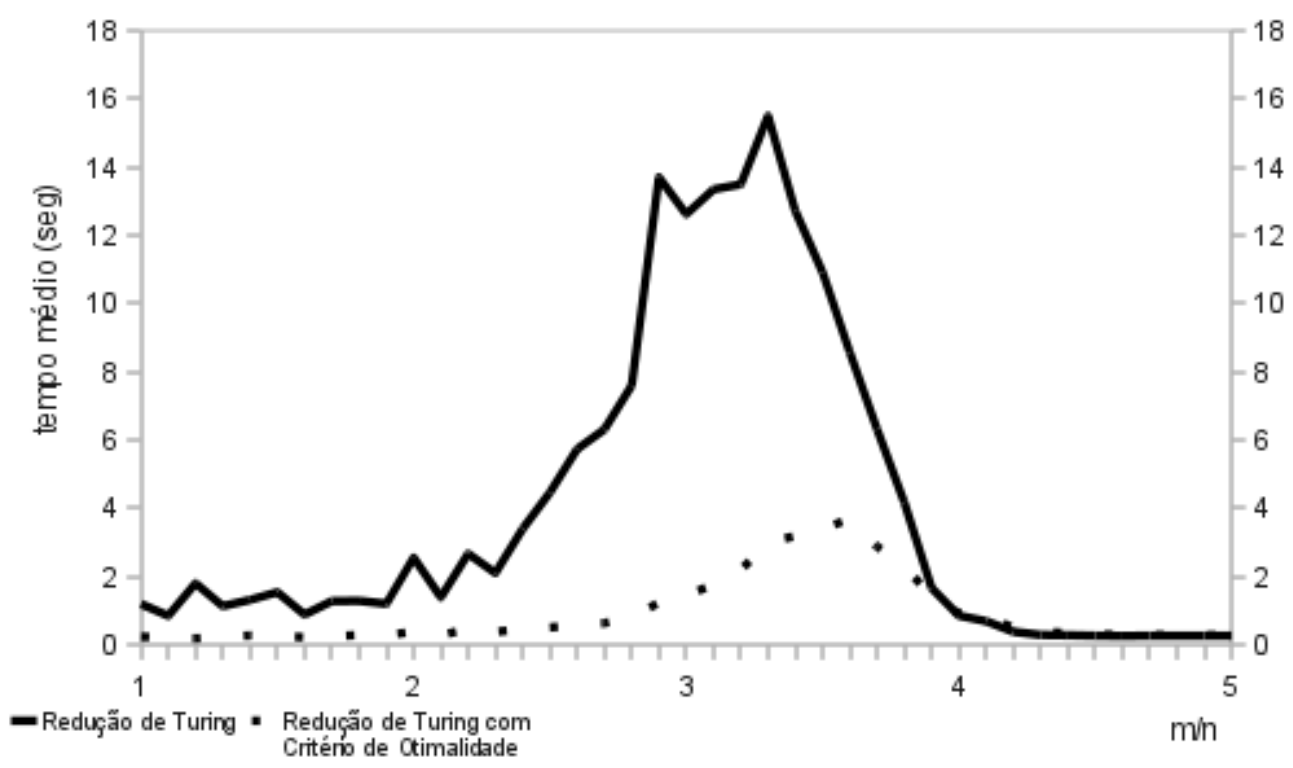

Figura 6.5: Tempo médio por instância PSAT, usando a Redução de Turing com e sem Critério de Otimalidade, para $n=100$ e $k=15$.

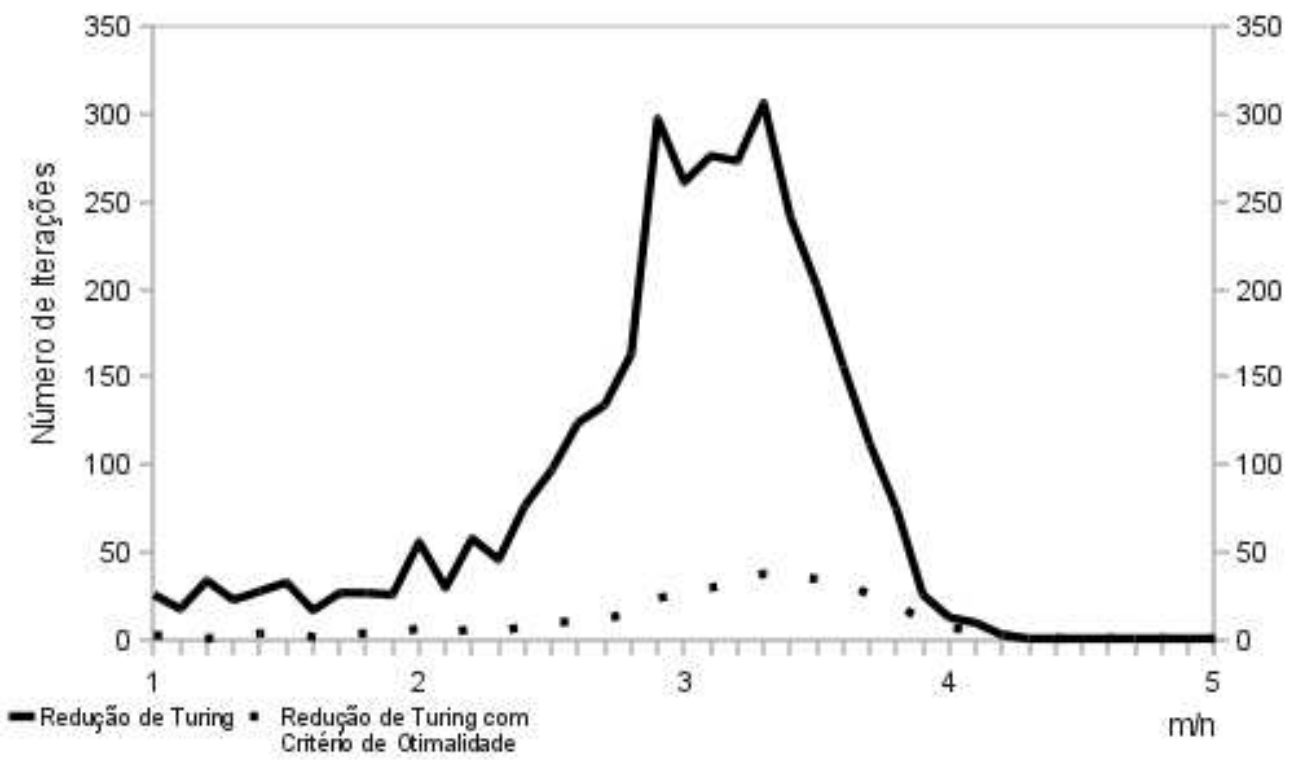

Figura 6.6: Número médio de iterações por instância PSAT, usando a Redução de Turing com e sem Critério de Otimalidade, para $n=100$ e $k=15$.

cláusulas, e $n$ é o número de variáveis, então as instâncias mais difíceis se concentram em torno de um ponto $m / n=P_{t}$. A intuição diz que uma instância com muitas variáveis para poucas cláusulas, baixo $m / n$, está pouco restringida e deve ser facilmente satisfeita; enquanto que uma instância com muitas cláusulas para poucas variáveis, alto $m / n$, está muito restringida e tem alta probabilidade de ser insatisfazível. Instâncias insatisfazíveis são tipicamente mais difíceis, tomando um tempo médio pouco maior que as satisfazíveis, quando submetidas a um SAT Solver. Entretanto, para resolver instâncias na vizinhança do ponto $m / n=P_{t}$, em que observamos aproximadamente metade das in- 
stâncias satisfazíveis, o tempo médio dos SAT solvers cresce abruptamente, indicando a dificuldade de tais instâncias. O ponto $P_{t}$ é conhecido como ponto de transição de fase.

\subsubsection{A Detecção da Transição de Fase no PSAT}

O fenômeno de transição de fase não havia sido reportado para o PSAT até o momento. Em parte dos gráficos da Seção 6.2, obervamos a curva típica do fenômento de transição de fase: instâncias satisfazíveis fáceis à esquerda, instâncias insatisfazíveis fáceis à direita e instâncias muito difíceis na transição, com pico de tempo de execução das implementações próximo ao ponto onde $50 \%$ das instâncias é satisfazível. Nos gráficos com $k / n$ maiores, a curva de satisfazibilidade aparece distorcida, o que talvez possa ser contornável com um aumento no total de variáveis $n$ e um número maior de amostras por ponto. Como $k=25$ é o nosso limite prático no estudo do perfil de complexidade do PSAT, ficamos restringidos a análise de pequenos $k / n$.

A forma normal atômica do PSAT, com cláusulas limitadas a 3 literais, parece trazer à luz seu fenômeno de transição de fase a partir de um subproblema especial, o 3-SAT, cuja a transição de fase é bem conhecida. Sabemos que, para instâncias na forma normal atômica com $k=0$, o PSAT é o próprio SAT. Limitando as cláusulas a um número fixo de literais, a transição de fase do SAT é detectada quando ordenamos as instâncias pela razão entre número de cláusulas $m$ e o número de variáveis $n$, estando próxima a $m / n=4,3$ no 3-SAT. Conforme aumentamos $k$, mantendo $n$ fixo, esperamos que aumente a razão de instâncias insatisfazíveis, para cada $m / n$. Assim, para um $n$ fixo, o ponto com $50 \%$ de instâncias satisfazíveis se desloca para a esquerda conforme aumentamos $k$, partindo de $k=0$, onde temos a transição de fase do 3-SAT.

Possivelmente a maior contribuição da forma normal atômica do PSAT na revelação do que parece ser seu fenômeno de transição de fase advenha da consideração de que instâncias PSAT aleatórias, com fórmulas no formato clausal, devem ter uma boa parte das probabilidade atribuídas iguais a 1 (conjunto denotado por $\Gamma$ ). Se há uma atribuição de probabilidade sobre uma fórmula em qualquer formato, quando a transformamos em uma atribuição de probabilidade sobre cláusulas, talvez com um tamanho específico (por exemplo com 3 literais), naturalmente deve surgir um conjunto de cláusulas com probabilidade 1. Assim, instâncias PSAT aleatórias fora da forma normal atômica, com todas a probabilidades atribuídas a fómulas em um formato específico (como 3-cláusulas) distribuídas uniformemente no intervalo $[0 ; 1]$ representam o universo de possíveis instâncias PSAT de uma maneira consideravelmente distorcida.

É interessante notar que a detecção da curva típica de tal fenômeno não se deve apenas a forma normal atômica, mas também a adequação do algoritmo a instâncias neste formato. Submetendo as mesmas instâncias do gráfico da Figura 6.1 a uma implementação do algoritmo Simplex com o método de geração de colunas apresentado no Capítulo 3 (que pode ser encontrada no endereço "http://www.pmr.poli.usp.br/ltd/Software/PPL/"), construímos o gráfico da Figura 6.7.

Embora a curva de satisfazibilidade não tenha se alterado, o tempo médio de execução parece crescer exponencialmente em $m / n$, sem apresentar a curva típica de transição de fase. Isso pode ser explicado pelo fato de tal abordagem não tratar probabilidades igual a 1 separadamente. Para cada clásula $\alpha \in \Gamma$, tem-se uma atribuição de probabilidade $p(\alpha)=1$. Assim, a base teria $m+k+1$ colunas, como já explicamos na Seção 5.1. Em tal abordagem, mesmo ao submetermos uma instância PSAT na forma normal atômica com $k=0$, e 3 literais por cláusula, equivalente a uma instância 3-SAT, não veríamos a transição de fase. 


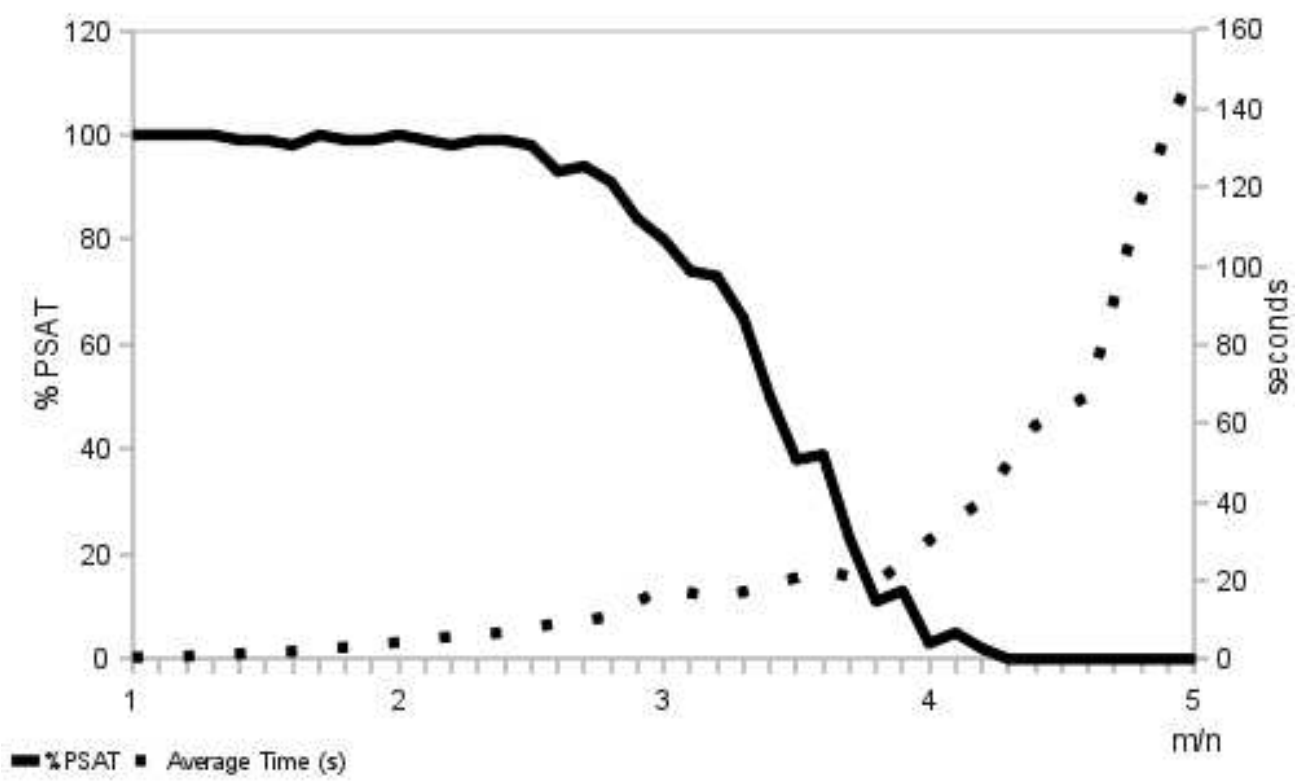

Figura 6.7: Perfil de complexidade do PSAT, para $n=40$ e $k=4$, levantado pelo Simplex com geração de colunas convencional.

\subsubsection{A Localização do Ponto Transição de Fase no PSAT}

Acreditando ter detectado o fenômeno de transição de fase no PSAT, interessa-nos avaliar a localização e o deslocamento de seu ponto. Com mais experimentos, variamos $k$ e $n$ a fim de investigar a relação entre tais parâmetros e a localização do ponto de transição de fase em $m / n$. Na presente Seção, utilizamos para experimentos apenas a implementação da Redução de Turing com Critério da Otimalidade, a mais rápida na prática. O gráfico da Figura 6.8 confirma como a transição de satisfazibilidade para insatisfazibilidade, que deve ser acompanhada pelo ponto de transição de fase, se desloca para a esquerda, quando aumentos $k$ com um $n$ fixo:

Com base nesses resultados, tentamos encontrar a transição de fase do PSAT sob outro ponto de vista, fixando $m$ e $n$ e variando $k$. Para $m / n<4,3$, com $k=0$, a maioria das instâncias deve ser satisfazível [GW94]. Conforme $k$ aumenta, a probabilidade de uma instância PSAT ser satisfazível deve diminuir, se aproximando de 0 quando $k$ se aproxima de $n$. Assim, em algum ponto $0 \leq k / n \leq 1$ o número de instâncias satisfazíveis deve ser aproximadamente $50 \%$. O gráfico da Figura 6.9, com $m=300$ e $n=80$, mostra o perfil de complexidade do PSAT em função de $k / n$.

Embora a curva de satisfazibilidade tenha se comportado como o previsto, caindo abruptamente de $100 \%$ para $0 \%$, o tempo médio por instância não apresentou o formato típico de transição de fase. Uma possível explicação seria que o aumento de $k$ configura um aumento no tamanho do problema que acarreta um aumento no número médio de iterações. Logo, fixamos $k=15$, variando $n$ e $m$ de modo a manter $m / n$ constante em 3 para procurar o fenômeno de transição de fase do PSAT em função de $k / n$. O gráfico da Figura 6.10 mostra tais resultados.

Novamente observamos a curva de satisfazibilidade no formato esperado, porém agora também o tempo médio por instância se aproxima do formato característico do fenômeno de transição de fase. Ainda assim, a queda no tempo médio das instâncias conforme $k / n$ aumenta após o pico não é tão acentuada como esperaríamos, o que talvez pudesse ser atingido com um maior $k$. 


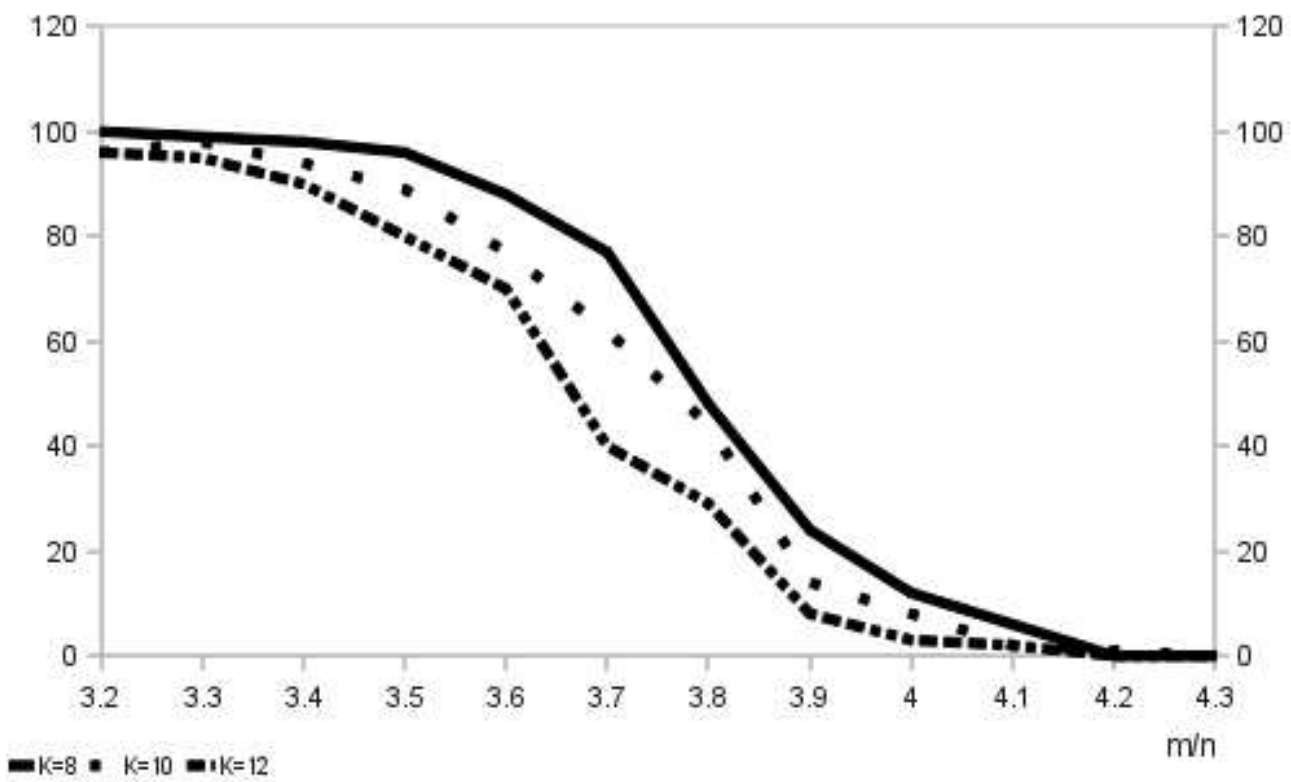

Figura 6.8: Porcentagem de instâncias satisfazíveis do PSAT em função da razão entre o número de cláusulas e o número de variáveis, para $n=150$ e $k=8,10$ e 12 .

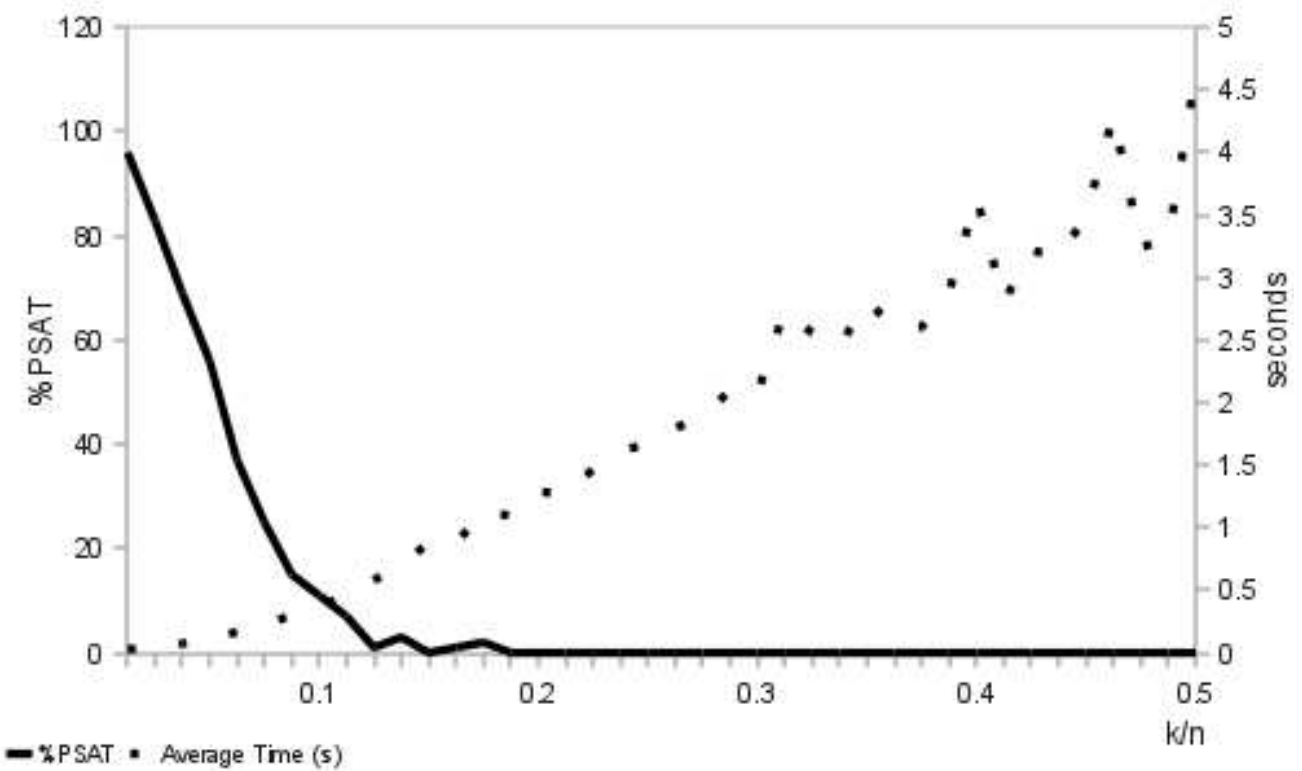

Figura 6.9: Perfil de complexidade do PSAT, para $m=300$ e $n=80$.

Observando os dados dos experimentos realizados, conjecturamos que o ponto de transição de instâncias satisfazíveis para instâncias insatisfazíveis (que deve acompanhar o ponto de transição de fase) em $m / n$ deve ser fixo para $k / n$ iguais; analogamente, o ponto de transição em $k / n$ deve ser o mesmo para $m / n$ iguais. O gráfico da Figura 6.11 mostra como a transição de satisfazibilidade para insatisfazibilidade, para $k / n$ fixo e variando $n$, mantém-se na mesma região em $m / n$.

Se tal conjectura for verdadeira, podemos esperar que, para cada $k / n$, temos uma transição de fase em $m / n$, com aproximadamente metade das instâncias satisfazíveis, que se mantém próxima a um mesmo ponto quando aumentamos $n$. Confiando nesta hipótese, procuramos uma estimativa 


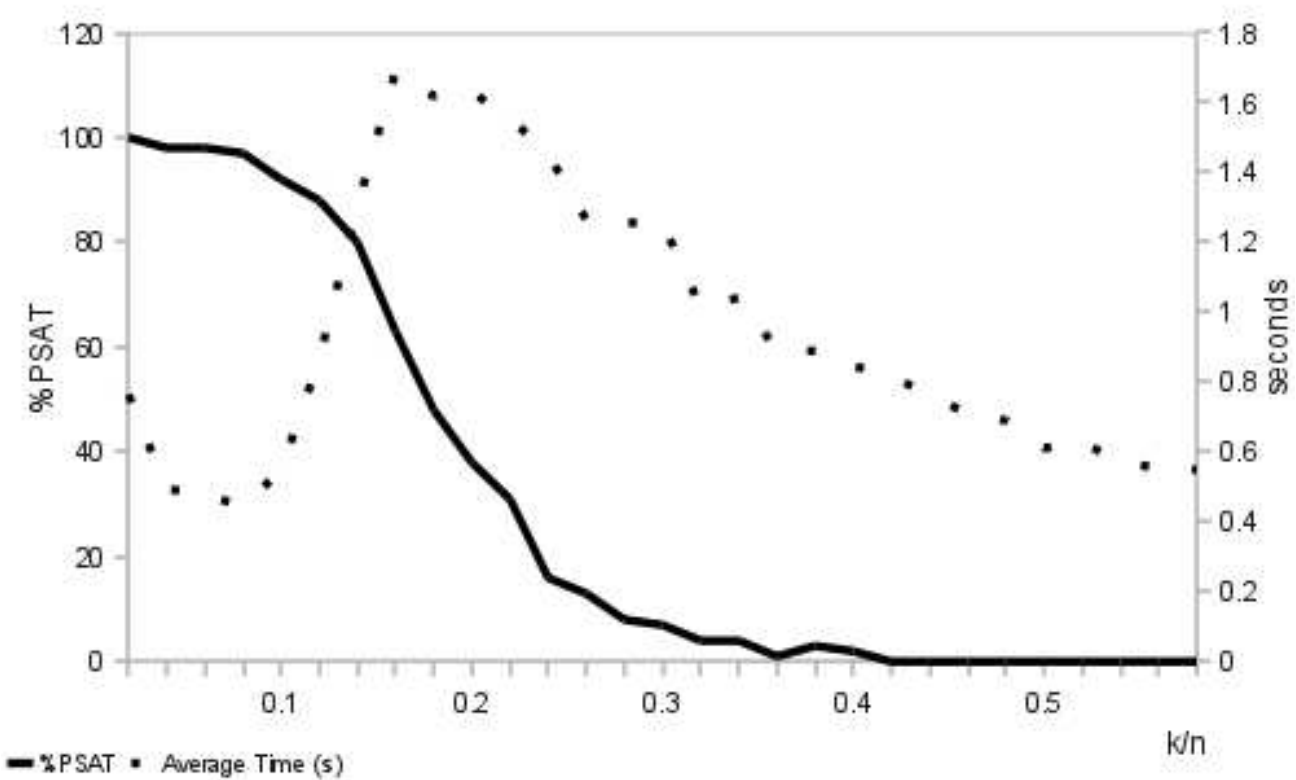

Figura 6.10: Perfil de complexidade do PSAT, para $m / n=3$ e $k=15$.

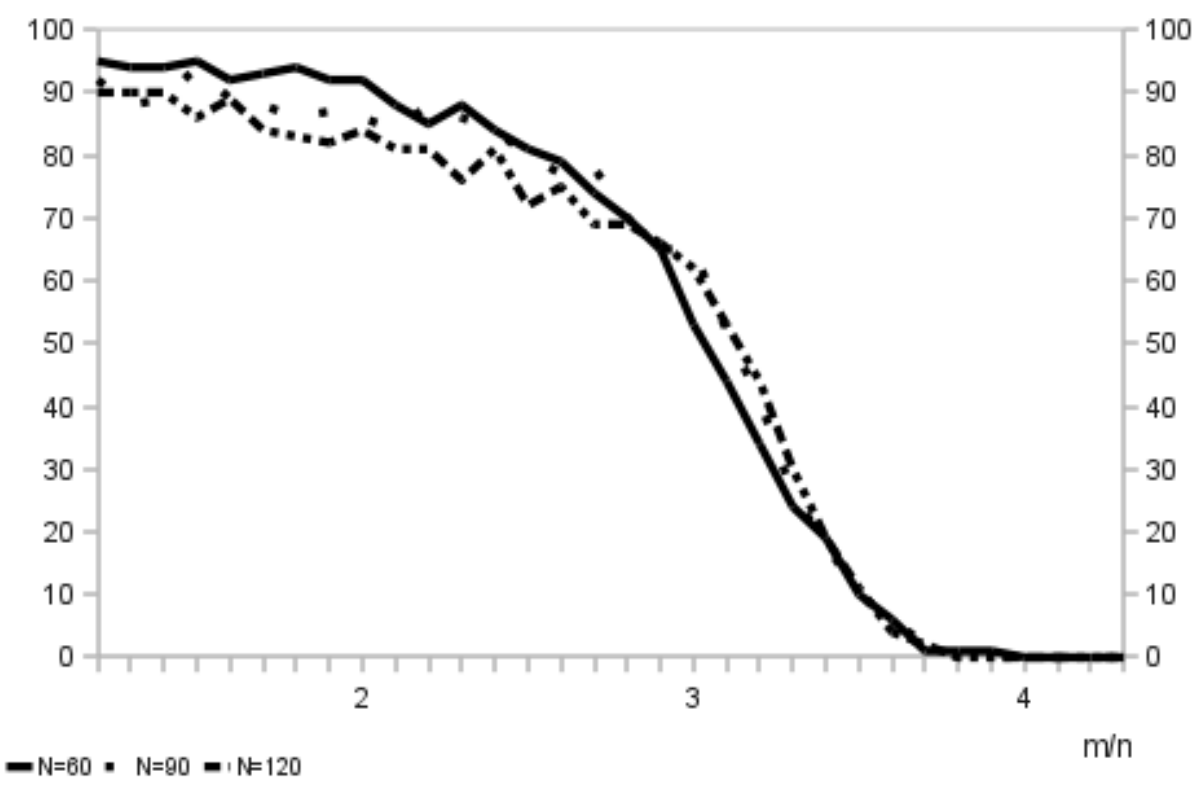

Figura 6.11: Porcentagem de instâncias satisfaziveis do PSAT em função da razão entre o número de cláusulas e o número de variáveis, para $k / n=1 / 6$ e $n=60,90$ e 120.

para entender como o ponto de transição de satisfazibilidade para insatisfazibilidade $m / n=P_{t}$ se desloca em função de $k / n$ no PSAT com $\Gamma$ sendo um 3-SAT. Queremos uma função $f(k / n)$ tal que $f(0)=4,3$, pois este é o ponto conhecido para a transição de fase do 3 -SAT. Novamente por observação empírica, testamos a estimativa $P_{t}=f(k / n)=4,3(1-k / n)^{2}$. A Tabela 6.1 mostra pontos $P_{50 \%}$ em $m / n$ onde $50 \%$ das instâncias são satifazíveis para diferentes $k$ 's e $n$ 's, levantados por extrapolação dos pontos vizinhos, comparando com o resultado de nossa estimativa $f(k / n)$.

Para $k / n$ maiores nossos experimentos mostram curvas distorcidas como a da Figura 6.4, que diminuem o sentido de uma análise da localização da transição de fase. Isso pode explicar a queda 
Tabela 6.1: Pontos em $m / n$ com $50 \%$ de instâncias satisfazíveis comparados à estimativa $4,3(1-k / n)^{2}$.

\begin{tabular}{|c|c|c|c|c|c|c|}
\hline$k / n$ & $n$ & $k$ & $m / n=P_{50 \%}$ & $f(k / n)$ & erro & erro (\%) \\
\hline 0.047 & 150 & 7 & 3.86 & 3.91 & 0.05 & $1.2 \%$ \\
\hline 0.050 & 100 & 5 & 3.80 & 3.88 & 0.08 & $2.1 \%$ \\
\hline 0.053 & 75 & 4 & 3.74 & 3.85 & 0.11 & $3.0 \%$ \\
\hline 0.053 & 150 & 8 & 3.80 & 3.85 & 0.05 & $1.4 \%$ \\
\hline 0.060 & 150 & 9 & 3.77 & 3.80 & 0.03 & $0.8 \%$ \\
\hline 0.067 & 75 & 5 & 3.80 & 3.75 & -0.05 & $-1.4 \%$ \\
\hline 0.067 & 150 & 10 & 3.76 & 3.75 & -0.01 & $-0.4 \%$ \\
\hline 0.073 & 150 & 11 & 3.70 & 3.69 & -0.01 & $-0.2 \%$ \\
\hline 0.080 & 75 & 6 & 3.75 & 3.64 & -0.11 & $-2.9 \%$ \\
\hline 0.080 & 150 & 12 & 3.66 & 3.64 & -0.02 & $-0.6 \%$ \\
\hline 0.088 & 80 & 7 & 3.54 & 3.58 & 0.04 & $1.1 \%$ \\
\hline 0.100 & 40 & 4 & 3.40 & 3.48 & 0.08 & $2.4 \%$ \\
\hline 0.100 & 80 & 8 & 3.45 & 3.48 & 0.03 & $1.0 \%$ \\
\hline 0.100 & 100 & 10 & 3.55 & 3.48 & -0.07 & $-1.9 \%$ \\
\hline 0.100 & 150 & 15 & 3.56 & 3.48 & -0.08 & $-2.2 \%$ \\
\hline 0.150 & 100 & 15 & 3.25 & 3.11 & -0.14 & $-4.4 \%$ \\
\hline 0.167 & 60 & 10 & 3.10 & 2.99 & -0.11 & $-3.7 \%$ \\
\hline 0.167 & 90 & 15 & 3.15 & 2.99 & -0.16 & $-5.2 \%$ \\
\hline 0.167 & 120 & 20 & 3.16 & 2.99 & -0.17 & $-5.5 \%$ \\
\hline 0.200 & 100 & 20 & 2.90 & 2.75 & -0.15 & $-5.1 \%$ \\
\hline 0.250 & 80 & 20 & 2.40 & 2.42 & 0.02 & $0.8 \%$ \\
\hline 0.250 & 100 & 25 & 2.20 & 2.42 & 0.22 & $9.9 \%$ \\
\hline 0.300 & 50 & 15 & 2.00 & 2.11 & 0.11 & $5.3 \%$ \\
\hline
\end{tabular}

na eficácia medida da estimativa proposta para $k / n \geq 0,15$. Para $k / n$ ainda maiores, as curvas de satisfazibilidade caem lenta e gradualemente em função de $m / n$, dadas nossas limitações práticas, impedindo qualquer localização de um ponto de transição. Como já ressaltamos, a limitação em $k$ na viabilidade dos experimentos limita o $n$ quando $k / n$ é fixo, e a transição de fase perde definição com $n$ 's pequenos.

Como os resultados com o 3-PSAT (onde o $\Gamma$ é um 3-SAT) suportam a estimativa, para $k / n \leq$ 0,3 , acreditamos que esta seja uma boa aproximação para o L-PSAT, onde teríamos $P_{t}=P_{t, k=0}(1-$ $k / n)^{2}$, em que $P_{t, k=0}$ é o ponto de transição de fase em $m / n$ para o SAT composto por L-cláusulas, equivalente a um L-PSAT com $k=0$. Entretanto, não realizamos experimentos para suportar tal hipótese. 


\section{Capítulo 7}

\section{Conclusões}

\subsection{Contribuições e Considerações Finais}

Neste trabalho, apresentamos alternativas para resolver o PSAT atráves de reduções ao SAT. Mostramos como uma redução (canônica) polinomial para o SAT é inviável na prática para decidir o PSAT e propusemos reduções de Turing resultantes da adpatação do Simplex para tratar instâncias na forma normal atômica. Finalmente, utilizando instâncias neste formato, investigamos o perfil de complexidade do PSAT com a implementação dos algoritmos propostos e detectamos curvas típicas do fenômeno de transição de fase, esperado em todos problemas NP-completos, mas ainda desconhecido neste problema. Os principais resultados deste trabalho estão condensados no artigo [FDB11], a ser apresentado na Conferência Internacional Conjunta sobre Inteligência Artificial (IJCAI) de 2011.

A forma normal atômica, uma vez que se mostrou natural ao revelar um caminho para o estudo do fenômeno de transição de fase, pode ser adotada como o formato padrão para instâncias PSAT, padronizando a entrada de algorititmos com o intuito de comparar seu desempenho. Além disso, com este mesmo formato padrão também consegue-se representar atribuições de probabilidades imprecisas, sem precisar de um tratamento separado para esta variante do problema.

A complexidade embutida na redução canônica do PSAT ao SAT evidencia a maior dificuldade computacional de se revolver o primeiro, embora ambos sejam NP-completos. Mesmo se dispuséssemos de um SAT Solver polinomial, possível se $\mathrm{P}=\mathrm{NP}$, a redução canônica de precisão limitada levaria o PSAT a um SAT com número quadrático de variáveis, o que acarretaria um custo computacional consideravalmente maior, embora ainda polinomial.

A já bem estabelecida abordagem do PSAT como um problema de programação linear, e o emprego do eficiente algoritmo Simplex para resolvê-lo, parece ainda a melhor maneira de driblar sua complexidade. O número de iterações é linear no caso médio do Simplex, e o problema auxiliar de geração de colunas, embora NP-difícil, tem se mostrado solúvel para instâncias com $k$ 's satisfatórios, mesmo via redução ao SAT. Logo, tal abordagem deve viabilizar o uso prático do PSAT, e da lógica proposicional probabilística em que ele surge, em diversos ramos da Inteligência Artificial, como raciocínio, representação do conhecimento e aprendizado. 


\subsection{Sugestões para Pesquisas Futuras}

Para melhor entender o fenômeno de transição de fase no PSAT, seria necessário lenvantar o perfil de complexidade para $k / n$ maiores, com $n$ e $k$ suficientemente grandes para verificar se curva de satisfazibilidade tem o formato típico esperado. Partindo da Redução de Turing com Critério de Otimalidade aqui apresentada, uma ideia seria adiar os casos de "overflow"para $k$ 's maiores. Para isso, uma alternativa parece ser acoplar a tal implementação algum programa que decida o MAXSAT Ponderado Parcial sem a exigência de pesos inteiros.

Observando a aplicação de técnicas de programação linear para abordar o PSAT, mostradas no Capítulo 3, notamos que podemos ganhar eficiência na resolução do PSAT se o fizermos com o MAXSAT Ponderado. Para instâncias PSAT na forma normal atômica, o MAXSAT Ponderado oriundo do problema auxiliar recai no MAXSAT Ponderado Parcial, onde um subconjunto de cláusulas deve ser satisfeito obrigatoriamente (peso "infinito"). Para cada instância PSAT, as instâncias MAXSAT Ponderado (Parcial) que surgem a cada iteração do Simplex (veja a Seção 3.4) são sobre o mesmo conjunto de cláusulas. Essa característica não é explorada para ganho de eficiência pelas heurísticas propostas na literatura. No caso de instâncias MAXSAT Ponderado Parcial, oriundas de uma instância PSAT na forma normal atômica $\langle\Gamma, \Psi\rangle$, o subconjunto de cláusulas a serem necessariamente satisfeitas é sempre o próprio $\Gamma$. Uma ideia para o ganho de eficiência seria, por exemplo, a propagação das cláusulas aprendidas de $\Gamma$ para as futuras iterações. Além deste fim prático, podemos estudar essa dualidade entre MAXSAT Ponderado Parcial e PSAT na forma normal atômica para investigar a transição de fase do primeiro, em sua versão de problema de decisão.

Como observamos na Seção 6.3, um tratamento especial de instâncias na forma normal atômica, quando resolvemos o PSAT via Simplex com geração de colunas, faz com que seu custo computacional diminua drasticamente. Porém, para cláusulas com probabilidade 1 serem tratadas separadamente, em uma instância na forma normal atômica, não precisamos necessariamente usar um SAT Solver (ou MAXSAT Solver) para resolver o problema auxiliar. Outro possível trabalho futuro seria usar minimização numérica de funções pseudo-booleanas para resolver este problema auxiliar, adicionando restrições referentes a cláusulas com probabilidade 1 em forma de inequações, mantendo o tamanho da base independente da quantidade de tais cláusulas, assim ganhando eficiência. Tal modificação provavelmente possibilitaria a detecção do fenômeno de transição de fase, além da comparação do desempenho deste algoritmo númerico com aqueles baseados em SAT Solvers aqui apresentados. 


\section{Apêndice A}

\section{Listagem de Código Fonte}

O Algoritmo 4.1, de redução canônica do PSAT ao SAT, foi implementado em C++, porém ainda não está na sua forma final. Neste apêndice nos limitamos a listar o código fonte da implementação das funções descritas na Seção 4.3.2, para suportar a análise de sua complexidade na Tabela 4.1.

Os códigos aqui listados imprimem as cláusulas relativas às funções que implementam, já acrescentando estas a instância SAT que está sendo construída no formato clausal DIMACS. Para tal, é necessário um certo gerenciamento do progresso da construção. Assim, parte do código aqui é irrelevante para a função implementada de fato, mas esta parte não interfere no tempo de pior caso que estamos interessados.

1

2 //implementa a função Replica(), já repetida $k+1$ vezes, onde $k$ é o número de átomos com probabilidades atribuidas em |Psi;

3 // tempo de pior caso: O(k/|Gamma/), equivalente a k chamadas a uma função Replica com tempo $O(/ \mid$ Gamma/).

4 // /lGamma/ é o tamanho da instância SAT armazenada aqui no arquivo "gamma.txt".

5 void ClauseGen : : printGamma(int nVar, int nProb, int nClause) \{

$6 \quad$ long i, j, lit, temp, tempTop $=0$;

7 if (varGamma != -1) \{

8 tempTop $=$ topAtom;

9 topAtom $=$ varGamma;

$10\}$

11 else varGamma = topAtom;

2 countClause $+=$ nClause $*($ nProb +1$)$;

3 FILE* gamma;

14 gamma = fopen ("gamma.txt", "r");

15 for $(i=0 ; i<$ nProb $+1 ; i++)\{$

16

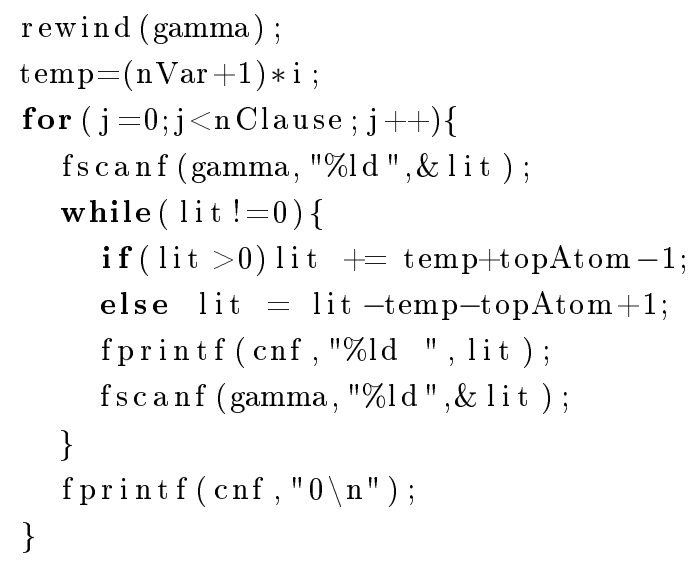


$28\}$

29 if $($ nProb $>0)$ topAtom $+=(\mathrm{nVar}+1) *(\mathrm{nProb}+1)$;

30 else topAtom $+=$ nVar;

31 if (tempTop>topAtom) topAtom = tempTop;

32 fclose (gamma);

$33\}$

34

35

36 //implementa a função Soma();

$37 / /$ tempo de pior caso: O(bits), onde bits é o número de bits de cada parcela

38 void ClauseGen::eq_sum( long*sum, long * p1, long *p2, int bits)\{

39 int $\mathrm{k}$, carry, carrytemp1, carrytemp 2, lastcarry, sumtemp;

$40 \quad \mathrm{c}$ arry $=$ topAtom ++ ;

41 eq_and2(carry, p1[0], p2[0]);

42 eq_xor $2(\operatorname{sum}[0], \mathrm{p} 1[0], \mathrm{p} 2[0])$;

43 for $(\mathrm{k}=1 ; \mathrm{k}<\mathrm{bits} ; \mathrm{k}++)\{$

$44 \quad$ lastcarry $=$ carry ;

$45 \quad$ carrytemp $1=$ topAtom ++ ;

46 eq_and2 (carrytemp1, p1[k], p2[k]);

47 sumtemp=topAtom ++ ;

48 eq_xor2( sumtemp, p1[k], p2[k]);

49 eq_xor $2(\operatorname{sum}[\mathrm{k}]$, sumtemp, lastcarry);

$50 \quad$ carrytemp $2=$ topAtom ++ ;

51

60 void ClauseGen:: eq_mul( long* product, long * p1, long *p2, int bits1, int bits 2 ) $\{/ /$ bits $1<=$ bits 2

61 int i, j, k, tbits, bitstemp;

62 long** parcelas, *temp, **partialsums;

63 if (bits $1>$ bits 2$)\{$

$64 \quad$ temp $=\mathrm{p} 1$;

$65 \mathrm{p} 1=\mathrm{p} 2 ;$

$66 \quad \mathrm{p} 2=$ temp;

67 bitstemp=bits 1 ;

$68 \quad$ bits $1=$ bits 2 ;

$69 \quad$ bits $2=$ bitstemp ;

$70\}$

$71 \quad$ parcelas $=$ new $\operatorname{long} *[$ bits 1$] ;$

72 for $(i=0 ; i<$ bits $1 ; i++)$ parcelas $[i]=$ new long $[$ tbits $]$;

$73 \quad$ tbits $=$ bits $1+$ bits 2 ;

74 for $(\mathrm{i}=0 ; \mathrm{i}<\mathrm{bits} 1 ; \mathrm{i}++)\{/ /$ gera parcelas, multiplicando p2 por cada bit de p1

75 for $(j=0 ; j<$ tbits $; j++)$ parcelas $[i][j]=$ topAtom ++ ;

76 for $(j=0 ; j<i ; j++) \operatorname{andN}(1,-$ parcelas $[i][j])$;

77 for $(j=0 ; j<b i t s 2 ; j++) e q \_a n d 2(\operatorname{parcelas}[i][j+i], p 1[i], p 2[j]) ;$

78 for $(j=i+b i t s 2 ; j<$ tbits $; j++) \operatorname{andN}(1,-$ parcelas $[i][j])$; 
\}

if $($ bits $1==1)\{$

for $(j=0 ; j<$ tbits $; j++)$ eq_andN $(2, \operatorname{product}[j], \operatorname{parcelas}[0][j])$;

return ;

\}

if $($ b it s $1==2)\{$

eq_sum( product, parcelas [1], parcelas [0], tbits);

return ;

\}

partialSums $=$ new long $*[$ bits $1-2]$;

for $(i=0 ; i<$ bits $1-2 ; i++)$ partialsums $[i]=$ new long [tbits ];

for $(i=0 ; i<b i t s 1-2 ; i++)$ for $(j=0 ; j<$ tbits $; j++)$ partialsums [i $][j]=$ topAtom ++ ;

eq_sum(partialsums [0], parcelas [0], parcelas [1], tbits );

for $(i=1 ; i<$ bits $1-2 ; i++)$ eq_sum(partialSums [i ], partialSums [i -1$]$, parcelas $[i+1]$, tbits);

eq_sum(product, partialSums [bits $1-3]$, parcelas [bits1-1],tbits );

$94\}$

95

96 //implementa a função leq() (apenas trocando a ordem os números a serem comparados)

$97 / /$ tempo de pior caso O(bits)

$98 / / a$ função eq(n1,n2,b) poderia se implementada com geq(n1,n2,b) e geq(n2,n1,b), tendo o mesmo tempo assintótico $O(b)$, onde $b$ é o número de bits

99 void ClauseGen : geq (long* p1, long* p2, int bits) \{

100 long conj, disj, greater, equal;

101 int i ;

$102 \operatorname{conj}=$ topAtom ++ ;

103 eq_equiv2(conj, p1[0], p2[0]);

104 for $(i=0 ; i<$ bits $-1 ; i++)\{$

105 greater $=$ topAtom ++ ;

106 eq_and2(greater, p1[i],-p2[i]);

107 dis j $=$ topAtom ++ ;

108 eq_or2(disj, greater, conj);

$109 \quad$ equal $=$ topAtom ++ ;

110 eq_equiv2(equal, p1 [i +1$], p 2[i+1])$;

$111 \quad \operatorname{conj}=$ topAtom ++ ;

112 eq_and2(conj, equal, disj);

$113\}$

114 greater $=$ topAtom ++ ;

115 eq_and2 (greater, p1[bits -1$],-$ p2 [bits -1$])$;

116 or 2 (greater, conj);

$117\}$

118

119

120 //implementa a função naoNulo();

121 //tempo de pior caso: $O(b)$, que é o tempo de pior caso de orNlist(b,n1).

122 void ClauseGen : naoNulo (long* n1, int b) \{ or Nlist (b, n1);

$124\}$

125

126 //implementa a função paraBinario();

$127 / /$ tempod e pior caso: $O(b)$, onde b é o número de bits.

128 void ClauseGen : : paraBinario(long $* x$, int $n$, int b) \{ 
129

130

131

132

133

134

$135\}$

136

137

138 //funções auxiliares, chamadas pelas funções acima;

$139 / / a$ função orNlist(), quando chamada pela função naoNulo(det, bits) tem tempo de pior caso O(bits);

$140 / / a s$ demais funções auxiliares ou tem tempo de pior caso $O(1)$, ou $O(N)$, mas aqui estas são chamadas com $N=1$;

141 void ClauseGen:: xor2( long a, long b) \{

142 countClause $+=2$;

143 fprintf (cnf, "\%ld \%ld $0 \backslash \mathrm{n} "$, a, b) ;

144 fprintf(cnf, "\%ld \%ld $0 \backslash \mathrm{n} ",-\mathrm{a},-\mathrm{b})$;

$145\}$

146

147 void ClauseGen::eq_xor2( long r, long a, long b) \{

148 countClause $+=4$;

149 fprintf(cnf, "\%ld \%ld \%ld $0 \backslash \mathrm{n} ",-\mathrm{r}$, a, b);

150 fprintf(cnf, "\%ld \%ld \%ld $0 \backslash \mathrm{n} ",-\mathrm{r},-\mathrm{a},-\mathrm{b})$;

151 fprintf(cnf, "\%ld \%ld \%ld $0 \backslash \mathrm{n} "$, r, $-\mathrm{a}, \mathrm{b})$;

152 fprintf (cnf, "\%ld \%ld \%ld $0 \backslash \mathrm{n} "$, r, a, $-\mathrm{b})$;

$153\}$

154

155 void ClauseGen : : orN ( int $\mathrm{n}, \ldots)\{$

$156 \quad$ count Clause $+=1$;

157 va_list args;

158 va_start $(\operatorname{args}, \mathrm{n})$;

159 int $\mathrm{j}$;

160 for $(\mathrm{j}=0 ; \mathrm{j}<\mathrm{n} ; \mathrm{j}++)$ fprintf (cnf, "\%ld ", va_arg(args, long $))$;

161 fprintf ( cnf, "0\n");

162 va_end (args);

$163\}$

164

165 void ClauseGen : : or Nlist ( int $\mathrm{n}$, long $*$ list ) \{

166 int i ;

$167 \quad$ countClause $+=1$;

168 for $(i=0 ; i<n ; i++)$ fprintf $(\mathrm{cnf}$, "\%ld ", list [i ] );

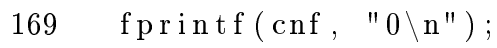

$170\}$

171

172 void ClauseGen : ClauseGen : or $2(\operatorname{long} a, \operatorname{long} b)\{\operatorname{orN}(2, a, b) ;\}$

173

174 void ClauseGen : : eq_orN ( int $\mathrm{n}$, long $\mathrm{r}, \ldots)\{$

$175 \quad$ count $\mathrm{Clause}+=\mathrm{n}+\mathbf{1}$;

176 va_list args;

177 va_start (args, r);

178 int j ;

179 fprintf ( cnf, "\%ld ",-r); 
180

181

182

183

184

$185\}$

186

187 void ClauseGen : : eq_or $2\left(\operatorname{long} \mathbf{r}, \operatorname{long}\right.$ a, long b) $\left\{\mathrm{eq}_{-}\right.$orN $\left.(2, \mathrm{r}, \mathrm{a}, \mathrm{b}) ;\right\}$

188

189 void ClauseGen : : andN ( int $n, \ldots)\{$

$190 \quad$ count Clause $+=\mathbf{n}$;

191 va_list args;

192 va_start (args, n);

193 int j;

$194 \operatorname{for}(\mathrm{j}=0 ; \mathrm{j}<\mathrm{n} ; \mathrm{j}++)$ fprintf( $\mathrm{cnf}, " \% \mathrm{ld} \quad 0 \backslash \mathrm{n} "$, va_arg( $\operatorname{args}, \operatorname{long}))$;

195 va_end (args);

$196\}$

197

198 void ClauseGen : and2( long a, long b) $\operatorname{andN}(2, a, b) ;\}$

199

200 void ClauseGen : : eq_andN ( int n, long r, ...) \{

201 countClause $+=\mathbf{n}+1$;

202 va_list args;

203 va_start (args, r);

204 int j;

205 fprintf ( cnf, "\%ld ", r );

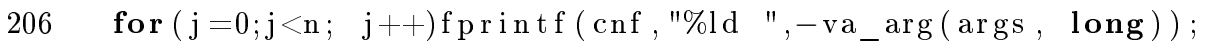

207 fprintf ( cnf, "0\n");

$208 \quad$ va_start (args, r) ;

$209 \operatorname{for}(\mathrm{j}=0 ; \mathrm{j}<\mathrm{n} ; \mathrm{j}++)$ fprintf ( $\mathrm{cnf}, " \% \mathrm{ld} \% \mathrm{ld} 0 \backslash \mathrm{n} "$, va_arg( $\operatorname{args}, \mathbf{l o n g}),-\mathrm{r})$;

$210 \quad$ va_end $(\operatorname{args})$;

$211\}$

212

213 void ClauseGen : : eq_and2( long r, long a, long b) $\left\{\mathrm{eq}_{-}\right.$andN $\left.(2, \mathrm{r}, \mathrm{a}, \mathrm{b}) ;\right\}$ 
APÊNDICE A 


\section{Apêndice B}

\section{Exemplo de Redução Canônica}

Neste exemplo mostramos como o Algoritmo 4.2, da redução canônica de precisão limitada do PSAT ao SAT, constrói uma instância SAT $\Lambda$ satisfazível se, e somente se, uma instância PSAT $\langle\Gamma, \Psi\rangle$ na forma normal atômica possui solução com até $b_{\pi}$ bits de precisão. Então mostramos a valoração que satisfaz $\Lambda$, encontrada por um SAT Solver, e o par $A, \pi$ que atesta a satisfazibilidade de $\langle\Gamma, \Psi\rangle$.

As cláusulas de $\Lambda$ serão listadas no formato DIMACS, e as suas variáveis serão denotadas por números naturais .

Exemplo B.0.1. Seja $\langle\Gamma, \Psi\rangle$ uma instância PSAT na forma normal atômica, onde $\Gamma=\left\{\neg x_{1} \vee\right.$ $\left.\neg x_{2} \vee x_{3}, x_{2} \vee x_{4} \vee x_{5}, \neg x_{1} \vee x_{3} \vee x_{5}, \neg x_{1} \vee x_{4} \vee x_{6}\right\}$ e $\Psi=\left\{p\left(x_{1}\right)=0,57 ; p\left(x_{2}\right)=0,14\right\}$. Simularemos a execução do Algoritmo 4.2, da redução canônica de precisão limitada do PSAT ao SAT, para a entrada $\langle\Gamma, \Psi\rangle$ e precisão $b_{\pi}=3$.

O algoritmo começa construindo $p^{\prime}$ inteiro com os $b_{\pi}=3$ bits da representação de $p$. As 8 configurações possíveis destes 3 bits representam as probabilidades $0,1 / 7,2 / 7, \ldots, 7 / 7$, correspondentes aos inteiros $0,1,2, \ldots, 7$ de acordo com a notação binária usual. Assim, temos $p_{1}^{\prime}=1, p_{2}^{\prime}=4$ e $p_{3}^{\prime}=7$, este representando a condição $\sum \pi=1$ ou $\sum \pi^{\prime}=7$.

Antes de prosseguirmos com a construção das cláusulas, convém apresentar $\Gamma$ no formato DIMACS, onde a variável $x_{i}$ é representada pelo número $i$ :

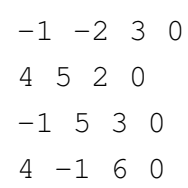

A instância SAT começa então a ser construída pela replicação dessas cláusulas 3 vezes, para diferentes variáveis. Note que as variáveis 1,2 e 3 representarão uma valoração sobre as variáveis de $\Psi$ e, logo, uma coluna da matriz que procuramos. Uma variável 7 será adicionada para representar a última linha desta coluna, representando a condição $\sum \pi=1$ ou $\sum \pi^{\prime}=7$. Então, somando 7 e 14 a cada variável deste grupo inicial de 7 variáveis, temos 1 grupo de variáveis para cada replicação de $\Gamma$. A partir daí, usando a saída da implementação do algoritmo, listamos a construção de cada clásula, apresentando as variáveis, seguindo a nomenclatura do algoritmo 4.2.

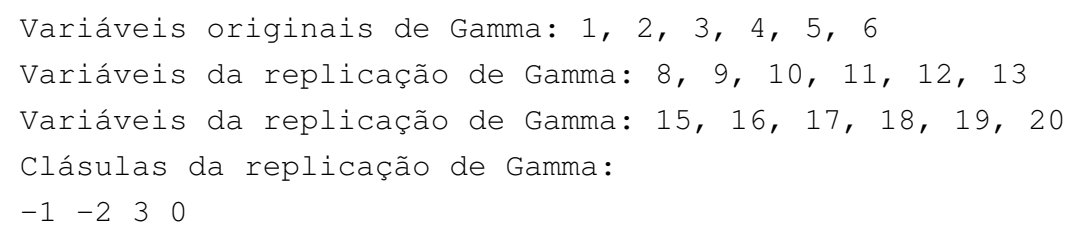




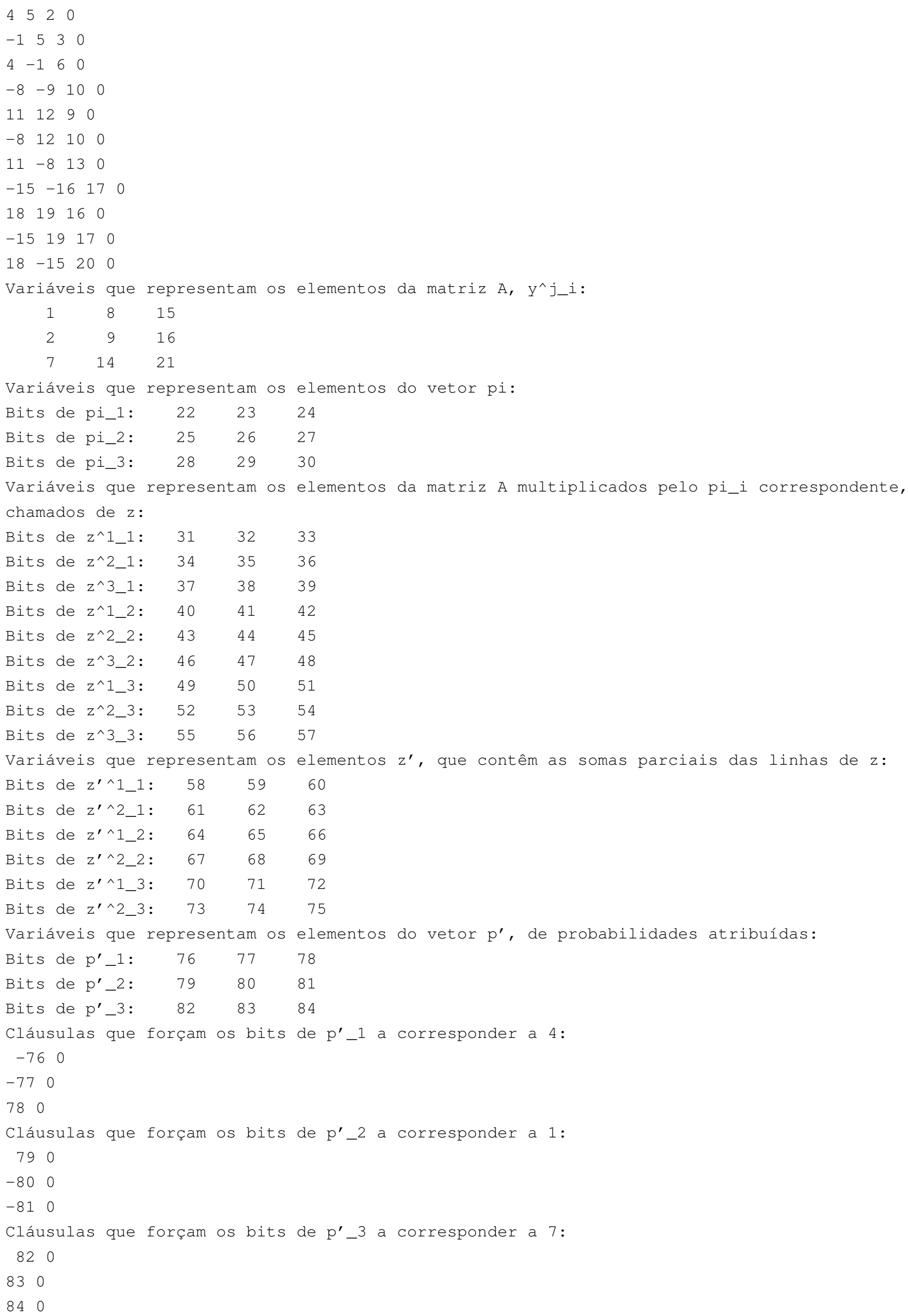


Cláusulas que fazem com que os elementos da última linha de A sejam iguais a 1:

70

140

210

Cláusulas que fazem $\mathrm{z}^{\wedge} 1 \_1=\mathrm{y}^{\wedge} 1 \_1 \cdot \mathrm{pi}{ }^{1}$ :

$31-1 \quad-22 \quad 0$

$1-310$

$22-310$

$\begin{array}{llll}32 & -1 & -23 & 0\end{array}$

$\begin{array}{lll}1 & -32 & 0\end{array}$

$23-32 \quad 0$

$\begin{array}{llll}33 & -1 & -24 & 0\end{array}$

$1-33 \quad 0$

$24-330$

Cláusulas que fazem $\mathrm{z}^{\wedge} 1{ }^{2}=\mathrm{y}^{\wedge} 1 \_2 \cdot \mathrm{pi}{ }^{2}$ :

$\begin{array}{llll}34 & -8 & -25 & 0\end{array}$

$8-34 \quad 0$

$25-340$

$35-8-26 \quad 0$

$\begin{array}{llll}8 & -35 & 0\end{array}$

$26-350$

$\begin{array}{llll}36 & -8 & -27 & 0\end{array}$

$8-360$

$27-36 \quad 0$

Cláusulas que fazem $z^{\wedge} 1 \_3=y^{\wedge} 1 \_3 \cdot p i \_3$ :

$\begin{array}{llll}37 & -15 & -28 & 0\end{array}$

$\begin{array}{llll}15 & -37 & 0\end{array}$

$\begin{array}{llll}28 & -37 & 0\end{array}$

$\begin{array}{llll}38 & -15 & -29 & 0\end{array}$

$15-38 \quad 0$

$29-38 \quad 0$

$39-15-30 \quad 0$

$\begin{array}{lll}15 & -39 & 0\end{array}$

$30-390$

Cláusulas que fazem $\mathrm{z}^{\wedge} 2 \_1=\mathrm{y}^{\wedge} 2 \_1 \cdot \mathrm{pi} \_1$ :

$\begin{array}{llll}40 & -2 & -22 & 0\end{array}$

$2-400$

$22-40 \quad 0$

$\begin{array}{llll}41 & -2 & -23 & 0\end{array}$

$\begin{array}{lll}2 & -41 & 0\end{array}$

$23-410$

$\begin{array}{llll}42 & -2 & -24 & 0\end{array}$

$2-420$

$24-420$

Cláusulas que fazem $\mathrm{z}^{\wedge} 2{ }^{2}=\mathrm{y}^{\wedge} 2{ }^{2}$.pi_2:

$\begin{array}{llll}43 & -9 & -25 & 0\end{array}$

$\begin{array}{llll}9 & -43 & 0\end{array}$

$25-430$

$\begin{array}{llll}44 & -9 & -26 & 0\end{array}$

$9-44 \quad 0$

$26-440$

$\begin{array}{llll}45 & -9 & -27 & 0\end{array}$

$9-45 \quad 0$ 
$27-450$

Cláusulas que fazem $z^{\wedge} 2 \_3=y^{\wedge} 2 \_3 \cdot p i \_3$ :

$\begin{array}{llll}46 & -16 & -28 & 0\end{array}$

$16-46 \quad 0$

$28-46 \quad 0$

$\begin{array}{llll}47 & -16 & -29 & 0\end{array}$

$16-47 \quad 0$

$29-47 \quad 0$

$\begin{array}{llll}48 & -16 & -30 & 0\end{array}$

$16-48 \quad 0$

$30-48 \quad 0$

Cláusulas que fazem $z^{\wedge} 3 \_1=y^{\wedge} 3$-1.pi_1:

$\begin{array}{llll}49 & -7 & -22 & 0\end{array}$

$\begin{array}{lll}7 & -49 & 0\end{array}$

$22-490$

$\begin{array}{llll}50 & -7 & -23 & 0\end{array}$

$7 \quad-50 \quad 0$

$23-50$

$\begin{array}{llll}51 & -7 & -24 & 0\end{array}$

$7 \quad-510$

$24-510$

Cláusulas que fazem $z^{\wedge} 3 \_2=y^{\wedge} 3 \_2 \cdot p i \_2$ :

$\begin{array}{llll}52 & -14 & -25 & 0\end{array}$

$14-52 \quad 0$

$25-520$

$\begin{array}{llll}53 & -14 & -26 & 0\end{array}$

$14-53 \quad 0$

$26-53 \quad 0$

$\begin{array}{llll}54 & -14 & -27 & 0\end{array}$

$14-54 \quad 0$

$27-54 \quad 0$

Cláusulas que fazem $z^{\wedge} 3 \_3=y^{\wedge} 3$ _3.pi_3:

$\begin{array}{llll}55 & -21 & -28 & 0\end{array}$

$21-550$

$28-55 \quad 0$

$\begin{array}{llll}56 & -21 & -29 & 0\end{array}$

$21-56 \quad 0$

$29-560$

$\begin{array}{llll}57 & -21 & -30 & 0\end{array}$

$21-57 \quad 0$

$30-57 \quad 0$

Clásulas que fazem $z^{\prime \wedge} 1 \_1=z^{\wedge} 2 \_1+z^{\wedge} 1 \_1$ :

$\begin{array}{llll}85 & -31 & -34 & 0\end{array}$

$31-850$

$34-85 \quad 0$

$\begin{array}{llll}-58 & 31 & 34 & 0\end{array}$

$\begin{array}{llll}-58 & -31 & -34 & 0\end{array}$

$\begin{array}{llll}58 & -31 & 34 & 0\end{array}$

$\begin{array}{llll}58 & 31 & -34 & 0\end{array}$

$\begin{array}{llll}86 & -32 & -35 & 0\end{array}$

$32-86 \quad 0$

$35-86 \quad 0$

$-8732 \quad 350$ 


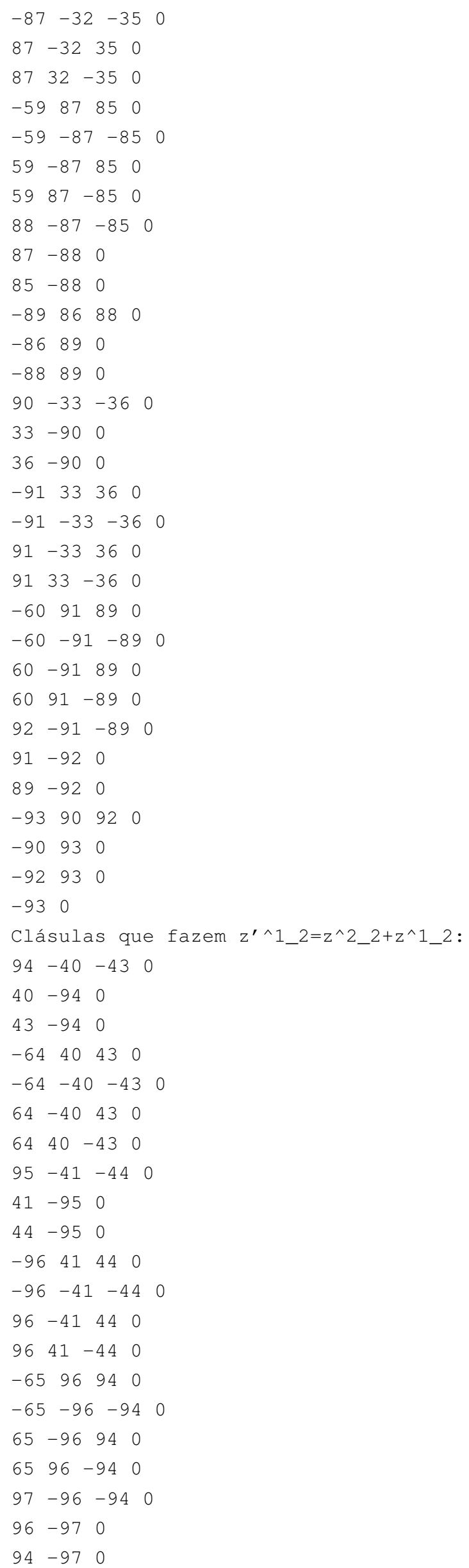




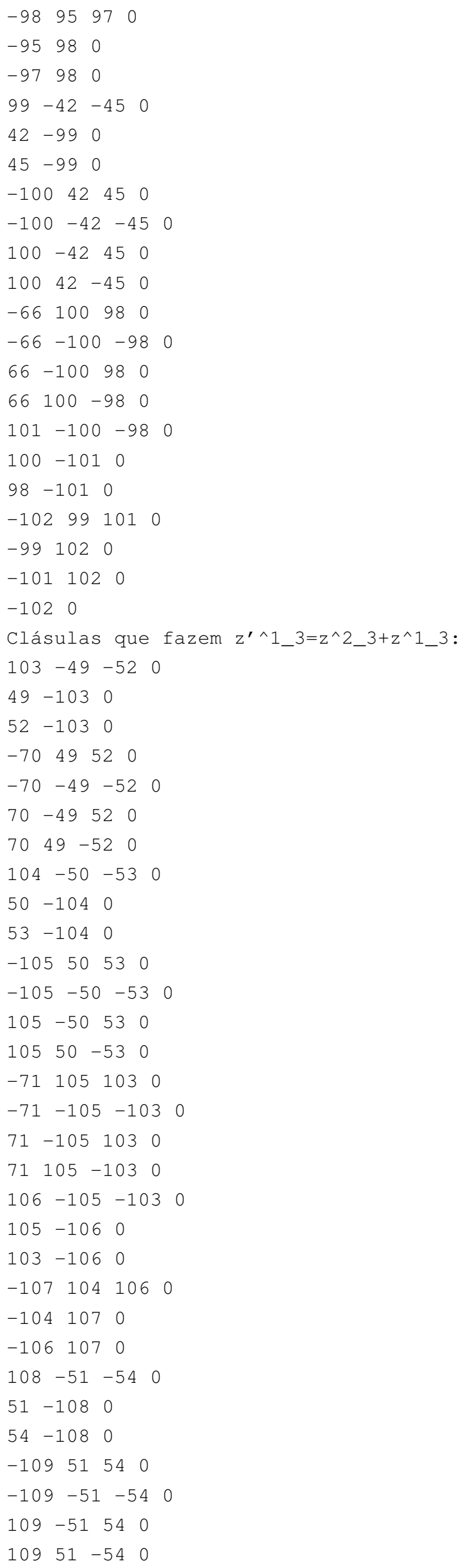




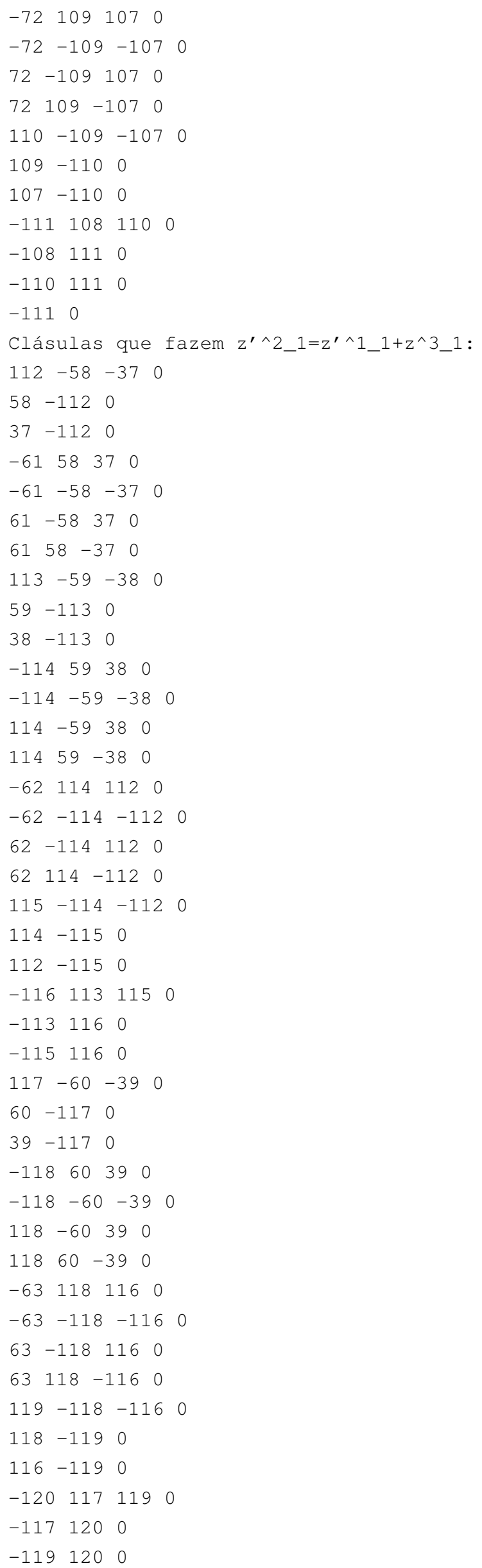


$-120 \quad 0$

Clásulas que fazem $z^{\prime \wedge} 2 \_2=z^{\prime \wedge} 1 \_2+z^{\wedge} 3 \_2$ :

$121-64-46 \quad 0$

$\begin{array}{llll}64 & -121 & 0\end{array}$

$46-1210$

$-6764460$

$\begin{array}{llll}-67 & -64 & -46 & 0\end{array}$

$\begin{array}{lllll}67 & -64 & 46 & 0\end{array}$

$\begin{array}{lllll}67 & 64 & -46 & 0\end{array}$

$\begin{array}{llll}122 & -65 & -47 & 0\end{array}$

$65-122 \quad 0$

$47-122 \quad 0$

$\begin{array}{llll}-123 & 65 & 47 & 0\end{array}$

$\begin{array}{llll}-123 & -65 & -47 & 0\end{array}$

$\begin{array}{llll}123 & -65 & 47 & 0\end{array}$

$\begin{array}{llll}123 & 65 & -47 & 0\end{array}$

$\begin{array}{llll}-68 & 123 & 121 & 0\end{array}$

$-68-123-1210$

$68-123 \quad 1210$

$\begin{array}{lllll}68 & 123 & -121 & 0\end{array}$

$124-123-1210$

$123-124 \quad 0$

$121-124 \quad 0$

$\begin{array}{llll}-125 & 122 & 124 & 0\end{array}$

$-1221250$

$\begin{array}{lll}-124 & 125 & 0\end{array}$

$126-66-48 \quad 0$

$66-1260$

$48-126 \quad 0$

$\begin{array}{llll}-127 & 66 & 48 & 0\end{array}$

$\begin{array}{llll}-127 & -66 & -48 & 0\end{array}$

$\begin{array}{llll}127 & -66 & 48 & 0\end{array}$

$\begin{array}{llll}127 & 66 & -48 & 0\end{array}$

$\begin{array}{llll}-69 & 127 & 125 & 0\end{array}$

$-69-127-1250$

$\begin{array}{llll}69 & -127 & 125 & 0\end{array}$

$\begin{array}{llll}69 & 127 & -125 & 0\end{array}$

$128-127-125 \quad 0$

$127-128 \quad 0$

$125-128 \quad 0$

$\begin{array}{llll}-129 & 126 & 128 & 0\end{array}$

$-1261290$

$\begin{array}{lll}-128 & 129 & 0\end{array}$

$-1290$

Clásulas que fazem $z^{\prime \wedge} 2 \_3=z^{\prime \wedge} 1 \_3+z^{\wedge} 3 \_3$ :

$130-70-55 \quad 0$

$\begin{array}{llll}70 & -130 & 0\end{array}$

$\begin{array}{llll}55 & -130 & 0\end{array}$

$\begin{array}{llll}-73 & 70 & 550\end{array}$

$\begin{array}{llll}-73 & -70 & -55 & 0\end{array}$

$\begin{array}{llll}73 & -70 & 55 & 0\end{array}$

$\begin{array}{lllll}73 & 70 & -55 & 0\end{array}$

$\begin{array}{llll}131 & -71 & -56 & 0\end{array}$ 


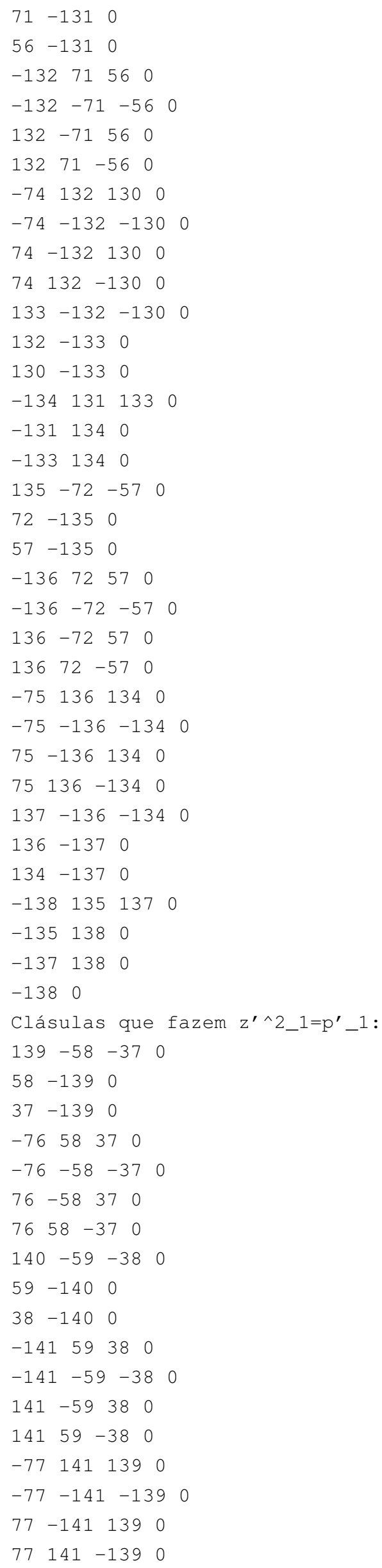




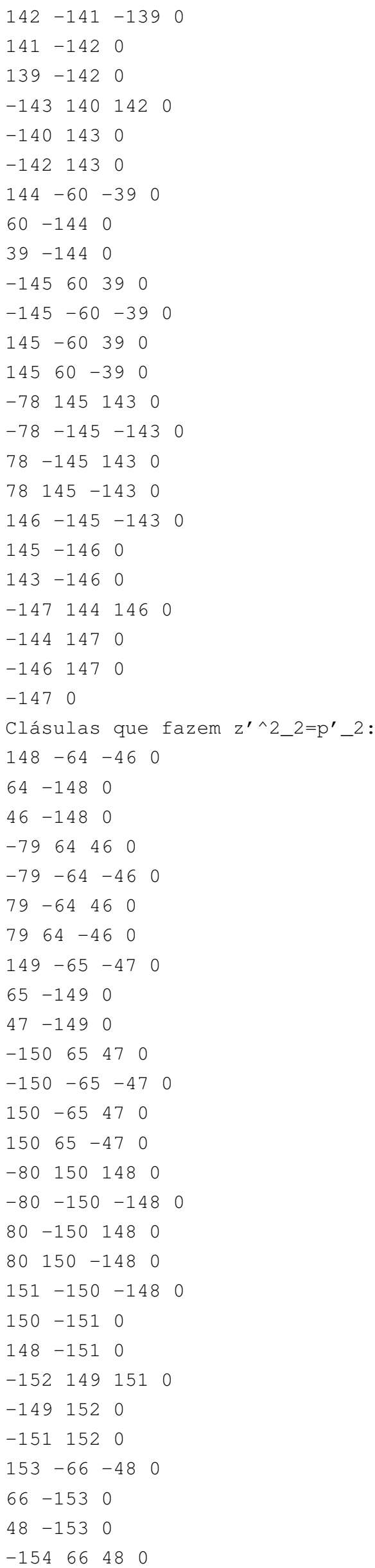




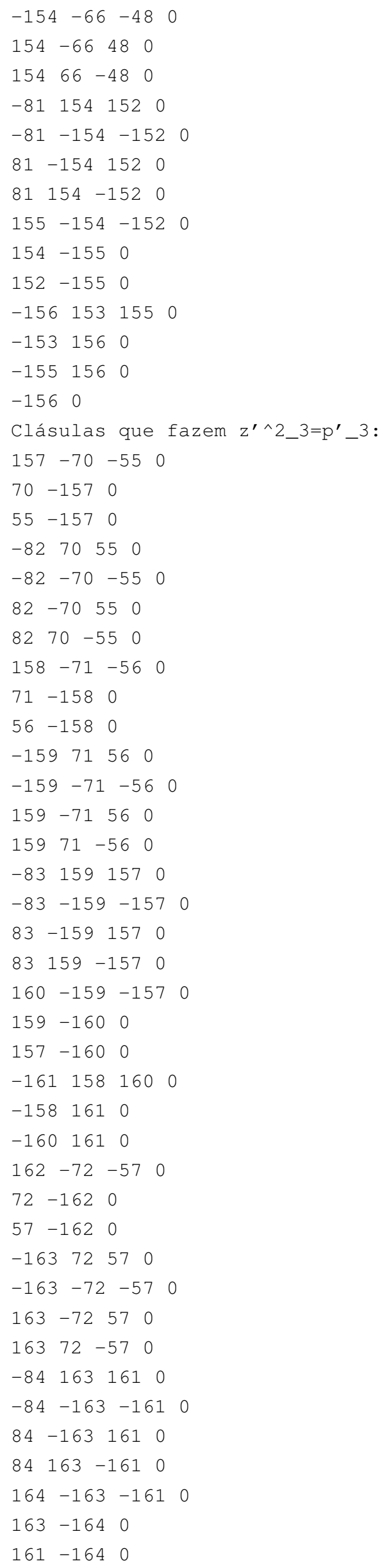




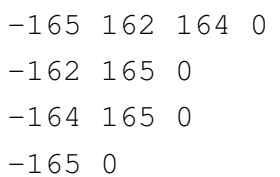

Temos agora uma instância SAT $\Lambda$ com 165 variáveis e 483 cláusulas, que é retornada pelo algoritmo. A título de ilustração, vamos decidir a satisfazibilidade probabilística de $\langle\Gamma, \Psi\rangle$ através da satisfazibilidade clássica de $\Lambda$. Submetendo então $\Lambda$ ao SAT Solver zChaff [MMZ $\left.{ }^{+} 01\right]$, obtemos:

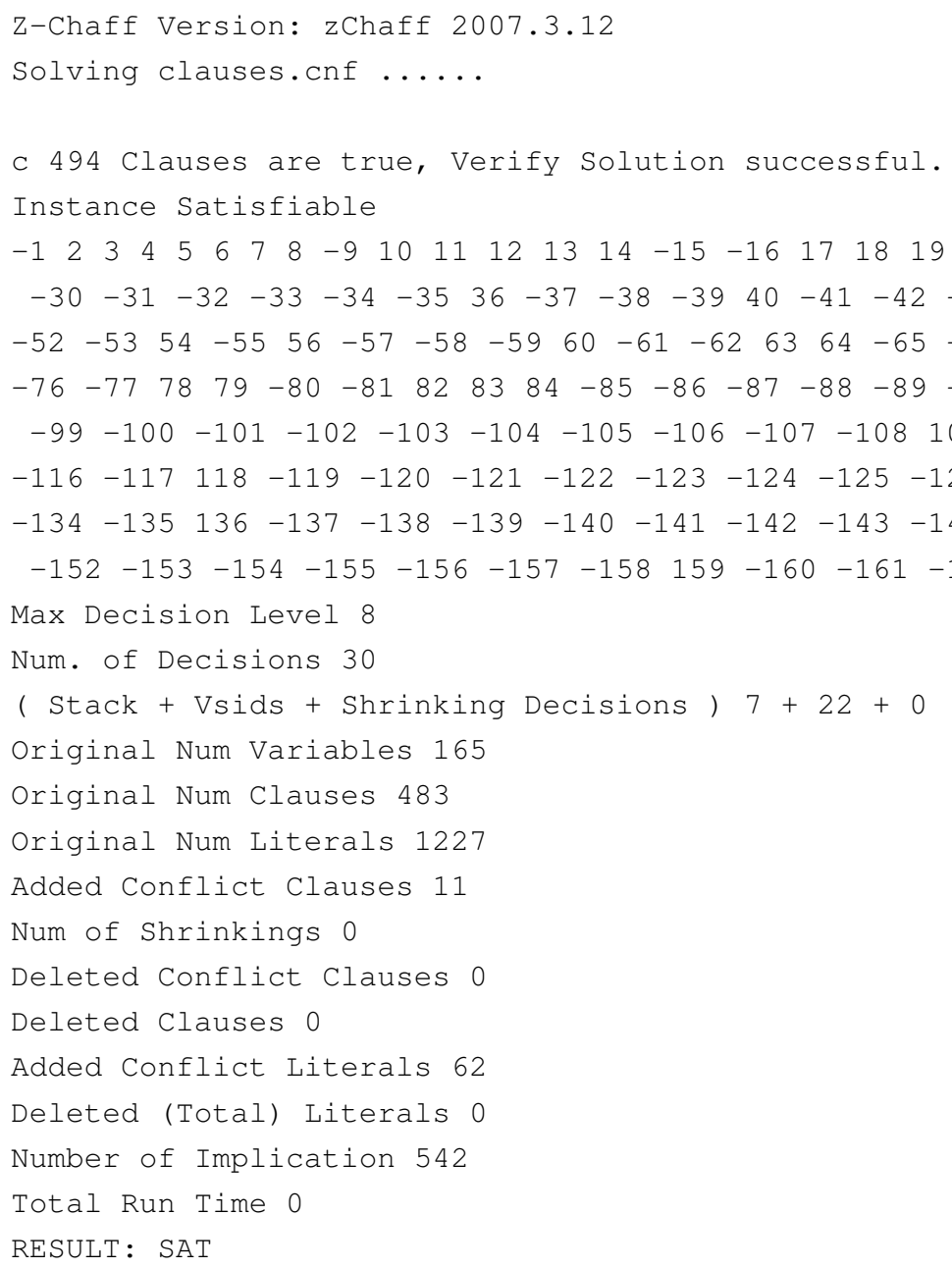

Tem-se que $\Lambda$ é satisfazível, então $\langle\Gamma, \Psi\rangle$ também deve ser. Finalmente, ainda nos aproveitando da saída de uma implementação do Algoritmo 4.2 acoplado ao zChaff, recuperamos a solução da instância PSAT $\langle\Gamma, \Psi\rangle$ :

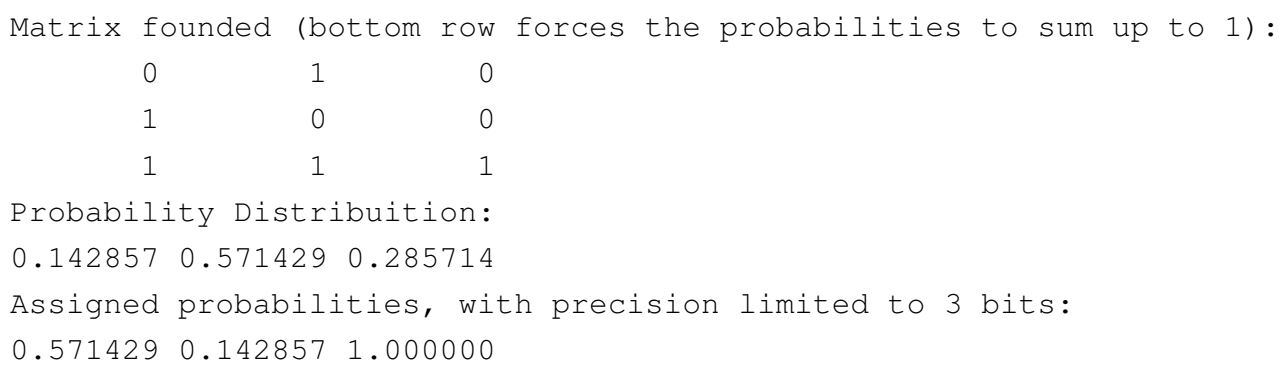




\section{Referências Bibliográficas}

[ALMP08] J. Argelich, C.M. Li, F. Manya, e J. Planes. The first and second Max-Sat evaluations. Journal on Satisfiability, Boolean Modeling and Computation, 4:251-278, 2008. 25, 53

[AMP05] T. Alsinet, F. Manya, e J. Planes. Improved exact solvers for weighted Max-SAT. Em Theory and Applications of Satisfiability Testing, páginas 371-377. Springer, 2005. 25

[AP01] K.A. Andersen e D. Pretolani. Easy cases of probabilistic satisfiability. Annals of Mathematics and Artificial Intelligence, 33(1):69-91, 2001. 9

[Boo54] G. Boole. An Investigation of the Laws of Thought: on which are Founded the Mathematical Theories of Logic and Probabilities. Walton and Maberly, 1854. 1, 3

[CKT91] P. Cheeseman, B. Kanefsky, e W.M. Taylor. Where the really hard problems are. Em Proceedings of the 12th IJCAI, páginas 331-337. Citeseer, 1991. 58

[CLRS01] T.H. Cormen, C.E. Leiserson, R.L. Rivest, e C. Stein. Introduction to Algorithms. MIT press, 2001. xi

[Col02] G. Coletti. Coherent numerical and ordinal probabilistic assessments. Systems, Man and Cybernetics, IEEE Transactions on, 24(12):1747-1754, 2002. 16

[Coo71] S.A. Cook. The complexity of theorem-proving procedures. Em Proceedings of the third annual ACM symposium on Theory of computing, página 158. ACM, 1971. 1, 5, 27

[CS96] G. Coletti e R. Scozzafava. Characterization of coherent conditional probabilities as a tool for their assessment and extension. INTERNATIONAL JOURNAL OF UNCERTAINTY FUZZINESS AND KNOWLEDGE BASED SYSTEMS, 4:103-128, 1996. 16

[CS02] G. Coletti e R. Scozzafava. Probabilistic Logic in a Coherent Setting. Kluwer Academic Pub, 2002. 16

[CV98] A. Capotorti e B. Vantaggi. An algorithm for coherent conditional probability assessments. Em Proceedings IV Congresso Nazionale SIMAI, volume 2, páginas 144-148, 1998. 16

[Dav] M. Davis. Turing reducibility? Notices of the AMS, 53(10). 39

[dF49] B. de Finetti. Sull'impostazione Assiomatica del Calcolo Delle Probabilità (Ch. 5 in Probability, Induction, Statistics, Wiley, London). Annali Univ. Trieste, 19:3-55, 1949. 16

[DF74] B. De Finetti. Theory of probability, 1974. 1

[DGLMS03] S. De Givry, J. Larrosa, P. Meseguer, e T. Schiex. Solving Max-SAT as weighted CSP. Em Principles and Practice of Constraint Programming-CP 2003: 9th International Conference, CP 2003, Kinsale, Ireland, September/October 2003: proceedings, página 363. Springer Verlag, 2003. 25 
[FDB10a] M. Finger e G. De Bona. A logic based algorithm for solving probabilistic satisfiability. Em Advances in Artificial Intelligence-IBERAMIA 2010: 12th Ibero-American Conference on AI, Bahía Blanca, Argentina, November 1-5, 2010, Proceedings, página 453. Springer-Verlag, 2010. 50

[FDB10b] M. Finger e G. De Bona. A refuted conjecture on probabilistic satisfiability. Em Advances in Artificial Intelligence-SBIA 2010: 20th Brazilian Symposium on Artificial Intelligence, São Bernardo Do Campo, Brazil, October 23-28, 2010, Proceedings, página 293. Springer-Verlag, 2010. 10

[FDB11] M. Finger e G. De Bona. Probabilistic satisfiability: logic-based algorithms and phase transition. Em Proceedings of the 22nd International Joint Conference on Artificial Intelligence (IJCAI'11) - a ser publicado, 2011. 1, 65

[FS71] D.K. Faddeev e I.S. Somins'kyi. Book of Problems in Higher Algebra. Vyshcha Shkola, Kiev, 1971. 29, 44

[GJ79] M.R. Garey e D.S. Johnson. Computers and Intractability. A Guide to the Theory of NP-Completeness. A Series of Books in the Mathematical Sciences. WH Freeman and Company, San Francisco, Calif, 1979. 8, 9, 27

[GKP88] G. Georgakopoulos, D. Kavvadias, e C.H. Papadimitriou. Probabilistic satisfiability. Journal of Complexity, 4(1):1-11, 1988. 7, 8, 9, 12, 13, 16

[GW94] I.P. Gent e T. Walsh. The SAT phase transition. Em ECAI, páginas 105-105. Citeseer, 1994. 58,61

[Hai65] T. Hailperin. Best possible inequalities for the probability of a logical function of events. American Mathematical Monthly, 72(4):343-359, 1965. 1

[Hai86] T. Hailperin. Boole's Logic and Probability. North-Holland Pub. Co., 1986. 3

[HJ00] P. Hansen e B. Jaumard. Probabilistic satisfiability. Handbook of Defeasible Reasoning and Uncertainty Management Systems: Algorithms for uncertainty and defeasible reasoning, página $321,2000.3,12,15,24,25$

[JHPdA91] B. Jaumard, P. Hansen, e M. Poggi de Aragao. Column generation methods for probabilistic logic. INFORMS Journal on Computing, 3(2):135, 1991. 15, 23, 24

[KP90] D. Kavvadias e C.H. Papadimitriou. A linear programming approach to reasoning about probabilities. Annals of Mathematics and Artificial Intelligence, 1(1):189-205, 1990. 13, 17, 20, 22, 23

[LMMP09] C. Li, F. Manyà, N. Mohamedou, e J. Planes. Exploiting cycle structures in Max-SAT. Theory and Applications of Satisfiability Testing-SAT 2009, páginas 467-480, 2009. 55

[MLLP07] G. Morales-Luna, G.D.I. Luna, e M. Puebla. Approximation algorithms for MaxSAT. Relation, 10(1.22):108, 2007. 22

$\left[\mathrm{MMZ}^{+}\right.$01] M.W. Moskewicz, C.F. Madigan, Y. Zhao, L. Zhang, e S. Malik. Chaff: Engineering an efficient SAT solver. Em Design Automation Conference, 2001. Proceedings, páginas 530-535, 2001. 55, 84

[MSL92] D. Mitchell, B. Selman, e H. Levesque. Hard and easy distributions of SAT problems. Em Proceedings of the National Conference on Artificial Intelligence, páginas 459-459. Citeseer, 1992. 58

[Nil86] N.J. Nilsson. Probabilistic logic* 1. Artificial Intelligence, 28(1):71-87, 1986. 1, 6, 12, 15,17 
[PS98] C.H. Papadimitriou e K. Steiglitz. Combinatorial Optimization: Algorithms and Complexity. Dover Pubns, 1998. 8, 17, 19, 42, 48, 53

[PT01] V.V. Prasolov e V.M. Tikhomirov. Geometry, volume 200 of Translations of Mathematical Monographs. American Mathematical Society, 2001. 7

[Sch99] U. Schoning. A probabilistic algorithm for k-SAT and constraint satisfaction problems. Em FOCS, página 410. Published by the IEEE Computer Society, 1999. 35

[SFM06] F.S.C. Silva, M. Finger, e A.C.V. Melo. Lógica para Computação. Thomson, 2006. 5

[War98] J.P. Warners. A linear-time transformation of linear inequalities into conjunctive normal form* 1. Information Processing Letters, 68(2):63-69, 1998. 44, 49, 53 